\title{
Elucidating Function in Early Diverging Non-Flagellated Fungi Using Metabolomics and Proteomics
}

\author{
Gregory R. Boyce
}

Follow this and additional works at: https://researchrepository.wvu.edu/etd

\section{Recommended Citation}

Boyce, Gregory R., "Elucidating Function in Early Diverging Non-Flagellated Fungi Using Metabolomics and Proteomics" (2017). Graduate Theses, Dissertations, and Problem Reports. 5245.

https://researchrepository.wvu.edu/etd/5245

This Thesis is protected by copyright and/or related rights. It has been brought to you by the The Research Repository @ WVU with permission from the rights-holder(s). You are free to use this Thesis in any way that is permitted by the copyright and related rights legislation that applies to your use. For other uses you must obtain permission from the rights-holder(s) directly, unless additional rights are indicated by a Creative Commons license in the record and/ or on the work itself. This Thesis has been accepted for inclusion in WVU Graduate Theses, Dissertations, and Problem Reports collection by an authorized administrator of The Research Repository @ WVU. For more information, please contact researchrepository@mail.wvu.edu. 
Elucidating function in early diverging non-flagellated fungi using metabolomics and proteomics

\author{
Gregory R. Boyce
}

Dissertation submitted to the Davis College of Agriculture, Natural Resources and Design at West Virginia University in partial fulfillment of the requirements for the degree of

\author{
Doctor of Philosophy \\ in \\ Genetics and Developmental Biology
}

\author{
Matthew T. Kasson, Ph.D., Co-Chair \\ Joseph Morton, Ph.D., Co-Chair \\ Daniel Panaccione, Ph.D. \\ Teiya Kijimoto, Ph.D. \\ Greg Kilby, Ph.D.
}

Division of Plant and Soil Sciences

Morgantown, West Virginia

2017

Keywords: Metabolomics, Mucoromycota, Zoopagomycota

Copyright 2017 Gregory R. Boyce 


\section{Abstract \\ Exploring Metabolic Capacity in Two Distinct Early Diverging Fungal Symbioses}

\section{Gregory Boyce}

The obligate lifestyle of many of the early diverging non-flagellated fungi have long precluded them from functional studies reserved primarily for their easily cultured, more derived counterparts. Modern -omics-based tools including transciptomics, proteomics and metabolomics have facilitated a better understanding of many fungi but have yet to be employed in the study of early diverging non-flagellated fungi with few exceptions. Using global and targeted metabolomics and prototeomics across the symbiotic spectrum, a series of studies were undertaken to better understand metabolism of three symbiotic interactions: two AM fungusplant associations including Rhizophagus dimorphicus - grass, R. clarus - legume, and one fungus-insect interaction, Massospora - cicada. For Rhizophagus dimorphicus, a previously undescribed dimorphic AM fungus, a multi-omics approach was taken to better understand the metabolic differences underlying phenotypic differences. The results of the multi -omics approach revealed a truncated proteome and metabolome being expressed in the white morphotype when compared to the dark morphotype. These differences in the proteome and the metabolome of these synanamorphs suggest a potential compartmentalization of metabolism in $R$. dimorphicus. However further investigation is required to fully understand this phenomenon. To better understand the interactions among AMF fungi, plant host, and environment, an applied metabolomics approach was used to elucidate the impact of each variable individually and combined on the primary metabolism of Rhizophagus clarus, another well described AMF member. Two leguminous plant species, Robinia pseudoacia (black locust) and Trifolium pretense (red clover) were inoculated and maintained at two different $\mathrm{pH}(\mathrm{pH} 4.5$ and 7.5). Individual hosts and both soil $\mathrm{pH}$ yielded distinct metabolite profiles from fungal spores, with soil $\mathrm{pH}$ having a greater influence on overall metabolism. Pathway analysis showed significant changes in intermediates and end products of the glutamate catabolism pathway as a function of change in medium $\mathrm{pH}$. The results of this study provide insight into how AMF fungi regulate the $\mathrm{pH}$ of their host tissues, the result of which may facilitate widespread colonization across suboptimal soil conditions. Finally, global and targeted metabolomics were used to better understand obligate entomopathogenic fungi, Massospora species, and compare two contemporary Massospora - cicada consortia, M. cicadina-infected periodical cicadas (Magicicada spp.) and M. levispora comb nov.-infected banger-wing cicadas (Platypedia putnami) to better help elucidate factors influencing host colonization and putative behavioral modification. Results of the global metabolomics uncovered a diverse assortment of secondary metabolites including psilocybin from $M$. levispora comb. nov. and cathinone from M. cicadina. These psychotropic compounds may enhance aggressiveness/stamina of infected cicadas to ensure continued spore dispersal despite debilitating infections that likely result in fatigue, decreased muscle strength and general malaise. Such discoveries as presented here have only begun to scratch the surface of the vast metabolic capacity of these two groups of enigmatic fungi. Using a systems biology approach has been shown to be an effective strategy to investigate the complex functionality of these two symbiotic systems. 


\section{Table of Contents}

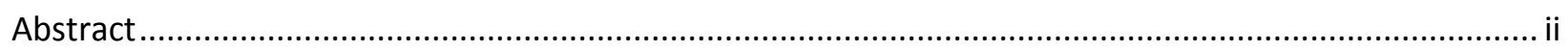

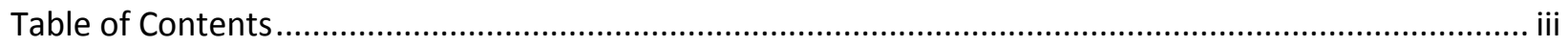

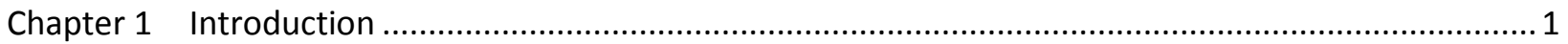

Chapter 2 Rhizophagus dimorphicus sp. nov., a dimorphic species in Glomeraceae (Glomeromycota), produces glomoid spores with two contrasting phenotypes and a partitioning of divergent metabolisms 7

Introduction . 18

Chapter 3 Applied metabolomics reveals host and environmental influence on metabolism

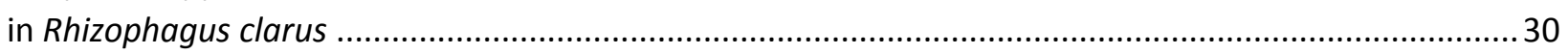

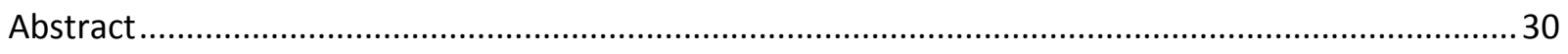

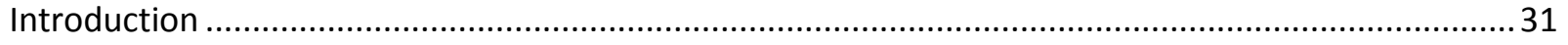

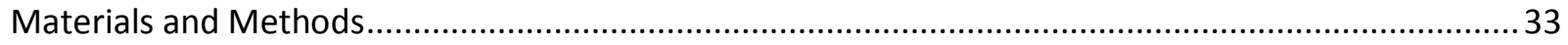

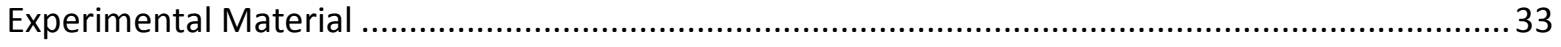

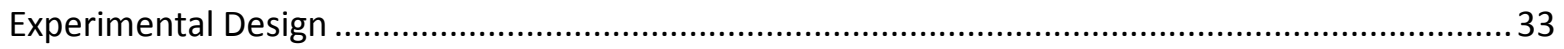




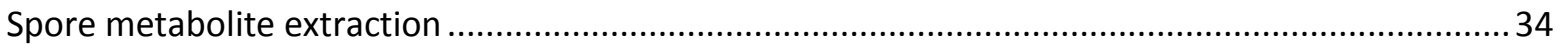

Normalization of samples by spore protein content ….................................................................... 35

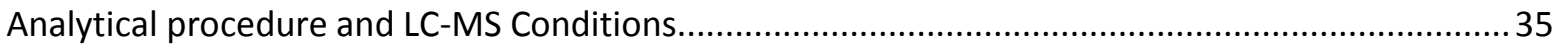

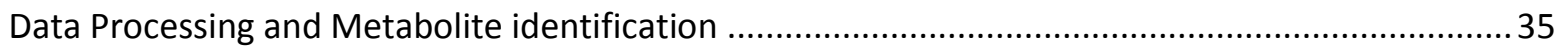

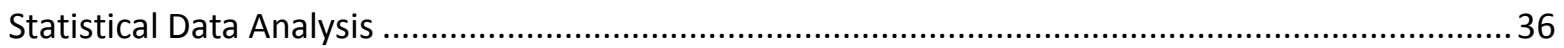

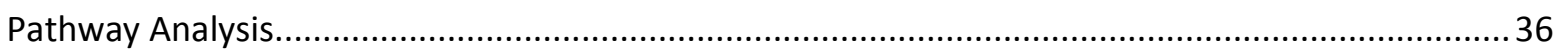

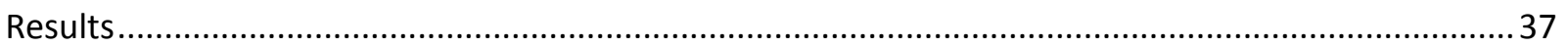

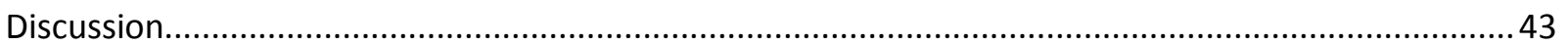

Chapter 4 Metabolomics of the cicada pathogen Massospora confirms psilocybin and cathinone production in early diverging non-flagellated fungi .............................................................................. 45

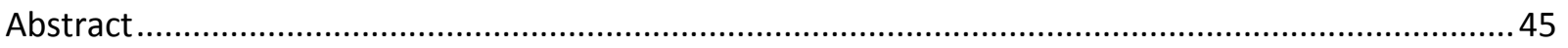

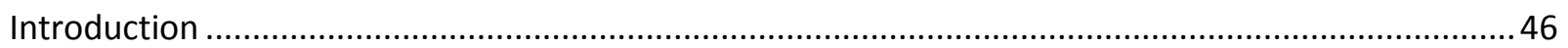

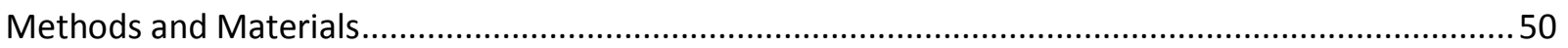

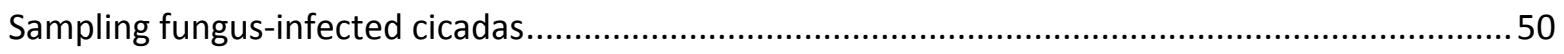

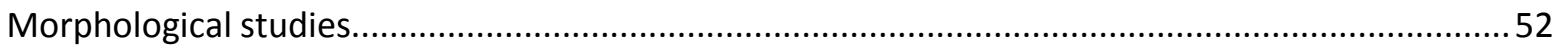

DNA extraction, amplification, sequencing, and phylogenetic analyses ........................................ 52

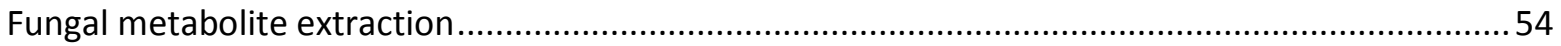

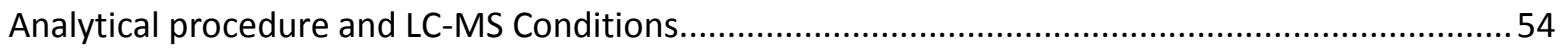

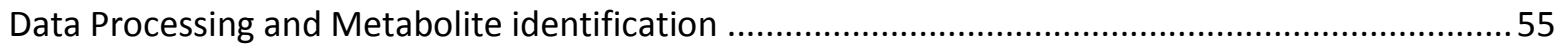

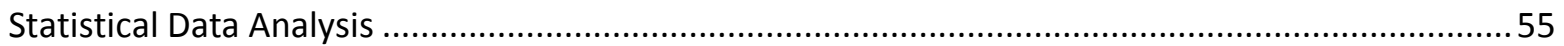

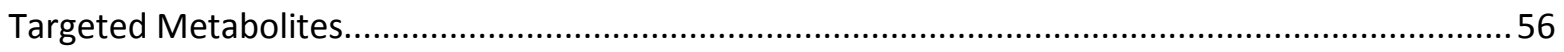

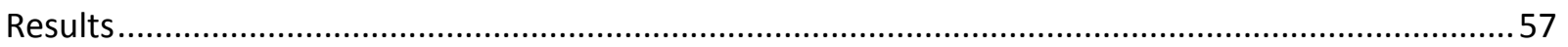

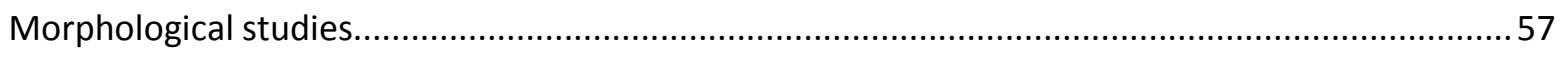

Molecular identification and phylogenetic diversity in Massospora ..................................................59

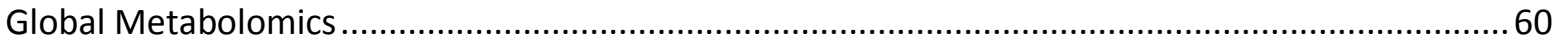

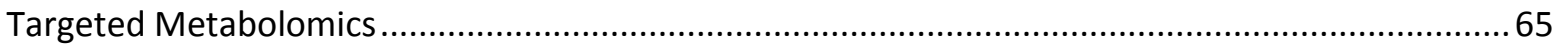

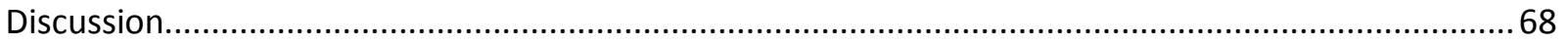

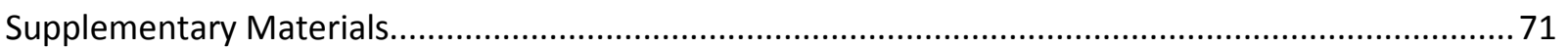

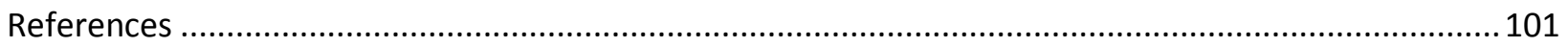




\section{Chapter 1 Introduction}

Metabolomics is the analysis of the organism's complete metabolite complement produced by the genome and proteome of an organism (Bhadauria et al. 2007, Zhou et al. 2012). The study of metabolomics involves the identification and quantification of small molecule metabolites. Multiple analytical tools can be implemented for the study of metabolomics, including gas chromatography mass spectrometry (GC-MS), nuclear magnetic resonance (NMR), and liquid chromatography mass spectrometry (LC-MS) (Yoshida et al. 2009, Zhou et al. 2012, Dona et al. 2016, Markley et al. 2017). These tools allow for the qualitative or quantitative measurement of the functional properties that directly affect the metabolism of an organism. Recent increases in the availability of bioinformatics tools, metabolite databases and analytical instrumentation have made these studies possible (Shulaev 2006, Doyle 2011, Sugimoto et al. 2012).

The chemo-diversity found within Kingdom Fungi make these organisms perfectly suited to metabolic exploration. Through secondary metabolism, fungi are able to produce many different compounds that have importance in the pharmaceutical, agricultural, food, and natural products industries. The ability for fungi to produce theses economically important secondary metabolites has drawn attention of biochemists and natural product scientists (Aly et al. 2010). The implementation of a robust analytical approach to understanding the metabolic processes involved in the production of theses biochemicals could provide valuable insight in how to best enhance their production. LC-MS based global metabolomics analysis have been employed to 
elucidate the most efficient conditions for culturing of fungi and to increase production of their secondary metabolites (Verduyn et al. 1992). Analyzing the metabolic flux within a fungal system also can provide valuable information into the response of organisms to environmental changes and to characterize physiological changes in an organism during its life cycle (Doyle 2011). The core enzymes required to complete metabolic pathways typically are highly conserved (Peregrín-Alvarez et al. 2009). However, how a specific organism utilizes and organizes these enzymes can greatly impact the end products of these pathways (PeregrínAlvarez et al. 2009). This variability is what drives the study of metabolomics, especially in fungi, due to their vast metabolic potential (Sauer et al. 2002) and the nature of their interactions with their host(s).

The Zygomycetes are one group of fungi that could be better understood through a global metabolomics analysis are obligately biotrophic fungi found primarily within members of the Mucoromycota and Zoopagomycota. These systems are complex and are comprised of numerous unculturable fungi with restricted host ranges. The two groups from these classes of fungi that will be examined in this work will be the Entomophthorales (Zoopagomycota) and the Glomeromycotina (Mucoromycota).

The Zoopagomycota, whose members are considered the earliest diverging lineage of nonflagellated fungi, comprise 19 genera and 228 described species worldwide. Multiple systematic biological approaches have helped to elucidate some aspects of zygomycete evolution (Małagocka et al. 2015, Meier et al. 2015, Li et al. 2017). Yet many of the basic mechanisms that drive pathogenicity and behavioral variation still are not understood compared to data on their Ascomycotan counterparts (de Bekker et al. 2013). The implementation of a proven analytical 
approach, such as LC-MS based metabolomics, can help elucidate these complex biological relationships.

Arbuscular mycorrhizal fungi (AMF) also are obligate fungal symbionts, but they reside in soil and form associations with over $80 \%$ of vascular plants on every continent. The first appearance of these fungi directly coincides with the appearance of land plants (Davison et al. (2015). These fungi also have been shown to form this association with plants in almost any terrestrial ecosystem (Smith and Read 2008). The association between plants and AMF improves phosphorus and water uptake, and in a few circumstances seem to provide pathogen and toxicity protection to the plant (Jeffries et al. 2003). In exchange, the fungus obtains carbon from photosynthetic output of the plant (Davison et al. 2015). The AMF association with plants has been shown to play an important role in improving species richness, biodiversity, and plant community stability (Van der Heijde et al. 2008).

Arbuscular mycorrhizal fungi encompass $>250$ species described to date (http://schuessler.userweb.mwn.de/amphylo). AMF taxonomy originally was based on spore morphology and mode of spore formation (Gerdemann JW 1974, Morton JB 1990). More recently, molecular based approached have been used for identification and phylogenetic classification of these fungi (Redecker et al. 2013). The study of the 18S rRNA gene (SSU) used for phylogenetic classification(SCHÜßLER et al. 2001) did not provide a complete unified result because some of the molecular data did not agree with the morphological evolution described by Morton (1990) and Schüßler (2001). The sequencing of ribosomal DNA has been the primary source for molecular based phylogeny of arbuscular mycorrhizal fungi, but other genes have been used with varying success. A study of partial sequences of the $\beta$-tubulin gene for phylogenetic analysis of 45 species of AMF showed that sequence data was not congruent with 
SSU data at the order level, but provided congruence at the family and species level (Msiska and Morton 2008). The high variation of the exons found in this gene between species could account for some of the inconsistencies measured in this study. Stockinger et al (2010) reconstructed a phylogeny of AMF species using the RPB1 gene that correlated reasonably well with the phylogenies of rRNA genes. This single copy gene contains enough variable regions to provide resolution at the species level and above. Variation in intron organization between taxonomic groups has created some major challenges in finding suitable functional genes for sequencing and phylogenetic analysis. Metabolomics can provide an effective tool for understanding and identifying functional genes and their products for molecular targets.

Lisette et al. (2000) extracted protein from spores of several species and ran the extracted proteins on one dimensional polyacrylamide gels to obtain unique protein profiles for each species. These data provided the first evidence that species of AMF contain unique proteomes, but they were unable to identify these proteins and their functions from gel analysis alone. One of their most important findings was measurement of distinct variation in the concentration of total protein in spores of different AMF species. The amount of protein per spore averaged $20 \mathrm{ng}$ across the Glomus species analyzed. Improvements in mass spectrometery and sequences of 28,232 genes in the Rhizophagus irregularis genome (Tisserant et al. 2013) provided more information on the identity and functional attributes of these proteins. The theoretical proteome was translated from the genome information and the resultant UniProt database allowed for searching global proteomic digest sequences to identify proteins. Still, much functional information is absent because a majority of the theoretical proteins found in this database have not yet been characterized. This issue is less apparent when studying the small molecule metabolite components of a biological system because core enzymes tend to be more conserved. 
However, the manner in which a specific organism utilizes and organizes these enzymes can greatly impact the end products of these pathways (Peregrín-Alvarez et al. 2009). This variability is what drives the study of metabolomics, especially in fungi (Sauer et al. 2002).

In this study, both entomopathogenic fungi and arbuscular mycorrhizal fungi are studied at the biochemical level in their obligate interactions with their hosts (insects and plants, respectively). Each of these symbioses, defined here as close and long-term interactions between two phylogenetically distant organisms, can be parasitic or mutualistic, respectively (Douglas, 1994). Both mutualistic and parasitic symbioses have biological importance, and understanding their metabolic pathways could provide valuable insight into the functional interactions between host and fungal symbiont (Schardl et al. 2004, Smith et al. 2011). These interactions can have an impact on the metabolism of both the host and the symbiont (Russell et al. 2013). Fungal-Insect symbiotic interactions have been shown to increase the production of phenylalanine and tryptophan in both the host and the fungus (Russell et al. 2013). These two aromatic amino acids are the primary building blocks for a variety of secondary metabolites that provide defense against pathogens and predation (Siddiqui et al. 2012, Tohge et al. 2013). The plant-fungus interaction that occurs with arbuscular mycorrhizal fungi can increase the levels of the terpenoids accumulated in plant tissues (Welling et al. 2016, Sharma et al. 2017), which in turn can increase the plant's defense against herbivorous insects (Sharma et al. 2017). These mutualistic interactions can supplement and modify the host's metabolism to improve fitness.

The metabolism of the pathogenic symbiosis involves complex interactions, where the fungal pathogen often modifies its environment or the metabolism of its host in order to survive (Miyara et al. 2010). Fungal pathogens with broad host ranges have the ability to alter their own secondary metabolism in order to increase their virulence on different hosts (Ito et al. 2004). 
These complex metabolic changes within both the mutualistic and pathogenic fungal symbioses can utilize metabolomic tools to elucidate mechanisms of interactions and their functional significance (Schardl et al. 2004, Smith et al. 2011, Russell et al. 2013). Moreover, analyses at the biochemical level can reveal unique as well as shared processes in contrasting mutualistic and pathogenic symbioses. 


\title{
Chapter 2 Rhizophagus dimorphicus sp. nov., a dimorphic species in Glomeraceae (Glomeromycota), produces glomoid spores with two contrasting phenotypes and a partitioning of divergent metabolisms
}

\begin{abstract}
A dimorphic species of arbuscular mycorrhizal fungi, Rhizophagus dimorphicus, was discovered in the International Culture Collection of Arbuscular Mycorrhizal Fungi (INVAM) originating from Brazil and Florida. The two spore phenotypes were so different they were originally thought to be two distinct species, however repeated culturing of each phenotype yielded mix cultures containing both. Analysis of a 750-800 bp region near the 5' end of the 28S rRNS gene (LSU) resulted in the grouping of the two spore phenotypes into a single clade that is a sister to other Rhizophagus clades. These results confirmed the dimorphic nature of this single species. The two synanamorphs produced by this dimorphic species include a dark reddish-brown morph that most closely resembles Septaglomus constrictum and white morph that resembles Rhizophagus clarus. The dark morphotype forms globose to subglobose spores with three distinct layers that range in size from 60-160 $\mu \mathrm{m}$. The subtending hyphae of the dark morph shows a constriction at the base of the subtending hyphae near the spore. The white morphotype also forms globose to subglobose spores with three layers that range in size from $60-120 \mu \mathrm{m}$. In addition to phylogenetic and morphological analysis a multi omics approach was taken to better understand the metabolic differences occurring within these two morphotypes. The global proteomics analysis revealed a truncated proteome being expressed in the white morphotype when compared to that of the dark morphotype. The global metabolomics showed a similar pattern, with the metabolome of the white spores lacking many of the secondary metabolites
\end{abstract}


found in the dark spores. These differences in the proteome and the metabolome of each spore morphotype suggest a potential compartmentalization of distinct metabolic processes.

\section{Introduction}

Two accessions deposited in the International Culture Collection of (VA) Arbuscular Mycorrhizal Fungi (INVAM) were deposited in 1988, cryopreserved until 2008, and then propagated in pot culture again thereafter. One culture originated from Brazil and the other from Florida. Both produced spores of identical black and white contrasting phenotypes, with the former sharing features of Septoglomus constrictum and the latter with some resemblance to Rhizophagus clarus. Both spore phenotypes were so different they were assumed to be separate species and new cultures of both strains were started from each spore phenotype. Surprisingly, both phenotypes sporulated together in each of the culture lineages and repeated attempts over the next eight years to separate the phenotypes in pure culture failed. Sporulation always was highly productive, but both morphotypes were inseparable. When cultures of each morphotype were started from single spores of the Florida strain, both phenotypes sporulated together. Genotyping using a 750-800 bp region near the 5' end of the 28S rRNA gene (LSU) grouped both morphotypes in the same clade and verified their dimorphic behavior. Two additional accessions originating in Taiwan and Colorado, USA were identified as synonymous from pot cultures started in 2005 and 2011, respectively. With four geographically distinct strains grouped by identical spore phenotypes, sporulation behavior and similarity in LSU sequences, sufficient evidence existed to group and define them as a new species, Rhizophagus dimorphicus.

The functional value of two spore morphotypes, especially when they are dramatically contrasting phenotypes, is worthy of investigation because fungi are modular organisms 
(Dighton et al. 1992). As such, they have no defined birth-death cycles, are flexible in component parts capable of starting new individuals (e.g. spores, hyphae), and those parts often are repetitive and form asynchronously $(\mathrm{REF})$. With a mobile population of nuclei that are able to migrate into different spores or hyphae at any time during the life cycle of a glomeromycotan fungus (Bever and Wang 2005),sample opportunities exist for partitioning of resources and responses to environmental perturbations. Global metabolomics and proteomics provides the tools to examine the biochemical processes occurring in the two synanamorphs of $R$.

dimorphicus. In this study, the hypothesis that these processes differ between synanamorphs is tested. Also, R. dimorphicus is formally described.

\section{Materials and Methods}

Standardized methods perfected over 26 years of culturing more than 1000 strains of glomeromycotan species were used to grow and characterize the four strains of $R$. dimorphicus (Morton et al., 1993). Starter material of each culture consisted of chopped roots, spores and mycorrhizal roots from a pre-exissting culture. This homogenized material was mixed in a growth medium consisting of coarse sand and a sandy loam soil (3:1 v/v) in a 15-cm diam pot, with $\mathrm{pH}$ adjusted to 6.2 and $<10 \mathrm{mg} / \mathrm{kg}$ P. The pot was seeded with Sorghum sudanense (L.) Pers. and grown for four months in a greenhouse with high-output fluorescent lighting (photon flux density of $345 \mu \mathrm{mol} \mathrm{m} \mathrm{s}^{-1}$, measured at the soil line) and a daylength of $14 \mathrm{~h}$. Ambient temperature varied from $22-30^{\circ} \mathrm{C}$ for duration of the culture period.

For single spore cultures, the same growth medium was used as that described above, but the medium was placed in $3.8 \times 21 \mathrm{~cm}\left(150 \mathrm{~cm}^{3}\right) \mathrm{SC} 10$ Supercell "cone-tainers" (Stuewe and Sons, Inc., Corvallis, OR). Spores were extracted from a mature pot culture by wet-sieving and sucrose gradient centrifugation (Gerdemann and Nicolson 1963), washed, collected under a dissecting 
microscope and surfaced cleaned by sonication in distilled water. Individual spores of each spore phenotype were selected randomly from the extracted population and pipetted onto intertwined roots of three 10-12 day-old sorghum (Sorghum sudanense L.) seedlings. Plants were transplanted into cone-tainers and grown in a growth room with $420 \mu \mathrm{E} \mathrm{m}^{-2} \mathrm{sec}^{-1}$ light intensity for a 14-hour day period and air temperature ranging from 25-28 C. Spores were sampled from these cone-tainers three months after transplanting and the populations viewed microscopically. Reculturing of these lineages was done using bulk inocula described above.

\section{Morphological analysis}

Spores collected from the field and from all pot cultures were preserved in $0.05 \%$ sodium azide and vials were deposited at the Oregon State University Herbarium and in the voucher collection of INVAM. Spores also were mounted permanently on glass slides in polyvinyl alcohol-lactic acid-glycerol (PVLG, Koske and Tessier, 1983) and in PVLG with Melzer's agent $(1: 1 \mathrm{v} / \mathrm{v})$. Spores were broken to varying degrees by applying pressure to the coverslip and examined with a Nikon Optiphot compound microscope equipped with differential interference contrast (DIC) optics. Selected slides also were deposited at the Oregon State University Herbarium and in the voucher collection of INVAM. Color photographs of mycorrhizae and spores can be viewed on the World Wide Web at http://invam.wvu.edu.

Morphological characters of the black and white synanamorphs of Rhizophagus dimorphicus overlapped enough with those described for Septoglomus constrictus and Rhizophagus clarus to conduct a comparative analysis with reference strains in INVAM. All 
comparisons were done using fresh spores extracted from actively growing pot cultures since some artefacts can arise in stored material.

\section{DNA extraction, amplification and sequencing}

Single sonicated spores of each synanamorph were selected for each amplification. A spore was crushed in a $0.2 \mathrm{~mL}$ microcentrifuge tube containing $14 \mu \mathrm{L}$ 10X Taq polymerase buffer (New England Biolabs, Ipswich, MA) with a UV sterilized micropestle (Kontes Pellet Pestle). Tube contents were transferred immediately to $94{ }^{\circ} \mathrm{C}$ water bath for 4 min, snap chilled and stored on ice.

Two rounds of $50 \mu 1$ PCR amplification were performed to generate enough product of a 700750bp LSU fragment for cloning (vanTuinen et al. 1998). The first round of amplification utilized primer pair ITS1 and NDL22, followed by a nested amplification with primers LR1 and FLR2 (White et al. 1990; van Tuinen et al. 1998; Trouvelot et al. 1999). The first PCR amplification contained $4 \mu$ spore DNA, $3 \mu 1$ 10x PCR buffer (New England BioLabs, Ipswich, MA), $0.2 \mathrm{mM}$ of each dNTP, $1.5 \mathrm{mM} \mathrm{MgCl} 2,5 \mathrm{pM}$ of each primer, and $0.1 \mu 1$ of Taq DNA polymerase (New England BioLabs, Ipswich, MA). The second round of PCR was similar except that only $1 \mu$ of first amplification product was used as template in $7 \mu 1$ 10x PCR buffer. Cycling parameters for both PCR reactions entailed initial denaturation at $94{ }^{\circ} \mathrm{C}$ for $4 \mathrm{~min}, 30$ cycles at $94{ }^{\circ} \mathrm{C}$ for $30 \mathrm{~s}$, annealing at $58^{\circ} \mathrm{C}$ for $1 \mathrm{~min}$, extension at $72{ }^{\circ} \mathrm{C}$ for $1 \mathrm{~min}$, and a final extension at $72{ }^{\circ} \mathrm{C}$ for $10 \mathrm{~min}$. Amplicons $(8 \mu \mathrm{l})$ were stained with ethidium bromide and electrophoresed on a $1.5 \%$ agarose gel and visualized by UV illumination, purified with QIAquick PCR Purification kit (Qiagen USA, Valencia, CA), cloned with pCR®4-TOPO plasmid vector and transformed using One Shot ${ }^{\circledR}$ TOP10 chemically competent cells 
(Invitrogen, Carlsbad, CA). Positive transformants were verified with colony PCR using LR1/FLR2 primers. Plasmid DNA containing the insert was purified using QIAprep Miniprep kit and sequenced at Davis Sequencing (Davis, CA, USA) using M13 primers. LSU sequences were deposited in NCBI XXXXXX. The sequence alignment is available on the INVAM website (http://invam.wvu.edu/).

\section{Phylogenetic analyses}

Sequence chromatographs were inspected in Biological Sequence Alignment Editor (BioEdit, www.mbio.ncsu.edu/BioEdit/bioedit.html) and subjected to a search on the NCBI nucleotide Basic Local Alignment Search Tool (nBLAST) to verify homology with other glomeromycotan fungal sequences. Nucleotide sequences were aligned using MUSCLE (Edgar 2004), inspected and edited in MEGA6 (Tamura et al. 2013). Phylogenetic trees were reconstructed using the maximum likelihood (ML) method with 1000 replications to assess bootstrap support and MEGA6 to determine the best evolutionary model and nucleotide substitution pattern.

\section{Global proteome analyses}

A sampling of 200 spores from an extracted population of spores of each synanamorph of R. dimorphicus were collected for global proteomic analysis. The spores were lysed in a protein extraction buffer consisting of $10 \mathrm{mM}$ ammonium bicarbonate ans $0.1 \%$ Progenta non-ionic acid labile surfactant. The spores were placed into a $0.5 \mathrm{~mL}$ microcentrifuge tube with $50 \mu \mathrm{L}$ of extraction buffer and crushed using a UV sterilized pestle. The spore samples then were sonicated for 20 minutes prior to a 1-hour incubation on ice. After incubation, spore samples 
were centrifuged at $14,000 \mathrm{xG}$ to pellet spore debris. The resulting supernatant was removed for proteolytic digestion.

Ten $\mathrm{mM}$ dithithreitol (DTT) was added $(25 \mu \mathrm{L})$ to each sample to reduce the protein. The samples were incubated for 1 hour at $37^{\circ} \mathrm{C}$, after which $25 \mu \mathrm{L}$ of $10 \mathrm{mM}$ iodoacetamide (IA) was added and the samples incubated at room temperature in the dark for one hour. Sequencing grade trypsin was prepared at a concentration of $1 \mu \mathrm{g} / \mu \mathrm{L}$ and a total of $4 \mu \mathrm{L}$ was added to each sample for digestion. The samples were incubated for 10 hours at $37^{\circ} \mathrm{C}$, after which they were acidified by adding $4 \mu \mathrm{L}$ of $10 \%$ formic acid and freeze dried prior to mass spectrometry analysis.

Samples were reconstituted in $50 \mu \mathrm{L}$ of $0.1 \%$ formic acid in $\mathrm{H} 2 \mathrm{O}$ for mass spectrometry analysis. For chromatography, nanoLC was performed on an Agilent 1260 Infinity Nanoflow using a ProntoSil C18, 75m x 150mm (200 ̊, 3mm) (nanoLCMS) at a flow of 150nL/min. Mobile phases consisted of A) $0.1 \%$ formic acid/water and B) $0.1 \%$ formic acid /acetonitrile. Mass spectrometry was analysis was performed using a Q Exactive Orbitrap (Thermo) operating in positive ion mode with a mass range of $400-2000 \mathrm{~m} / \mathrm{z}$ for precursor ions with Resolution set at 70,000 mass resolution in profile mode. Tandem mass spectrometry (MS/MS) spectra were collected with a mass range of $400-2000 \mathrm{~m} / \mathrm{z}$ with resolution set at 17,500 mass resolution in profile mode. Data Dependent Acquisition mode was used for MSMS data acquisition with the top Top10 ions selected for MS/MS (Normalized Collision Energy @ NCE 27) and Dynamic Exclusion set to 20 seconds. Proteomics LC-MS/MS data was processed using Proteome Discoverer (V 2.1, Thermo). Search engines included Sequest HT and Mascot. Precursor Tolerance was set to $10 \mathrm{ppm}$ and Fragment Mass Tolerance was set to $0.02 \mathrm{Da}$. Static Modifications were set to carbamindomethylation (C) and Dynamic Modifications were 
designated for deamidation (N\&Q) and oxidation (M). A Rhizophagus irregularis Fasta protein database was used for all queries. Confidence for protein identification was set to a minimum of two peptides per protein with 0.5\% Decoy False Discovery Rate. Scaffold (Proteome Software, Inc.) was used for determination of fold-changes in protein expression across samples. MS/MS data was imported into Scaffold and for Label-Free Quantitation the Total Precursor Intensities were compared pairwise for each spore morphotype. All fold-changes were calculated in reference to the Total Precursor Intensities (Normalized) for the Control samples. Quantitative analysis and statistical evaluation was performed using a T-test with Benjamin-Hochberg (Multiple Test Correction). Significance was set to $\mathrm{p}<0.05$ for detecting fold-change differences between species.

\section{$\underline{\text { Global metabolome analyses }}$}

A total of 500 spores from each of R. dimorphicus FL727N and Rhizophagus clarus WV235 were sonicated in methanol for 20 minutes to remove any plant or growth media related metabolites. This process was performed in triplicate. The fungal metabolome was extracted from sonicated spores of each morphotype through manual lysing in $200 \mu \mathrm{L}$ of extraction buffer in a $0.5 \mathrm{~mL}$ microcentrifuge tube with a UV sterilized micropestle. The extraction buffer consisted of $80 \%$ methanol and $20 \%$ high performance liquid chromatography (HPLC) grade $\mathrm{H} 2 \mathrm{O}$. The spore lysate was then sonicated at $14,000 \mathrm{x}$ for 20 minutes at $4^{\circ} \mathrm{C}$ to pellet proteins and cellular debris. The resulting supernatant was then removed for global metabolome analysis.

The Agilent LC-MS system (Agilent Technologies, Santa Clara, CA, USA) included an Agilent 1290 Infinity quaternary ultra-high pressure liquid chromatography (UHPLC) pump. This LC system was coupled to an Agilent 6530 quadrupole time of flight (Q-ToF) mass 
spectrometer with electrospray ionization. The chromatographic separations were performed using a Merck polymeric bead based ZIC-pHILIC column (100mmx2.1mm, $5 \mu \mathrm{m})$.

The LC-MS/MS data acquired using Agilent Mass Hunter Workstation was processed in Profinder software for batch recursive analysis. The datasets were subjected to spectral peak extraction with a minimum peak height of 600 counts and the charge state for each metabolite was restricted to two. Further, retention time and mass alignment corrections were performed using Agilent Profinder software version 2.3.1 on the runs to remove non-reproducible signals. The resulting features were then exported as .cef files to Mass Profiler Professional (MPP) software version 2.4.3 (Agilent Technologies, Santa Clara, CA, USA) for statistical analysis.

Statistical Data Analysis the extracted features were imported into MPP software for statistical analysis. Principle Component Analysis (PCA) was performed to check the quality of the samples and then the data containing filtered features were processed by unpaired t-test to find the difference between the dark and white synanamorphs. Only the analytes with $\mathrm{p}$ values $<0.05$ and fold change $(\mathrm{FC})>5$ were considered statistically significant. Additionally, multiple test corrections using Bonferroni were applied to reduce false positives and false negatives in the data. The statistically filtered data was exported to Mass Hunter for targeted MS/MS analysis.

\section{Taxonomy}

Rhizophagus dimorphicus nov. sp. Boyce, Kasson \& Morton

This species produces two morphologically distinct spore phenotypes (synanamorphs), one that is dark red-brown to black and one that is white to pale amber (Fig. 1A). In all cultures propagated to date, the black synanamorph sometimes sporulated alone but usually numbered more than twice that of the white synanamorph when they sporulated together. When present, both synanamorphs sporulated together within a root segment (Figs 1B-F), although the dark 
synanamorph often numbered at least twice or more that of the white synanamorph. The phenotype of each synanamorph was formed terminally from separate hyphae or branched from a shared hypha (Fig 1F-G).

Mycorrhizae of $R$. dimorphicus produce a typically dark staining reaction by $0.05 \%$ direct blue in roots of $S$. sudanense. Arbuscules and intraradical hyphae are similar in appearance to those of other species in Glomeraceae. The hyphae were mostly cylindrical and straight, ranging in width from 4-10 $\mu \mathrm{m}$, rarely formed coils and often branched at acute angles in cortical cells. Intraradical vesicles are interspersed with thicker-walled spores of both spore phenotypes often present together (Fig1D-E). A phylogeny of the LSU gene placed R. dimorphicus in an equivalent sister clade of $R$. clarus, $R$. intraradices, and $R$. irregularis (Fig. X).

\section{$\underline{\text { Dark synanomorph }}$}

Spores are smooth, globose to subglobose, 60-160 $\mu \mathrm{m}$ diam. $($ mean $=110 \mu \mathrm{m}, \mathrm{n}=100$; Fig. 2), and dark orange brown to black in reflected light. The median spore color is a dark reddish-black.

The spore wall consists of three layers with a composite thickness of $11.3 \mu \mathrm{m}(\mathrm{N}=50)$ (Fig. 3A-D). The outer layer (L1) is hyaline, 2-3 $\mu \mathrm{m}$ thick (mean $=2.2 \mu \mathrm{m}, \mathrm{n}=30$ ), staining amber in Melzer's reagent, sometimes sloughing with age. The middle permanent layer (L2) is dark red-brown, 5-8 $\mu \mathrm{m}$ thick (mean $=7.4, \mathrm{n}=50$ ), and rigid. The inner permanent layer (L3) also is red-brown, 2-4 $\mu$ m thick (mean $=3.2, \mathrm{n}=50$ ), and sometimes thin enough to produce folding in crushed spores. 
The subtending hypha varies from constricted near the spore base to cylindrical, $4-5 \mu \mathrm{m}$ wide for the former and 8-12 $\mu \mathrm{m}$ wide for the latter (Fig. 3D). The hyphal wall is concolorous with that of the outer layer of the spore wall for a short distance $(10-100 \mu \mathrm{m})$, after which the middle (layer 2) of the spore wall becomes the wall of the subtending hypha and transitions from an amber color to hyaline. The subtending hyphal outer layer ranges from 1-3 $\mu \mathrm{m}$ thick and the inner layer 2-4 $\mu \mathrm{m}$ thick at the base of the spore. There is a thin septum that is $<1 \mu \mathrm{m}$ thick present separating the spore contents from the subtending hyphae.

\section{White synanomorph}

Spores of the white synanamorph are smooth, globose to subglobose, 60-120 $\mu \mathrm{m}$ diam. (mean $=107 \mu \mathrm{m}, \mathrm{n}=100$; Fig. 2). The spore wall consists of three layers, all of which are hyaline (Fig. 4A-D). The outer layer (L1) produces a pale to dark red dextrinoid reaction in Melzer's reagent when present, especially in immature spores (Fig. 4B). This layer generally is less than $1-2 \mu \mathrm{m}$ thick (mean $=1.8 \mu \mathrm{m}$ ) but sloughs to create a rough surface (Fig. 4A) until it is shed completely (Fig. 4D). The middle layer (L2) is mostly rigid but has a small degree of plasticity when pressure is applied. This layer is $4-8 \mu \mathrm{m}$ thick (mean $=6.3 \mu \mathrm{m}, \mathrm{n}=40) \mu \mathrm{m}$, permanent and continuous with the wall of the subtending hypha. It does no react in Melzer's reagent (Fig. 4C-D). The inner layer (L3) also can be flexible (with folding; Fig. 4B), is 1-3 $\mu \mathrm{m}$ thick (mean $=2.1 \mu \mathrm{m}, \mathrm{n}=40)$, and is present as part of the subtending hyphal wall near the spore base (Fig. 4D).

The subtending hypha is consistently cylindrical to slightly flared, 6-10 $\mu \mathrm{m}$ wide at the spore, consisting of two hyaline layers, with a composite thickness of $1.5-3 \mu \mathrm{m}$. The middle layer of the spore wall (L2) comprises the main structural wall of the subtending hyphae, with 
the inner layer of the spore wall (L3) extending 1 to $5 \mu \mathrm{m}$ from the spore base (Fig. 4D). There is a thin septum that is $<1 \mu \mathrm{m}$ think separating the spore contents from the subtending hyphae.

\section{Global Proteomics Results}

The global proteomics data yielded 1,506, 1,327, and 888 proteins for $R$. clarus, $R$. dimorphicus (dark synanomorph), and $R$. dimorphicus (white synanomorph) respectively. Rhizophagus clarus and the two synanomorphs from $R$. dimorphicus shared expression of 723 proteins. The dark morphotype of $R$. dimorphicus expressed 111 unique proteins when compared to the white morphotype and $R$. clarus, while the white morphotype expressed only 9 unique proteins. A principal component analysis revealed that the proteomes of all three spore morphotypes grouped separate of each other, while that of the two synanomorphs of $R$. dimorphicus grouped closer to each other than with that of $R$. clarus (Fig. 5). These results show that white morphotype of $R$. dimorphicus expresses a truncated proteome in comparison to its darker synanomorph and $R$. clarus (Fig.5). The search results for the identification of the proteins detected revealed that $92 \%$ of the proteins identified were uncharacterized, so that function could not be assigned. Molecular function could be assigned to 175 proteins, with 95 proteins involved in catalytic activity, and 137 proteins involved in binding reactions. While the currently available protein database from UNIPROT is only a theoretical proteome generated from the genome sequence of $R$. irregularis, it cannot be used to effectively assign function to the detected proteins. Nevertheless, these data provide valuable information for assessing the complexity of the proteomes from these spores. 


\section{Global Metabolomics Results}

The global metabolomics analysis revealed two distinct metabolomes from the two morphotypes, these differences can be best visualized in the principal component analysis in Fig. 5. There were multiple classes of metabolites detected in the global analysis including lipids, free amino acids, nucleotides, and various secondary metabolites. The total detected metabolites from both of the morphotypes was 828 . Of these compounds 517 were significantly upregulated in the dark morphotype compared to the white. These significantly upregulated compounds in the dark synanamorph were primarily comprised of secondary metabolites including flavones, and alkaloids. The upregulated metabolites that were observed in the white synanamorph, were primarily comprised of phospholipids and fatty acids. A hierarchical clustering analysis was performed based on the results of the global metabolomes form the two spore types and the two morphotypes grouped into their own clades. The heat map represents the classes of metabolites and their up/down regulation between spore types. The heatmap data highlights the down regulation of the secondary metabolites that are found to be upregulated in the dark synanamorph compared to the white (Fig. 6).

Etymology: Latin dimorphicus, referring to the two contrasting spore phenotypes produced from a single thallus. 
Distribution and Habitat: This species is defined by four strains isolated from distant geographic locations. BR947 originated from the rhizosphere of Vitis species near Jundiai, Sao Paulo, Brazil, contributed by Eli Lopez on 4/25/1988, cryopreserved, reconstituted in 2014. CO215 was accessed in INVAM on 3/4/2011 by Robert Bills from native grasses on the Colorado Shortgrass Prairie (SGRB site). FL727N came from Bartow, Florida and was deposited by David Sylvia in 1988 after isolating from Styrax. TW115 was provided by Tomoko Oba on 8/29/2005 with no accompanying information.

Mycorrhizal associations: Associated with Vitis species, Styrax americanus, Buchloe dactyloides and Bouteloua gracilis in field samples; Paspalum notatum, S. sudanense, Trifolium pratense, and Robinia pseudoacacia in greenhouse-grown pot cultures.

Collections examined: Voucher specimens and living spores from pot cultures of BR947, CO215, FL727N, TW115: 18 Nov. 2016.

\section{Discussion}

The dimorphism of Rhizophagus dimorphicus is unique in the genus Rhizophagus, but this sporulation behavior occurs with low frequency across taxa in Glomeromycota (Redecker et al. 2009). Therefore, it is a trait that has evolved multiple times and is not sufficiently unique to have evolutionary consequence. Its functional role is unknown, but metabolomic analyses currently underway with $R$. dimorphicus and Am. leptoticha suggests there may be some partitioning and/or compartmentalization of pathways. This partitioning is evident in the metabolomics evidence presented in the current analysis. Spores of both synanamorphs are infective and form a mycorrhizal symbiosis, as evidenced by the establishment of successful single-spore cultures from both species. 
The habit of intraradical sporulation also is a convergent behavioral trait within Glomeromycota, but in Rhizophagus it is shared by all species in the clade. When interpreted in the context of all other morphological traits in the genus, it is a trait that further supports monophyly of the clade.

The darkly pigmented synanamorph bears closest resemblance to spores of Septoglomus constrictum. The similarities between these two species include the size distribution of the spores, spore color, and the presence of a constricted subtending hyphae in some spores. The dark morphotype also resembles $S$. constrictum in the L1 and L2 layers of the spore wall. The L1 layers of both species have a similar thickness and both can slough and be missing on older spores. The L2 layer of both species range from 5-9 $\mu \mathrm{m}$ in thickness, are both rigid, and are both red-brown to red-black in color (Trappe 1977).

The major difference between $S$. constrictum and the dark morphotype of $R$. dimorphicus is the presence of a third inner spore wall layer (L3) in $R$. dimorphicus that is pigmented and enhances the dark coloration of intact spores (Trappe 1977). Moreover, $R$. dimorphicus readily sporulates in roots, and this habit is rare in cultures of $S$. constrictum.

The white synanamorph mostly closely resembles the phenotype of $R$. clarus spores. The shared features between $R$. clarus and the white morphotype of $R$. dimorphicus include the three spore wall layers, the ability to sporulate prolifically within roots of their plant host, and the structure of the subtending hyphae (Nicolson and Shenck 1979). The subtending hyphal wall of $R$. clarus and the white morphotype of $R$. dimorphicus are both cylindrical with a thickness range of $7-9 \mu \mathrm{m}$. 
Spores of $R$. clarus and the white morphotype of $R$. dimorphicus differ in their size distribution, with the latter being smaller with a narrower range of distribution. Mean spore diam. of the white morphotype of $R$. dimorphicus and $R$. clarus is widely separated at $107 \mu \mathrm{m}$ and $182 \mu \mathrm{m}$, respectively. Spores of $R$. clarus also range in color from white to dark yellow because the innermost spore wall layer is yellow and coloration varies with thickness of this layer. Conversely, the innermost layer of the $R$. dimorphicus morphotype always is hyaline.

The global proteomics analysis revealed a truncated proteome in the white morphotype of R. dimorphicus. The unique proteins expressed by these spores were less than $25 \%$ of the unique expressed proteins from spores of the dark morphotype. While the vast majority of the proteins detected in the global proteomics analysis were shared between $R$. clarus and the two morphotypes of $R$. dimorphicus, the dark synanomorph expressed more than 100 unique proteins, which is comparable to the number of unique protein expressed in spores of $R$. clarus.

The global metabolomics data suggests that metabolism may be compartmentalized between the two morphotypes of $R$. dimorphicus. While the dark morphotype contained a more complex and diverse metabolome, with numerous secondary metabolites and intermediates from the general carbon metabolism pathway, the white morphotype harbored a greater amount of phospholipids and lipid precursors. This suggests that the functional metabolism of the two morphotypes are vastly different. Work currently is underway to analyze further both the proteome and metabolome of both synanamorphs to better characterize functional compartmentalization of metabolic processes. 


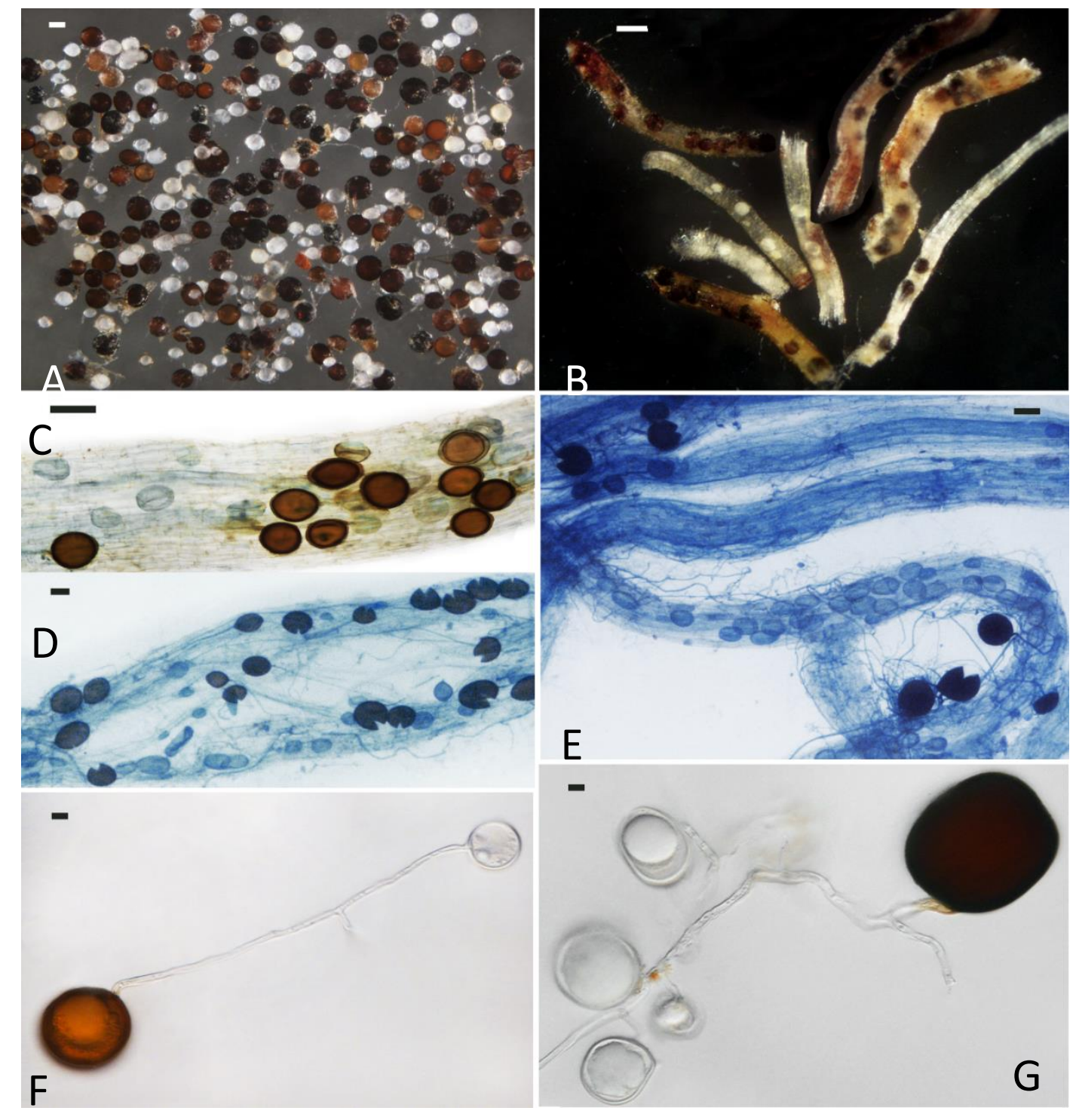

Figure 1. Sporulation behavior of the two synanamorphs of Rhizophagus dimorphicus strain FL727. A. Synanamorphs sporulating in a sudangrass culture grown for four months. B. 
Sporulation in unstained 4-mo-old sudangrass roots. C-D. Stained mycorrhizae containing both synanamorphs from a single spore culture of the dark spore phenotype. E. Stained mycorrhizae containing both synanamorphs from a single spore culture of the white spore phenotype. F.

Branched hypha producing each synanamorph terminally. G. Loose cluster showing formation of both synanamorphs from a shared hypha of origin. Bar in A, C-E $=100 \mu \mathrm{m}$; bar in $\mathrm{B}=200 \mu \mathrm{m}$, bar in $\mathrm{F}-\mathrm{G}=10 \mu \mathrm{m}$.

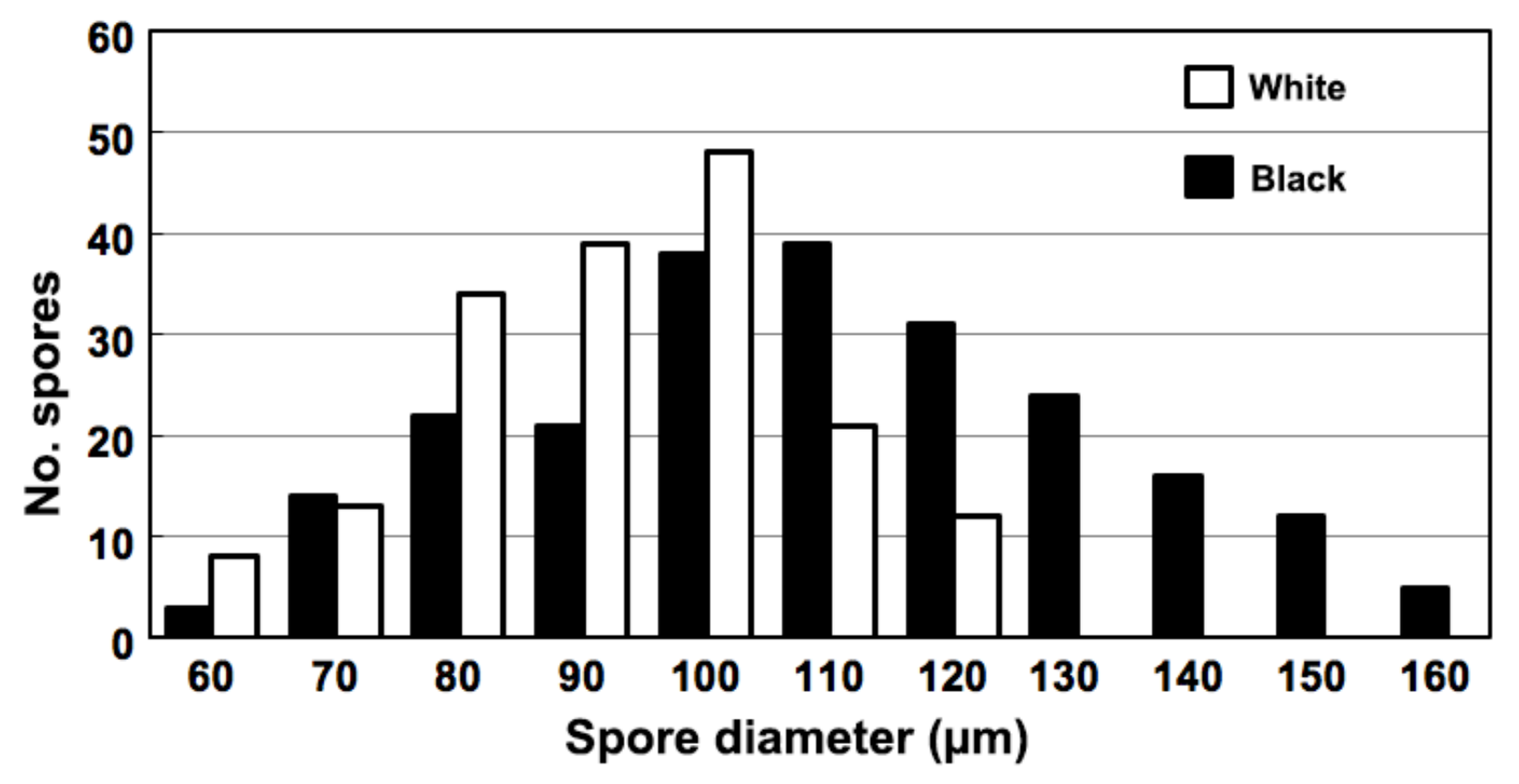


Figure 2. Spore diameter size distribution of the white and black synanamorphs of $R$. dimorphicus.

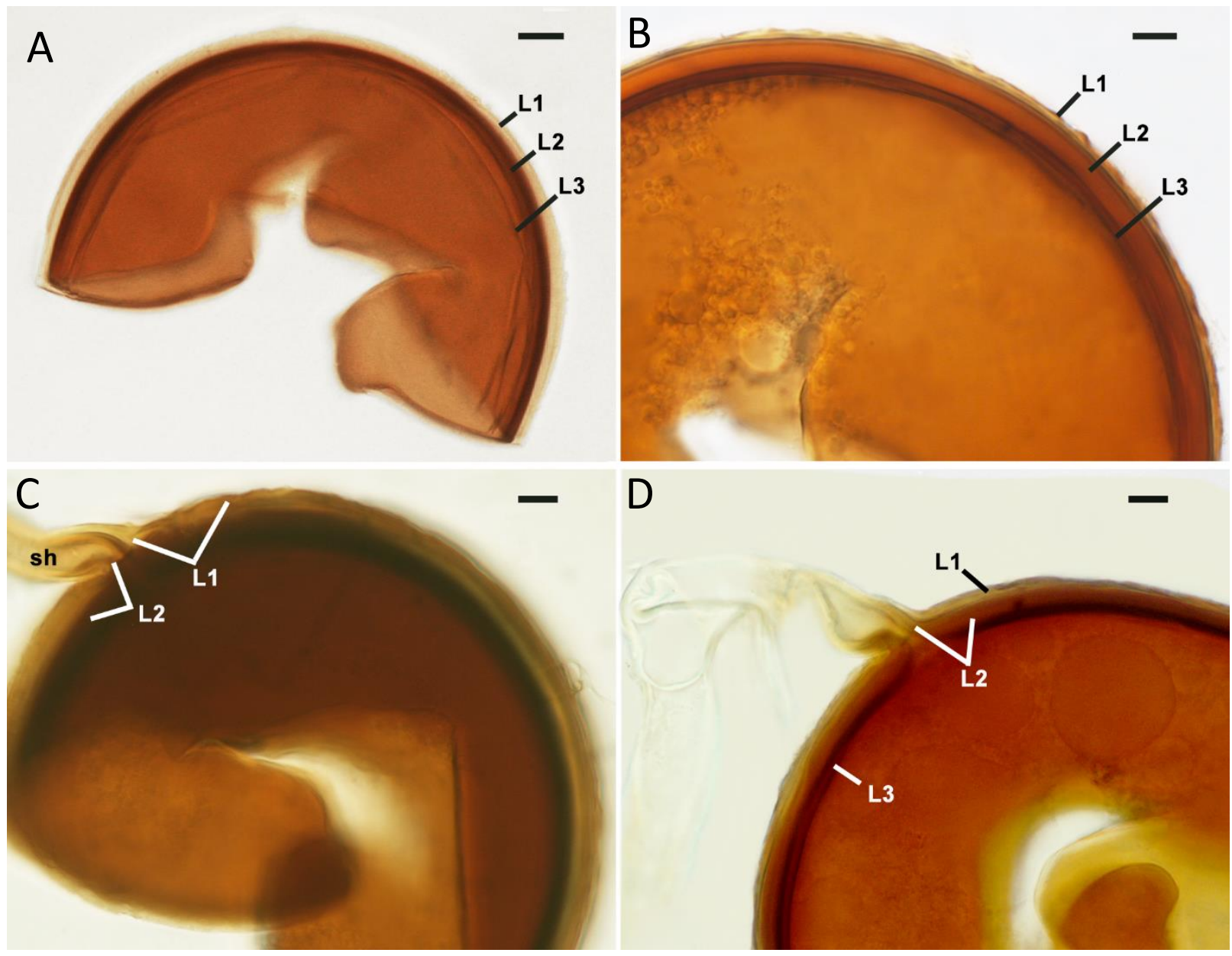


Figure 3. Representative images of the dark synanamorph of $R$. dimorphicus strain FL727 showing the three-layered spore wall structure. A. Spore mounted in PVLG, with the inner layer having some flexibility (folding). B. Spore mounted in Melzer's reagent. C. Spore in Melzer's reagent showing the two-layered subtending hypha at the spore base. D. Spore in Melzer's reagent exhibiting a constricted subtending hyphae.

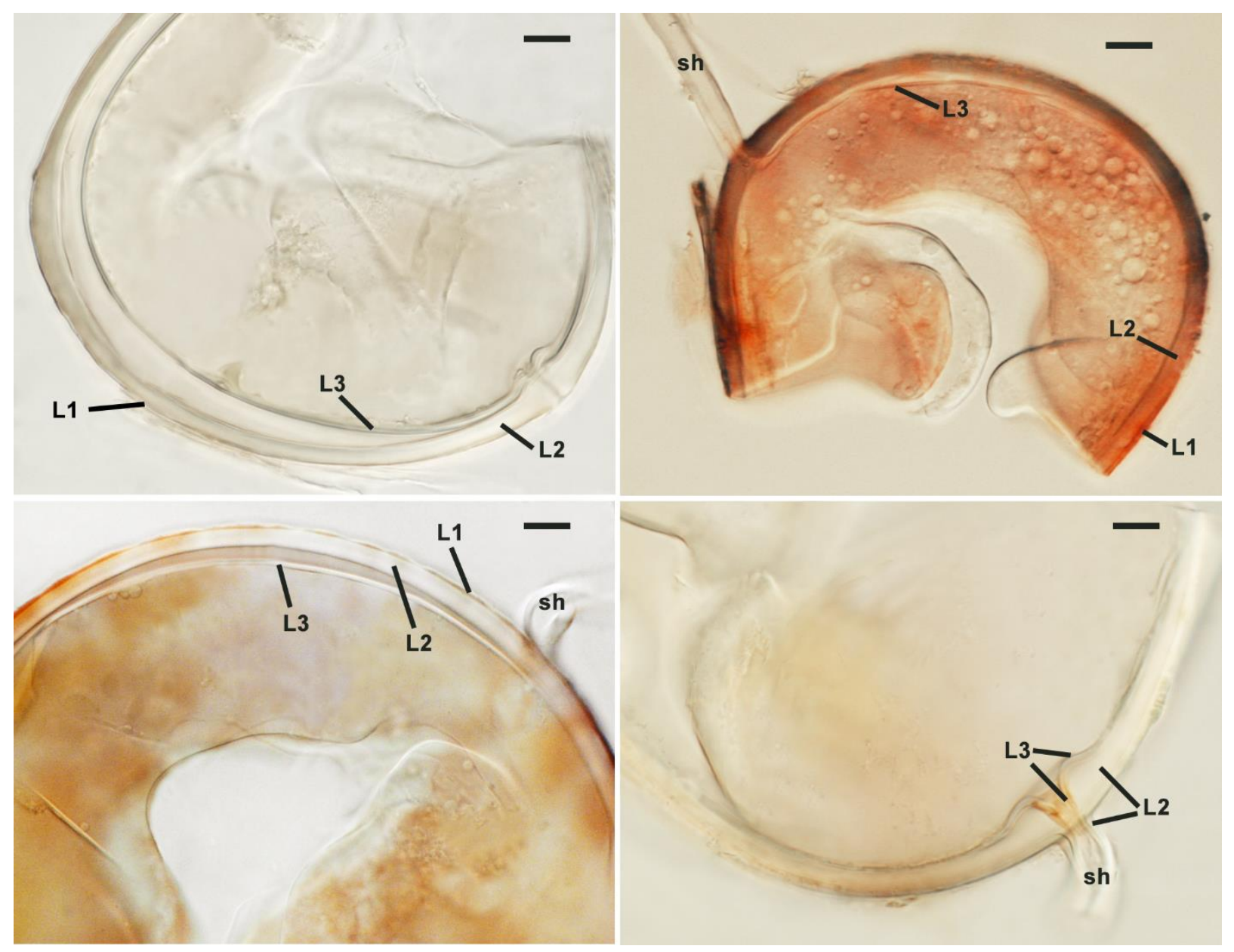

Figure 4. Representative images of the white synanamorph of $R$. dimorphicus strain FL727. A. Spore mounted in PVLG showing two permanent spore wall layers (L2, L3) and remnants of the 
sloughing outer (L1) layer. B. Young spore mounted in Melzer's reagent showing all three spore wall layers and the dark red reaction of L1. C. Spore in Melzer's reagent showing the lack of any reaction in the inner two wall layers (L2, L3). D. Spore in Melzer's showing the continuation of both inner spore wall layers in the subtending hypha and a sloughed outer layer (L1).

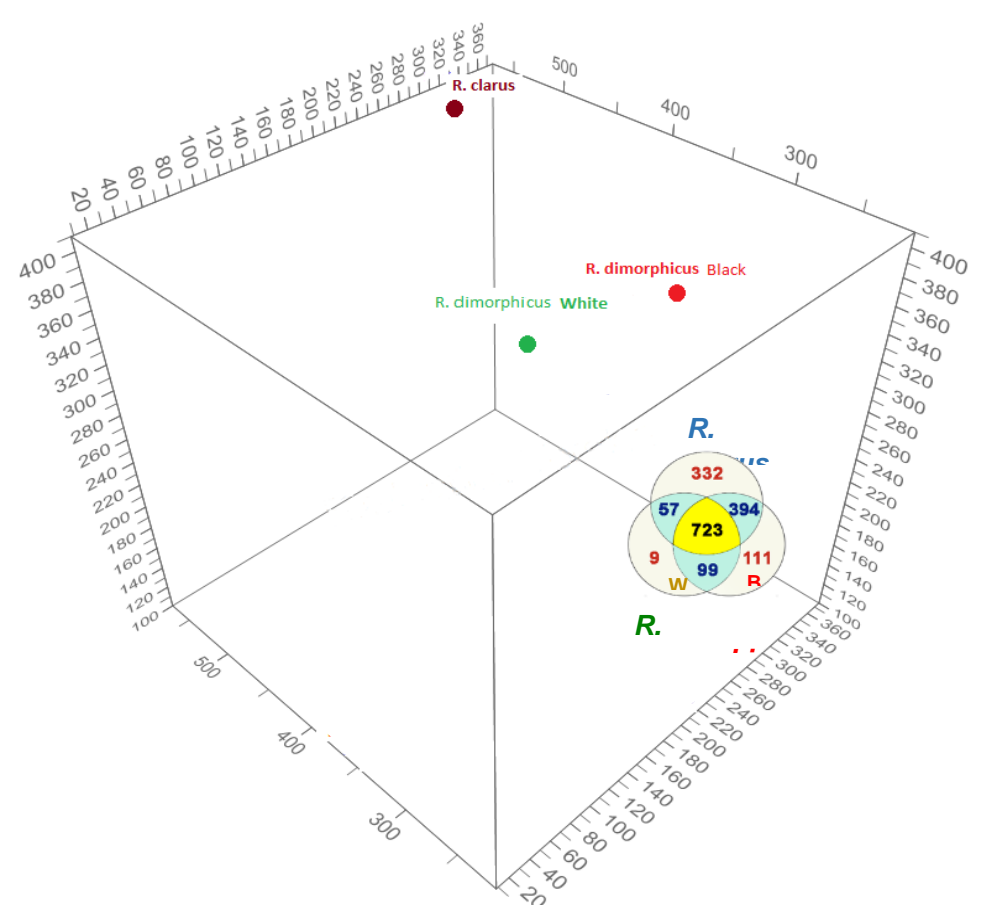


Figure 5. Principal component analysis (PCA) plot showing separation between the dark and white synanamorphs of $R$. dimorphicus strain FL727 and spores of $R$. clarus WV235. The Venn diagram shows the number of shared and unique proteins expressed by all three spore types from the two species.

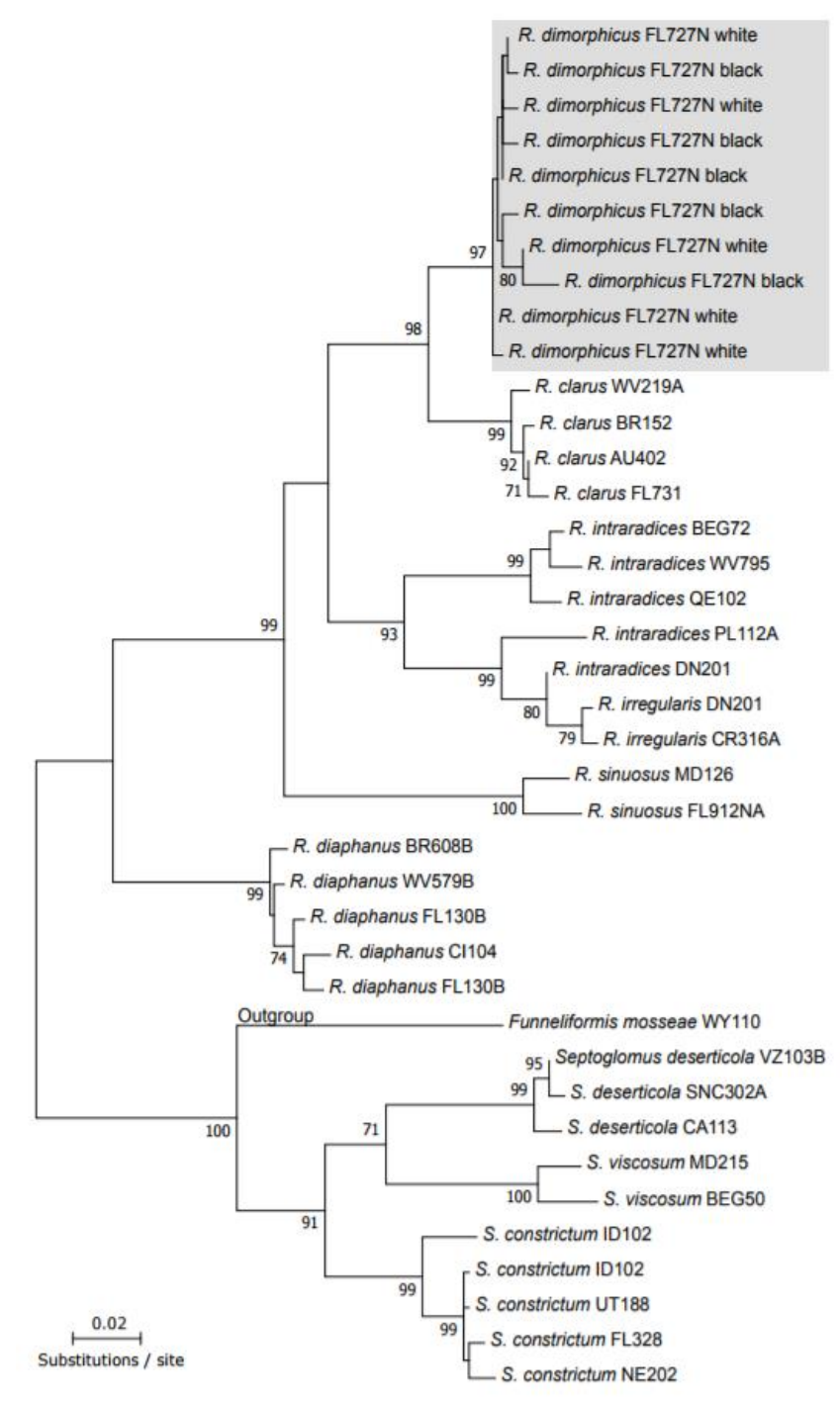


Figure 6. LSU maximum likelihood (ML) phylogenetic tree for Rhizophagus dimorphicus Bootstrap support is indicated near each node and only values greater than $70 \%$ are shown.
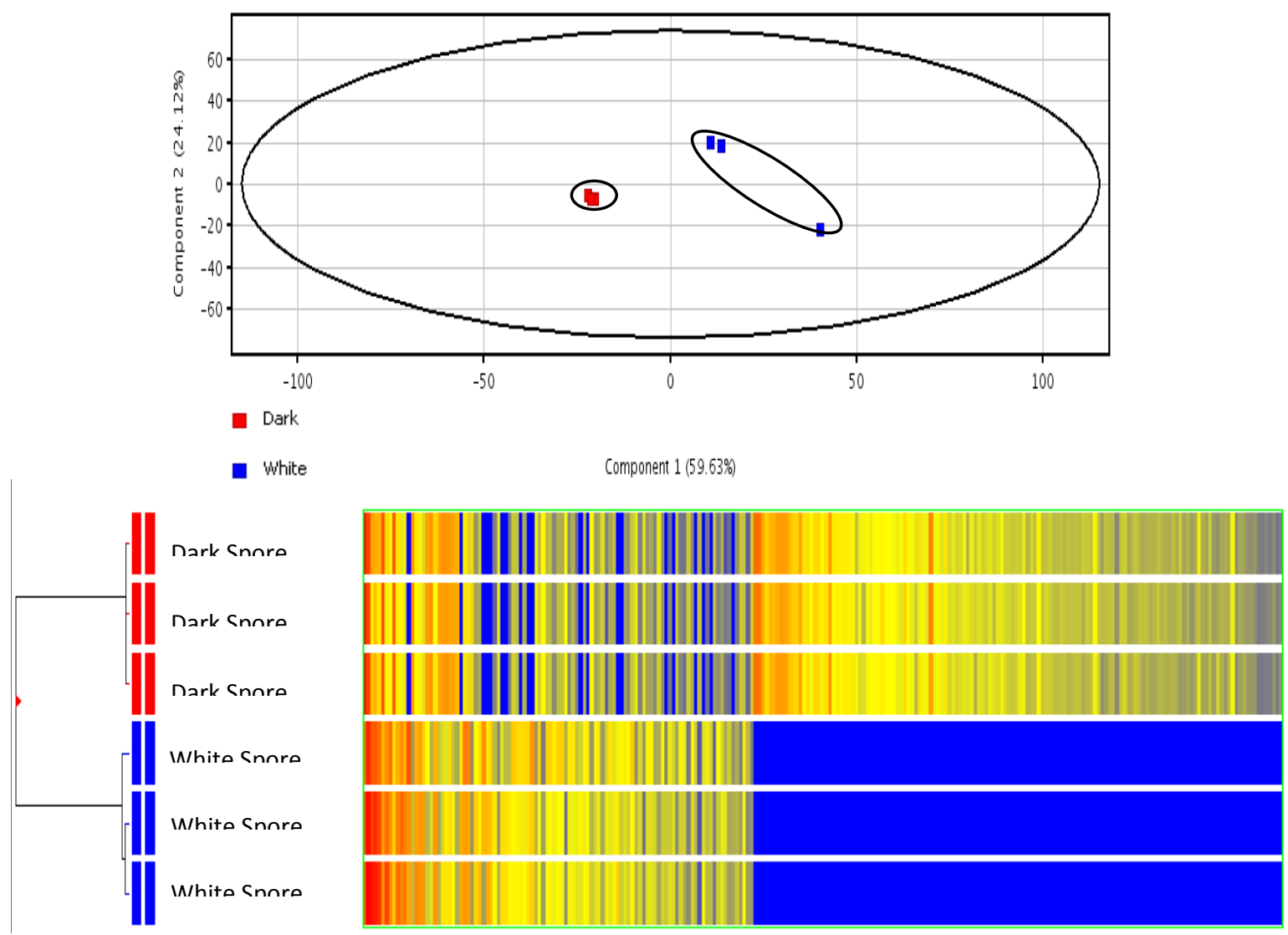

Figure 7. PCA from the global metabolomics analysis of the two snynanamorphs of $R$.

dimorphicus strain FL727 (top). The separation between the two morphotypes indicates a high level of variation between their metabolomes. The clustering analysis and heat map (bottom) confirm the trends in the PCA plot, showing the separation of the two morphotypes into separate 
clusters. The heat map visualizes the truncated metabolome of the white morphotype, with the large area of down-regulated metabolites depicted in blue.

\title{
Chapter 3 Applied metabolomics reveals host and environmental influence on metabolism in Rhizophagus clarus
}

\begin{abstract}
Arbuscular mycorrhizal fungi (AMF) are soil-inhabiting mutualists that obligately associate with a majority of vascular plant species and show little evidence for host specificity. Their obligate lifestyle and multinucleate state have impeded traditional genetic approaches. Yet, previous studies have confirmed that the AMF spores are metabolically active, and thus can serve to explore the metabolome of these fungi independent of their plant host. An applied metabolomics approach was used to elucidate the impact of host genotype and soil $\mathrm{pH}$ environment individually and together on the primary metabolism of Rhizophagus clarus, selected because it is a fungal mutualist occurring across a diversity of habitats and locations worldwide. The specific goal was to determine the relative role of host and soil $\mathrm{pH}$ on global metabolite expression in new spores. Two leguminous plant species, Robinia pseudoacia (black locust) and Trifolium pratense (red clover) were inoculated and grown at $\mathrm{pH} 4.5$ and 7.5 in a growth room. Fungal spores yielded distinct metabolic profiles in each host and in soil $\mathrm{pH}$ environment.
\end{abstract}


However, soil $\mathrm{pH}$ caused a greater influence on overall spore metabolism. Multiple classes of metabolites were detected, with 44 unique metabolites expressed as a result of a change in $\mathrm{pH}$ compared to 11 unique metabolites expressed in response to a change in plant host. Fifteen unique metabolites were attributed to a combined change of host and $\mathrm{pH}$. Pathway analysis showed significant changes in intermediates and end products of the glutamate catabolism pathway as a function of change in soil $\mathrm{pH}$. These results suggest that the capacity of $R$. clarus spores to catabolize glutamate into fumarate and ammonia contributes to regulation of $\mathrm{pH}$ in the rhizosphere. Metabolite expression in spores following mycorrhizal development provides new clues as to how an AMF fungus can regulate the $\mathrm{pH}$ of its host or soil environment and thus facilitate widespread colonization across a range of conditions.

\section{Introduction}

Arbuscular mycorrhizal fungi (AMF) are soil-inhabiting fungi that form mutualistic associations with over $80 \%$ of vascular plants, and are found on every continent. The first appearance of these fungi coincides with the appearance of land plants (Davison et al. 2015). These fungi also form this association with plants in almost any terrestrial ecosystem with little evidence of host plant preference (Smith and Read 2008). The association between plants and AMF improves phosphorus and water uptake as well as some level of pathogen and toxicity protection to the plant (Jeffries et al. 2003). In exchange, the fungus obtains carbon from photosynthetic output of the plant (Davison et al. 2015). The AMF symbiosis with plants has been shown to play an important role in improving species richness, biodiversity, and plant community stability (Van der Heijde et al. 2008).

This association has been shown to increase production of secondary metabolites by the plant (Chen et al. 2013) and also improve the host plant's nitrogen and phosphorus metabolism 
(Mensah et al. 2015). While the metabolic changes induced by the fungal symbiosis in the host plant have been explored, there has been little investigation of the changes in fungal metabolism occurring during this symbiosis. The fungal symbiont is able to consume up to $20 \%$ of the photosynthetic product in the form of carbohydrates(Bago et al. 1999). The carbon in the form of hexoses such as glucose and fructose are delivered to the fungus at the arbuscule, where it is then transported into the mycelia and used to synthesize lipids (Bago et al. 1999). The lipids then are sent to the extraradical mycelia where they are utilized in spore production and as storage compounds in spores (Pfeffer et al. 1999).

Newly-formed spores of arbuscular mycorrhizal fungi are metabolically active. The enzymes involved in tricarboxylic acid cycle, such as malate dehydrogenase, are more active in germinating spores than in intra-radical or extra-radical hyphae of Gigaspora margarita (Saito 1995). Enzyme activity of glucose-6-phosphate dehydrogenase also is greater in germinated spores than in somatic hyphae, while the activity of phosphofructokinase differed little between spores and hyphae. Therefore, the physiology of AMF spores can be used experimentally to explore the metabolome of the fungus separate from that of its plant host. While approaches have been taken to explore targeted enzyme activity within the spores of AMF (Bago et al. 2000), global metabolic activity of spores has not yet been investigated.

Fungi are known to have that ability to thrive in a wide range of environmental pH (Rousk et al. 2009, Martin et al. 2012, Yee et al. 2016). Arbuscular mycorrhizal fungi also are able to tolerate a range of metal impacted and soil $\mathrm{pH}$ environments(Coughlan et al. 2000). While species diversity may change in fungal populations exposed to varied soil $\mathrm{pH}$ conditions (e.g., Del Val et al. 1999), evidence indicates little impact on functionality of the symbiosis(Coughlan et al. 2000). When examining the effects of soil chemistry changes on sporulation and spore 
germination of AMF communities in saline soils, a range in soil $\mathrm{pH}$ environments had little impact (Aliasgharzadeh et al. 2001). The dominant AMF species in these high soil saline communities were from the genus Rhizophagus, which consist of species that tolerate a wide range of habitats worldwide (Savary et al. 2017). The metabolic processes occurring within the fungi in response to these environmental changes have not been explored. Therefore, Rhizophagus clarus was chosen as the model species for this work due to its pandemic distribution and tolerance to many environments. The goal of this work was to explore the global metabolome in spores of Rhizophagus clarus produced after the fungus was grown on two highly mycotrophic phylogenetically distant leguminous plant hosts in soils at $\mathrm{pH} 4.5$ and 7.5. Bioinformatics tools were used to discover functional metabolic pathways impacted by this combination of host-soil $\mathrm{pH}$ environments.

\section{Materials and Methods}

\section{Experimental Material}

The fungal isolate used in this study, Rhizophagus clarus WV235, was isolated originally from an abandoned strip mine site in Monongalia county West Virginia and obtained from International Culture Collection of Arbuscular and Vesicular Mycorrhizal Fungi (INVAM, West Virginia University).

\section{Experimental Design}

Pot culture inoculum of $R$. clarus WV235, which consisted of a sand and soil mixture $(3: 1 \mathrm{v} / \mathrm{v})$, mycorrhizal root fragments of Sorghum sudanense, asexual spores and external fungal hyphae was diluted 1:10 (v/v) with the same presterilized sand-soil potting medium with $\mathrm{pH}$ 
equilibrated to 4.5 and 7.5 using calcium chloride. Six sterilized Robinia pseudoacia (black locust) and six sterilized Trifolium pratense (red clover) seeds were sown into four replicate $4 \mathrm{x}$ $21 \mathrm{~cm}$ cone-tainers ${ }^{\mathrm{TM}}$ (Stuewe and Sons Inc., Corvallis, Oregon) and grown in a growth room

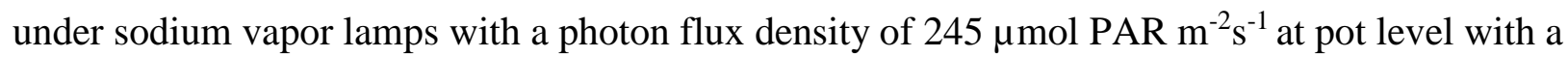
14-hour photoperiod for 10 weeks. Ambient temperature ranged from $22-30^{\circ} \mathrm{C}$ for the duration of the experiment.

After 10 weeks, the mycorrhizal plant in each cone-tainer was surrounded with a $40 \mu \mathrm{m}$ nylon mesh transplanting into the center of a $15-\mathrm{cm}$ diameter pot. The mesh allowed fungal hyphae to spread into the surrounding soil, but prevented spores from passing through. The soil around the periphery of the mesh-encased transplant was seeded with the same host, 4 plants per pot. Spores produced from the peripheral plants were collected at 6 and 10 weeks after emergence. Spores were extracted by wet-sieving through nested sieves with $500 \mu \mathrm{m}$ and $38 \mu \mathrm{m}$ openings, followed by sucrose-density gradient centrifugation. The step gradient consisted of a $20 \%$ and $60 \%$ sucrose and was centrifuged at $900 g$ for 2 minutes. Suspended spores were then removed and washed with tap water, placed in a petri dish, and manually collected using a Pasteur pipette and a stereomicroscope.

\section{Spore metabolite extraction}

Extracted spores were placed into $0.5 \mathrm{~mL}$ tubes and sonicated for 10 minutes. Following sonication, the spores were washed three times with 50:50 methanol and water to remove any residual plant metabolites from the outside surface of the spore. Washed spores then were manually lysed using a pestle in $50 \mu \mathrm{L}$ of a chilled $100 \%$ methanol to extract polar metabolites. Spore lysates were centrifuged at $14,000 \mathrm{x} g$ for 15 minutes at $4^{\circ} \mathrm{C}$ to pellet proteins and spore debris. The supernatant was removed for mass spectrometry analysis. 


\section{Normalization of samples by spore protein content}

Samples were normalized based on total protein concentration. The spore lysate was taken through a bicinchoninic acid assay (BCA assay) to determine protein concentration. The Pierce BCA Protein Assay Kit was used for total protein quantitation following the kit's recommended protocol. A volume totaling $500 \mu \mathrm{g}$ of total protein from each treatment was used to extract metabolites.

\section{Analytical procedure and LC-MS Conditions}

The Agilent LC-MS system (Agilent Technologies, Santa Clara, CA, USA) included an Agilent 1290 Infinity quaternary ultra-high pressure liquid chromatography (UHPLC) pump. This LC system was coupled to an Agilent 6530 quadrupole time of flight (Q-ToF) mass spectrometer with electrospray ionization. The chromatographic separations were performed using a Merck polymeric bead based ZIC-pHILIC column (100mmx2.1mm, $5 \mu \mathrm{m})$.

\section{$\underline{\text { Data Processing and Metabolite identification }}$}

The LC-MS/MS data acquired using Agilent Mass Hunter Workstation (*.d files) was processed in Profinder software for batch recursive analysis. The datasets were subjected to spectral peak extraction with a minimum peak height of 600 counts and the charge state for each metabolite was restricted to two. Further, retention time and mass alignment corrections were performed using Agilent Profinder software version 2.3.1 on the runs to remove non-reproducible signals. 
The resulting features were then exported as *.cef files to Mass Profiler Professional (MPP) software version 2.4.3 (Agilent Technologies, Santa Clara, CA, USA) for statistical analysis.

\section{$\underline{\text { Statistical Data Analysis }}$}

The extracted features were imported into MPP software for statistical analysis. Principle Component Analysis (PCA) was performed to check the quality of the samples, after which the data containing filtered features were analyzed by unpaired t-test to determine the differences between the control and roundup groups. Only the analytes with p values $<0.05$ and fold change (FC) $>2$ were regarded as statistically significant. Additionally, multiple test corrections using Bonferroni were applied to reduce false positives and false negatives in the data. The statistically filtered data was exported to Mass Hunter for targeted MS/MS analysis.

\section{Pathway Analysis}

A metabolomics pathway experiment was performed on the statistically significant data for the control and treatment groups using MPP software. Curated pathways such as BioCyc, KEGG and WikiPathways were used to map expression of significant compounds. 


\section{Results}

Rhizophagus clarus at two different soil pH conditions (4.5 and 7.5) and on two phylogenetically distant legume plant hosts (Robinia pseudoacacia and Trifolium pratense) yielded distinct metabolite profiles from fungal spores. While both the host and soil $\mathrm{pH}$ impacted the global metabolome of $R$. clarus spores, $\mathrm{pH}$ had the greater impact. A total of 715 distinct metabolites were detected from the global metabolomics analysis, of which 44 reached detectable levels as a result of a change in $\mathrm{pH}$ of the growth medium (Fig. 1). Only 11 unique metabolites were detected in response to a change in plant host, whereas 15 unique metabolites accumulated to detectable levels with a combined change of host and $\mathrm{pH}$. While qualitative differences in metabolites were detected in each of these treatments, some metabolites were shared among treatments but varied quantitatively depending on the environment in which the fungus was growing. The majority of the changes in metabolome occurred as an effect of a change in soil $\mathrm{pH}$. The effect of the host on changes in the spore metabolome was greater at $\mathrm{pH}$ 7.5 .

The impact of environmental effects on the global metabolome of $R$. clarus spores were evident in a principal component analysis (PCA) plot (Fig. 2), wherein $\mathrm{pH}$ of the growth medium provided the greatest separation between treatments. Principal component 1 contributed 27.75\% of the variation and consisted mostly of amino acids and secondary metabolites, while principal component 2 contributed $14.13 \%$ of the variation and consisted primarily of lipids and lipid precursors. A hierarchal clustering analysis performed on the normalized intensity values from the complete data set (Fig. 2) using a Euclidean similarity measurement showed the metabolomes of $R$. clarus spore samples clustered together based on $\mathrm{pH}$ of the growth media rather than the host on which they were grown. 


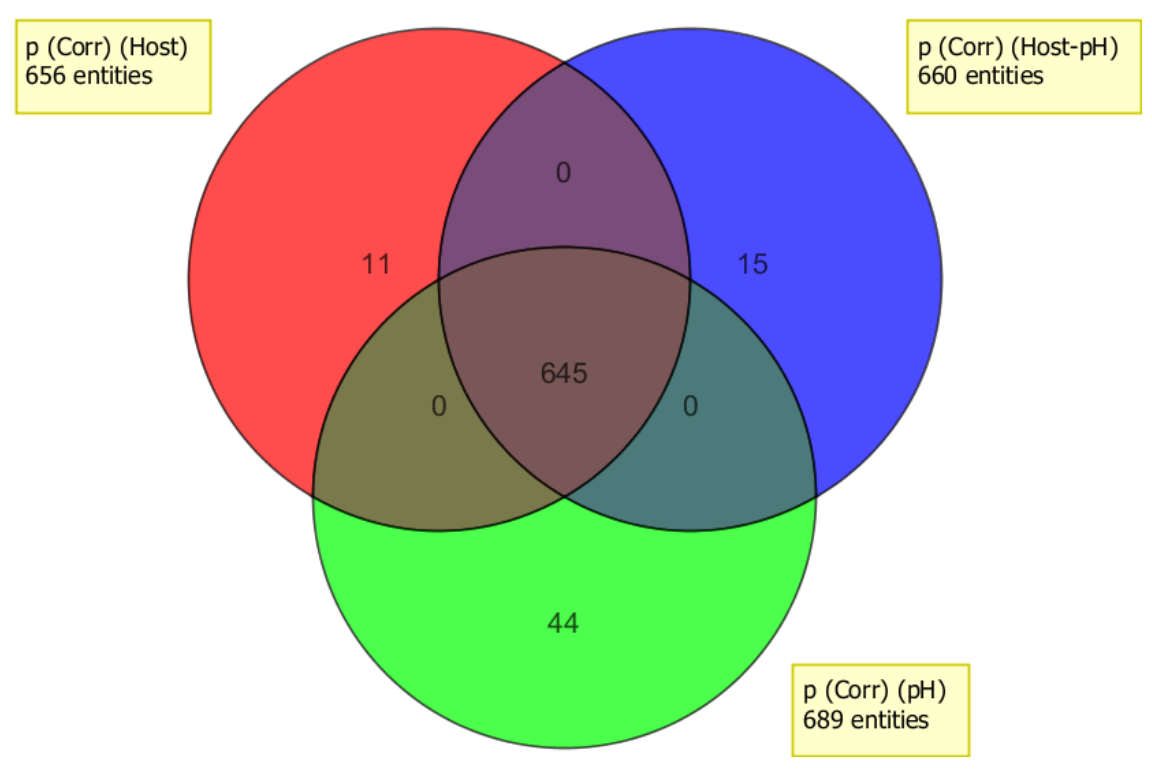

Figure 1. Venn diagram showing the number of significantly different unique metabolites detected in the metabolome of Rhizophagus clarus spores produced in response to three 
treatment variables: host species (Trifolium pretense, Robinia pseudoacacia), $\mathrm{pH}(4.5,7.5)$ of a sand-soil (3:1 v/v) growth medium, and host-pH interaction.
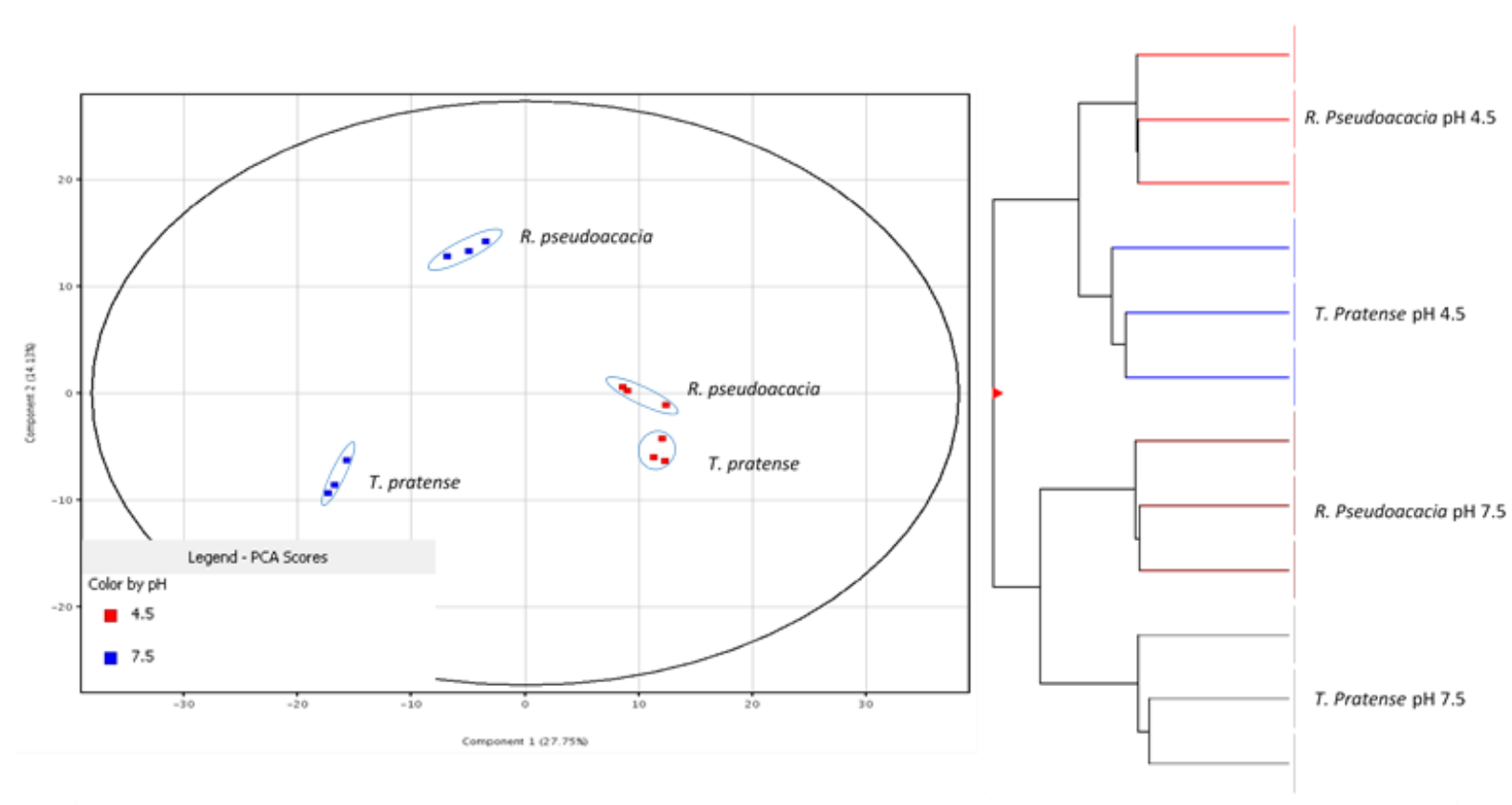
Figure 2. Variation in the global metabolome in $R$. clarus spores formed in three-month-old pot cultures of Robinia pseudoacadia and Trifolium pratense at two divergent $\mathrm{pH}$ environments (4.5 and 7.5) in a sand-soil (3:1 v/v) growth medium. Left: Principal component analysis of 715 detected metabolites. Right: A global hierarchical clustering analysis of these metabolites.

Multiple classes of metabolites were detected, including amino acids, nucleotides, nucleotide sugars, TCA cycle intermediates, secondary metabolites, lipids, and lipid precursors. Selected metabolites from each of these classes were targeted for further analysis based on a preliminary pathway analysis. The pathway analysis showed significant changes in intermediates and end products of the glutamate catabolism pathway as a function of change in medium pH (Fig. 3). Alpha-ketoglutarate and fumarate were upregulated in spores produced in both host species at $\mathrm{pH} 4.5$ compared to levels of expression measured at pH 7.5. Conversely, significantly lower concentrations of glutamate, glutamine, and aspartate were measured in the $\mathrm{pH} 4.5$ samples compared to those at $\mathrm{pH}$ 7.5. The absolute quantification data (Fig. 3) matched the trends observed from the full scan fold change data (Table 1) and show this pathway was up-regulated in the lower soil $\mathrm{pH}$ environment. 


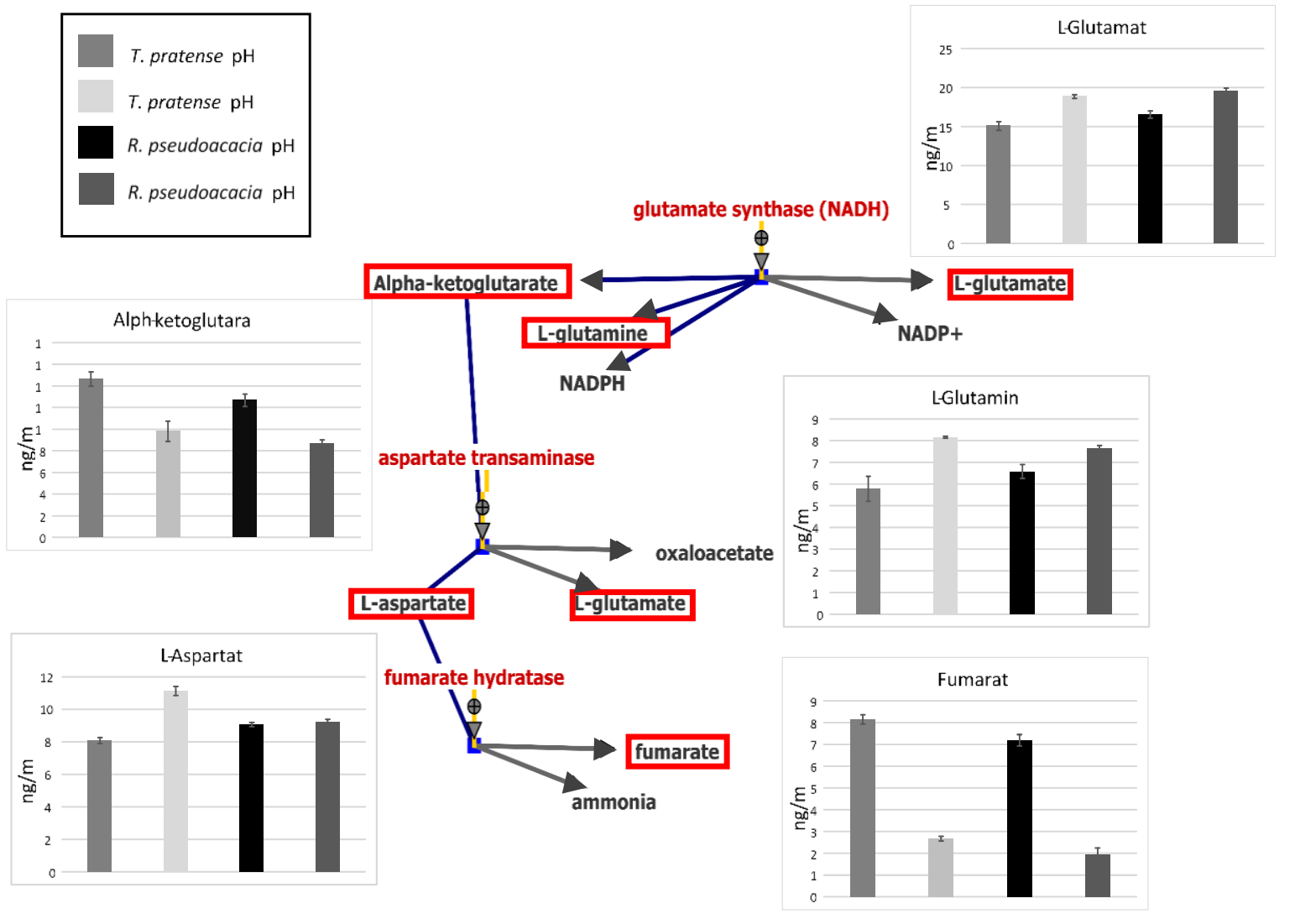


Figure 3. Illustration of the glutamic acid catabolism pathway together with absolute concentrations $(\mathrm{ng} / \mathrm{mL})$ of metabolites detected in this pathway from extracts of R. clarus spores sampled from three-month-old pot cultures of Robinia pseudoacacia and Trifolium pratense growing in a growth medium of sand-soil (3:1 v/v) equilibrated at $\mathrm{pH} 4.5$ and 7.5. Error bars represent standard deviation of samples from three replicate pot cultures of each treatment.

Table 1. Absolute concentrations (ng/mL) and standard deviation of targeted metabolites expressed in spores of $R$. clarus extracted from three-month old Trifolium and Robinia species growing in a sand-soil growth medium $(3: 1 \mathrm{v} / \mathrm{v})$ at two $\mathrm{pH} 4.5$ and 7.5.

\begin{tabular}{|c|c|c|c|c|c|}
\hline Metabolite & $\begin{array}{c}\text { Fold } \\
\text { change pH } \\
4.5 \text { vs. } 7.5\end{array}$ & $\begin{array}{l}\text { T. pretense } \\
\text { pH } 4.5\end{array}$ & $\begin{array}{l}\text { T. pretense } \\
\text { pH } 7.5\end{array}$ & $\begin{array}{c}\text { R. pseudoacacia } \\
\text { pH } 4.5\end{array}$ & $\begin{array}{c}\text { R. pseudoacacia } \\
\text { pH } 7.5\end{array}$ \\
\hline Ethanolamine & 2.4 & $14.4 \pm 0.7$ & BLQ & $9.3 \pm 0.7$ & $0.9 \pm 0.3$ \\
\hline myo-Inositol & -3.5 & $4.3 \pm 0.8$ & $8.7 \pm 0.9$ & $6.6 \pm 0.9$ & $9.3 \pm 0.8$ \\
\hline Choline & 1.2 & $8.9 \pm 0.5$ & $9.3 \pm 0.6$ & $9.7 \pm 0.7$ & $8.9 \pm 0.6$ \\
\hline Lactate & 1.8 & $1.5 \pm 0.2$ & $1.2 \pm 0.1$ & $1.6 \pm 0.2$ & $1.1 \pm 0.2$ \\
\hline Citrate & -1.4 & $4.3 \pm 0.3$ & $5.5 \pm 0.3$ & $4.5 \pm 0.3$ & $5.2 \pm 0.4$ \\
\hline Fumarate & 3.1 & $8.2 \pm 0.2$ & $2.7 \pm 0.1$ & $7.2 \pm 0.3$ & $1.9 \pm 0.3$ \\
\hline$\alpha$-ketoglutarate & 2.3 & $14.6 \pm 0.6$ & $9.8 \pm 0.9$ & $12.6 \pm 0.6$ & $8.6 \pm 0.4$ \\
\hline Alanine & -4.3 & $23.1 \pm 1.2$ & $47.8 \pm 0.3$ & $32.6 \pm 0.9$ & $38.6 \pm 0.7$ \\
\hline Arginine & -1.8 & $621.6 \pm 16.4$ & $755.3 \pm 23.7$ & $585.6 \pm 14.8$ & $685.6 \pm 15.2$ \\
\hline Aspartate & -1.2 & $80.8 \pm 1.9$ & $111.3 \pm 2.8$ & $90.6 \pm 1.3$ & $92.4 \pm 1.5$ \\
\hline Glutamate & -2.1 & $150.6 \pm 5.6$ & $188.3 \pm 2.4$ & $165.2 \pm 4.5$ & $195.6 \pm 3.2$ \\
\hline Glutamine & -4.6 & $57.8 \pm 5.7$ & $81.6 \pm 0.5$ & $65.3 \pm 3.3$ & $76.5 \pm 1.3$ \\
\hline Lysine & -2.3 & $86.8 \pm 8.1$ & $151 \pm 8.5$ & $110 \pm 27.2$ & $121 \pm 6.4$ \\
\hline Phenylalanine & 3.1 & $1.3 \pm 0.03$ & $0.2 \pm 0.1$ & $1.6 \pm 0.1$ & $0.6 \pm 0.1$ \\
\hline Proline & 1.6 & $7.9 \pm 0.2$ & $5.2 \pm 0.2$ & $8.7 \pm 0.6$ & $6.9 \pm 0.4$ \\
\hline Tyrosine & 1.6 & $10.2 \pm 0.2$ & $9.8 \pm 0.6$ & $9.7 \pm 0.7$ & $8.7 \pm 0.9$ \\
\hline Tryptophan & -1.2 & $3.1 \pm 0.6$ & $4.2 \pm 0.2$ & $6.2 \pm 0.6$ & $5.2 \pm 0.4$ \\
\hline
\end{tabular}

$B L Q$, below limit of quantification 


\section{Discussion}

The observed upregulation of the glutamate catabolism pathway as a response the lower $\mathrm{pH}$ of the growth medium shows that Rhizophagus clarus spores have the ability to catabolize glutamate into fumarate and ammonia, which may contribute to regulation of $\mathrm{pH}$ in the rhizosphere. Pathenogenic fungi have been shown to regulate the $\mathrm{pH}$ of their host issues through the secretion of ammonium to elevate the $\mathrm{pH}$ to modulate the host's immune response and breakdown tissue (Alkan et al. 2009). Colletotrichum coccodes virulence of tomato fruit has been directly tied to the amount of ammonium secreted by the pathogen (Alkan et al. 2009). The secreted ammonium has been shown to increase the levels of tissue-induced $\mathrm{H}_{2} \mathrm{O}_{2}$, which increased tissue necrosis in Solanum lycopersicum. Ammonium is a key biological molecule used by fungi for the alkalization of their environment. Ammonia can be secreted by the fungi and then subsequently converted by ureases to $\mathrm{NH}_{4}{ }^{+}$in the environment (Vylkova 2017). The significant fold changes in the intermediates of this pathway were confirmed in the targeted quantification experiments, providing evidence that the glutamate catabolism was highly upregulated in the $\mathrm{pH} 4.5$ samples compared to expression in the $\mathrm{pH} 7.5$ samples.

Rhizophagus clarus may release secondary metabolites that alter plant rhizosphere $\mathrm{pH}$. (Orozco-Patiño and Medina-Sierra 2013) found that $R$. clarus grown in association with Pueraria phaseoloides (kudzu) at $\mathrm{pH} 8.5$ and $\mathrm{pH} 6.0$ altered the $\mathrm{pH}$ of the growth medium, lowering and raising it, respectively, to a $\mathrm{pH}$ of 7.0. Rhizophagus clarus is able to successfully colonize plant hosts at $\mathrm{pH}$ levels as low as 4.0 (Clark et al. 1999). The ability for the R. clarus to change its metabolic processes to manipulate the rhizosphere could help explain the ability of this fungi to persist in such a wide range of soil $\mathrm{pH}$ environments. The upregulation of the 
glutamate catabolism pathway in spores suggests a possible metabolic mechanism that contributes to the manipulation of rhizosphere $\mathrm{pH}$.

The four-fold decrease in number of significantly changing metabolites observed between the two host species compared to the soil $\mathrm{pH}$ change may be due in part to the absence of host specificity by arbuscular mycorrhizal fungi (Albrecht et al. 1999, Davison et al. 2015). This lack of any major host impact on the metabolism of the spores of $R$. clarus suggests that the level of metabolic pressure on the fungus by the host plant is less than that of the soil environment. This result further strengthens existing evidence of wide host range and little host specificity (Bolan 1991).

The results of this experiment could help guide future experiments exploring the metabolism of the arbuscular mycorrhizal fungi. The lack of host influence on the metabolome of the fungi allows metabolomics experiments to be performed on any host that will accept the fungal association. The significant impact of the environmental changes on the fungal metabolome provides a new technique for investigating the function of these obligate symbionts. The ability to manipulate the environmental conditions in which these fungi are cultured to elicit different metabolic responses can be used to test new hypotheses about their functional capacity. Theses metabolic function experiments could be used to assign function to uncharacterized portions of the genome. 


\title{
Chapter 4 Metabolomics of the cicada pathogen Massospora confirms psilocybin and cathinone production in early diverging non-flagellated fungi
}

\begin{abstract}
The obligate lifestyle and large genome size of many of the entomopathogenic members of the Zoopagomycota have long precluded their study. Modern "omics"-based tools, including metagenomics, transciptomics and metabolomics, have facilitated a better understanding of these fungi despite barriers that still prevent traditional lab-based studies. Massospora is one of several members of the Entomophthorales for which a systems biology approach has yet to be employed to elucidate factors influencing host colonization and putative behavioral modification. A comparison of global and targeted metabolomes of two contemporary Massospora - cicada consortia, M. cicadina-infected periodical cicadas (Magicicada spp.) and M. platypediaeinfected banger-wing cicadas (Platypedia putnami) uncovered a diverse assortment of secondary
\end{abstract}


metabolites. These included psilocybin from M. platypediae and M. levispora and cathinone from M. cicadina. Fragmentation of pooled samples further validated their identity. Targeted quantification confirmed absolute concentration of psilocybin and psilocin, which are biologically significant as psychotropic compounds that could enhance aggressiveness/stamina of infected cicadas. Such a benefit would ensure continued spore dispersal despite debilitating infections that likely result in fatigue, decreased muscle strength and general malaise. Phylogenetic studies showed M. platypediae and M. levispora, both of which harbored psilocybin, grouped as a single clonal lineage and therefore are synonymized as M. levispora comb. nov. This study provides an initial view of the metabolic capacity of these enigmatic and cryptic fungi and offer clues of phylogenetic relationships heretofore unknown.

\section{Introduction}

The Entomophthorales (Zoopagomycota) comprise some of the most important insect- and arthropod-destroying "zygomycetes," including well-known examples such as Entomophthora muscae, causal agent of "summit disease" of flies, Entomophaga maimaiga, a virulent pathogen and biological control of gypsy moth, and Massospora cicadina, a behavior-modifying pathogen of periodical (13- and 17-year) cicadas (Cooley et al. 2017; Gryganskyi et al. 2017; Hughes et al. 2016; Spatafora et al. 2017). Many of these entomopathogens were formally described first by Thaxter (1888) and other early mycologists more than a century ago. Only recently have these species been phylogenetically resolved, including Arthropaga myriapodina, a recently described lethal summit pathogen of polydesmid millipedes (Gryganskyi et al. 2012, 2013; Hodge et al. 2017). 
The Zoopagomycota are considered the earliest diverging lineage of nonflagellated fungi, comprising 19 genera and 228 described species worldwide. Because of their large genome size and obligate lifestyle, they are underrepresented in GenBank with fewer than three publically available genomes and 125 DNA sequences representing only about 1-10\% of described species (Gryganskyi et al. 2017; Spatafora et al. 2017). Massospora cicadina, for example, is represented by only four DNA sequences (three $18 \mathrm{~S}$ and one $28 \mathrm{~S}$ ) from a single isolate (ARSEF 374). The overreliance on sequences derived from a single specimen poses risks to resolving species phylogenetically, and, at the same time, emphasizes the need for extensive taxa sampling to accurately characterize relationships among other memebrs of the Entomphthorales (Gryganskyi et al. 2012, 2013). Relationships between M. cicadina and the other twelve described Massospora species (Soper 1963, 1974, 1981) are unexplored because the group is so underrepresented. Powerful genomic, transcriptomic, and metabolomic approaches have helped elucidate some aspects of zygomycete evolution (Li et al. 2017; Małagocka et al. 2015; Meier et al. 2015; Sun et al. 2012; Zhou et al. 2014), yet many of the basic mechanisms that drive pathogenicity and behavioral manipulation, particularly among members of the Zoopagomycota (Cooley et al. 2017), are poorly understood compared to their Ascomycotan counterparts (de Bekker et al. 2013).

Despite gaps in Zoopagomycota systematics, much has been learned about their epizootiology. Massospora infections are conspicuous: the destruction of the intersegmental membranes of the cicada's abdomen incites a progressive sloughing off of the abdominal sclerites, revealing a clay-like expanding mass of infective conidia emerging from the posterior end of the insect. Over time, just the head and thorax of the living adult cicada remain and mass of conidia are passively disseminated during flight, feeding, and mating attempts. The latter 
renders the fungus sexually transmissible (Riley 1885, Butler 1886, Hopkins 1898, Goldstein 1929, Cooley et al. 2017). The lifecycle of the fungus is associated mostly with the later developmental stages of the cicada. Mature nymphs become infected by resting spores encountered underground during construction of their vertical emergence burrows, emergence, and eclosure into adults. Lastly, over a period of days, the fungus produces an exposed conidial mass that serves as inoculum for secondary infections of healthy cicadas. These infections give rise to azygospores that are reincorporated into to the soil to start the cycle again.

Within the Entomophthorales, complex infection and transmission strategies manipulate host behavior, such as the summit disease caused by ?????, where infected individuals move towards an elevated position to optimize spore dispersal (Gryganskyi et al. 2017, Hodges et al. 2017; Hughes et al. 2017, Roy et al. 2006). Species in Massospora and Strongwellsea, Entomophthora, Erynia, and Entomophaga are unique in that these fungi keep their hosts alive and interact in ways to control flight and/or dispersal behavior, thus ensuring that infected insects become a moving vector for spore dispersal (Cooley et al. 2017).

Several studies have examined behavior of Massospora-infected cicadas (Table S1). Most notably, Cooley and colleagues (2017) recently reported male M. cicadina-infected periodical cicadas with conidial infections exhibit precisely timed wing-flick signaling that attracts copulation attempts from conspecific males. This behavior normally is observed only in sexually receptive female cicadas. Likewise, Cooley (1999) reported Massospora levisporainfected male Okanagana rimosa exhibited similar sexual behavioral changes, resulting in bisexual behavior. Similar modifications in sexual behaviors have been observed in Diceroprocta spp. infected by $M$. diceroprocta (Jon Hastings, personal communication). Massospora platypediae-infected wing-banger cicadas (Platypedia putnami) also exhibited 
sexually ambiguous courtship behavior, moving towards other signaling cicadas regardless of sex and making frequent abdomen to abdomen contact (Murphy and Redden 2003). Together, these observations indicate that Massospora infections can give rise to an extended phenotype that hijacks cicadas, turning them into vectors for fungus transmission at the expense of the cicadas' own interests (Cooley et al. 2017).

The inability to culture a majority of the Zoopagomycota means that characterizing their activity, especially pathogenicity (e.g. secretion of secondary metabolites), requires approaches involving naturally infected individuals. Complications can arise because these individuals can be subject to secondary invasion by opportunistic fungi, bacteria, nematodes, and other microorganisms. Nonetheless, we used global and targeted metabolomics and metagenomics to compare two contemporary Massospora - cicada consortia, M. cicadina-infected periodical cicadas (Magicicada spp.) and M. platypediae-infected banger-wing cicadas (Platypedia putnami) to better understand factors influencing host colonization and putative behavioral modification.

This study was conducted to accomplish four objectives. The first was to reconstruct a phylogeny of three species of Massospora from annual and periodical cicadas and to explore their haplotypic diversity. Second, identification of species was validated by comparing spore morphology of specimens for which DNA sequences exist to that in published descriptions. Third, the total metabolic profiles of two contemporary Massospora - cicada consortia were compared to identify candidate metabolites important to entompathogenicity and behavioral modification. Last, targeted metabolomics were used to validate important up-regulated candidate metabolites from Massospora-infected cicadas. 


\section{Methods and Materials}

\section{$\underline{\text { Sampling fungus-infected cicadas }}$}

From May 28 to June 6, 2016, newly emerged Brood V 17-year periodical cicadas were visually inspected for Massospora fungal infections on the campus of West Virginia University

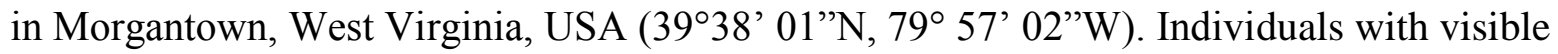
fungal plugs were transferred individually to sterile $20 \mathrm{~mL}$ vials, transported to the laboratory, and stored in a -20 C freezer until processing. Samples were obtained from 95 infected cicadas, of which 47 were from $M$. cassini, 41 from Magicicada septendecim, and seven from $M$. septendecula. A similar number of males and females were sampled across the three Brood V species, with 53 from females and 50 from males. Sampling was carried out on WVU property and did not require permits.

On June 1, 2016, additional geographically separated Brood V cicada populations were visually inspected for fungal infections. Seven infected specimens of $M$. septendecim and one of M. cassini were recovered from Hocking Co., OH. Concurrently, a collaborator provided an additional 34 infected Brood V specimens of $M$. septendecim collected from across five $\mathrm{OH}$ counties including Ashland, Cuyahoga, Hocking, Licking, and Lorain counties. Eight female, Massospora-infected, Brood VI specimens of Magicicada septendecim were collected in June, 2017 from North Carolina. All samples were collected and stored as previously described.

Twenty-three M. cicadina-infected specimens of Magicicada collected from 1978-2002 were provided from Dr. Chris Simon at the University of Connecticut, where they had been stored at room temperature, dried and pinned, since their collection. Dr. Gene Kritsky from Mount St. Joseph University provided fungal plugs from seven $M$. cicadina infected specimens 
of Magicicada collected from 1989-2008, three of which were thirteen year cicadas and four were 17-year cicadas.

In addition to periodic cicadas, two species of annual cicadas also were sampled and included in this study. On June 4, 2017, newly emerged banger-wing cicadas (Platypedia putnami) were inspected for Massospora infections $12 \mathrm{~km}$ northeast of Gallina, NM along the Continental Divide Trail. Sixteen infected individuals and one outwardly asymptomatic individual (to serve as a negative control) were identified and sampled as described above.

Nine Massospora levispora-infected specimens of Okanagana rimosa were collected by John Cooley from the University of Michigan Biological Station, Cheboygan and Emmet Counties, MI on June 20, 1998 (Cooley 1999). Infected individuals as well as outwardly asymptomatic individuals were placed immediately in individual 20-ml screw-cap vials containing $95 \%$ ethanol. Specimens were completely submerged and stored at $4 \mathrm{C}$ until October 2017, when specimens were sent to WVU for processing.

All fungus-infected and negative control cicadas were assigned a two letter code corresponding to the latin binomial (e.g. Massospora cicadina, MC) of the infecting strain followed by a unique number. Negative controls were designated NC1 for each species. Cicadas were processed aseptically, with half of the visible fungal plug removed with a sterile scalpel and transferred to a $1.5 \mathrm{ml}$ microcentrifuge tube for DNA extraction. Controls were processed similarly, where half of the most posterior segments as well as underlying host tissues were sampled. A majority of the remaining plug from infected individuals were used for global metabolomics analyses. Dry plugs were transferred aseptically to sterile $1.5 \mathrm{~mL}$ microcentrifuge tubes and stored at $20 \mathrm{C}$. A small sampling of spores was retained for morphological studies, although not all specimens were examined. 


\section{$\underline{\text { Morphological studies }}$}

Given the scarcity of Massospora sequences from NCBI GenBank, morphological comparisons were necessary to determine if data on putatively assigned Massospora species agreed with that of previously reported measurements for conidial and azygospore stages (Soper 1963, 1974). A portion of select fungal spore masses was harvested with a sterile scalpel and mounted in lactophenol for examination with light field microscopy. Slip covers were fastened with nail polish to allow slides to be archived and reexamined when necessary. Mean conidial/azygospore length $\mathrm{x}$ width and cicada host provided the main criteria to differentiate Massospora species. Slides were examined and photographed using a Nikon Eclipse E600 compound microscope (Nikon Instruments, Melville, New York) equipped with a Nikon Digital Sight DS-Ri1 high-resolution microscope camera. A sampling of 25 spores from each slide mount were measured using Nikon NIS-Elements BR3.2 imaging software. A total of 51 Massospora-infected cicadas were examined including 26 M. cicadina (15 conidial and 11 azygospore isolates), nine $M$. levispora (eight conidial and one azygospore isolates), and $15 M$. platypediae (14 conidial and one aygospore isolates).

\section{DNA extraction, amplification, sequencing, and phylogenetic analyses}

Fungal genomic DNA was extracted from harvested fungal plugs using a modified Wizard kit (Promega, Madison, WI, USA) as previously described (Short et al. 2015). DNA was suspended in $75 \mu 1$ Tris-EDTA (TE) buffer and stored at -20 C. Portions of the nuclear $18 \mathrm{~S}$ (SSU) and 28S (LSU) ribosomal DNA regions were amplified with the primer combinations 
NS24/NSSU1088R (Hodge et al. 2017) and LR0R/LR5 (Vilgalys and Hester 1990) using

BioLine PCR kits (Bioline USA Inc.,Taunton, MA, USA). PCR conditions were as follows. LSU: initial denaturation at $94^{\circ} \mathrm{C}$ for 2 minutes, 35 cycles of denaturation at $94^{\circ} \mathrm{C}$ for 30 seconds, annealing at $51.1^{\circ} \mathrm{C}$ for 45 seconds, and elongation at $72^{\circ} \mathrm{C}$ for 90 seconds, and final elongation at $72^{\circ} \mathrm{C}$ for 5 minutes; SSU: initial denaturation at $94^{\circ} \mathrm{C}$ for 5 minutes, 36 cycles of denaturation at $94^{\circ} \mathrm{C}$ for 30 seconds, annealing at $49^{\circ} \mathrm{C}$ for 30 seconds, and elongation at $72^{\circ} \mathrm{C}$ for 60 seconds, and final elongation at $72^{\circ} \mathrm{C}$ for 7 minutes. Amplified products were visualized with SYBR gold (Invitrogen, Grand Island, NY, USA), which then were loaded onto a 1-1.5\%, wt/vol agarose gel made with 0.5-1\% Tris-borate-EDTA buffer (Amresco, Solon, OH, USA). All products were purified with ExoSAP-IT (Affymetrix, Inc., Santa Clara, CA, USA) and submitted to Eurofins MWG Operon (Huntsville, AL,USA) for Sanger sequencing. Chromatograms were assembled and inspected in MEGA 7 (Kumar et al. 2016).

Phylogenetic trees were reconstructed using LSU and SSU sequences generated from 18 and 21 Massospora sequences, respectively, representing three Massospora species, M. cicadina, M. levispora and M. platypediae (Table X). The concatenated set consisted of four sequences, two from M. cicadina and one each from M. levispora and M. platypediae. Thirteen additional published sequences spanning the known diversity of the Entompohthorales were included to help resolve relationships among Massospora and its close allies (Hodge et al. 2017). One isolate of Conidiobolus pumilus (strain ARSEF 453) served as an outgroup. Sequences were aligned using CLUSTAL-W (Larkin et al. 2007). Alignments were visually inspected, after which optimized nucleotide substitution model (Tamura 3-parameter $+\mathrm{G}$ ) was selected using ModelTest X.X (Posada and Crandall, 1998). Partial deletion with site coverage cutoff of 95\% 
was used. Maximum likelihood (ML) trees were estimated using Mega 7. Phylogenetic support was assessed by bootstrap analysis with 1000 replicates using MEGA 7.

\section{Fungal metabolite extraction}

Fungal plugs were weighed and transferred into sterile $1.5 \mathrm{~mL}$ microcentifuge tubes. Metabolite extracts from each fungal sample were normalized to a final concentration of $10 \mathrm{mg}$ of fungal tissue to $1 \mathrm{~mL}$ and polar metabolites were extracted in a buffer consisting of $80 \%$ HPLC grade methanol and $20 \%$ water. Samples then were sonicated for 10 minutes. The sonicated samples were centrifuged at $14,000 \mathrm{x}$ g for 15 minutes at $4^{\circ} \mathrm{C}$ to pellet proteins and cellular debris. The supernatant was removed and dried down using lyophilization prior to analysis. Samples were reconstituted in $100 \mu \mathrm{L}$ of $50 \%$ methanol and $50 \%$ water for mass spectrometry analysis.

\section{Analytical procedure and LC-MS Conditions}

The Agilent LC-MS system (Agilent Technologies, Santa Clara, CA, USA) included an Agilent 1290 Infinity quaternary ultra-high pressure liquid chromatography (UHPLC) pump. This LC system was coupled to an Agilent 6530 quadrupole time of flight (Q-ToF) mass spectrometer with electrospray ionization. The chromatographic separations were performed using a Merck polymeric bead based ZIC-pHILIC column (100mmx2.1mm, $5 \mu \mathrm{m})$.

Mobile phase A consisted of $10 \mathrm{mM}$ ammonium acetate and mobile phase B consisted of $100 \%$ acetonitrile. Metabolites were separated on a gradient that went from $95 \%$ mobile phase to $5 \%$ mobile phase $\mathrm{B}$ over 20 minutes with 7-minute re-equilibration at the end of the chromatographic run. 
The mass spectrometer was operated in both positive and negative ion mode for the analysis. Technical replicates were acquired for each sample. Data dependent MS/MS was performed on triplicate pooled samples for fragmentation and library searching.

\section{Data Processing and Metabolite identification}

The LC-MS/MS data acquired using Agilent Mass Hunter Workstation (*.d files) were processed in Agilent Profinder software version 2.3.1 for batch recursive analysis. The datasets were subjected to spectral peak extraction with a minimum peak height of 600 counts and the charge state for each metabolite was restricted to two. Further, retention time and mass alignment corrections were performed using Agilent Profinder software version 2.3.1 on the runs to remove non-reproducible signals. The resulting features then were exported as *.cef files to Mass Profiler Professional (MPP) software version 2.4.3 (Agilent Technologies, Santa Clara, CA, USA) for statistical analysis.

\section{$\underline{\text { Statistical Data Analysis }}$}

The extracted features were imported into MPP software for statistical analysis. Principle Component Analysis (PCA) was performed to check the quality of the samples after which the data containing filtered features were processed by one way ANOVA to ascertain differences between control and fungal groups. Only the analytes with p values $<0.05$ and fold change (FC)

$>20$ were treated as statistically significant. Additionally, multiple test corrections using Bonferroni were applied to reduce false positives and false negatives in the data. 


\section{$\underline{\text { Targeted Metabolites }}$}

The absolute quantification of psilocin and psilocybin from the M. cicadina and $M$. platypediae fungal plug metabolite extracts described above, M. levispora extracts that were stored long term were not able to be analyzed for global metabolite changes were able to be analyzed in this targeted experiment. This analysis was performed using a 5500 QTRAP mass spectrometer (SCIEX Inc., Concord, Ontario, Canada). Chromatographic separations were performed using an HPLC system consisting of two Shimadzu LC 20 AD pumps that included a degasser and a Shimadzu SIL 20 AC auto sampler (Shimadzu Corp. Kyoto, Kyoto Prefecture, Japan). Analytes were separated on a 3.0x150 mm Imtakt Scherzo SW-C18 column (Imtakt USA, Portland, Oregon). The HPLC column oven was set to $40^{\circ} \mathrm{C}$ for the analysis, with an $8 \mu \mathrm{L}$ injection volume for each sample. Mobile phase A consisted of HPLC grade $\mathrm{H} 2 \mathrm{O}$ with $0.1 \%$ formic acid, while mobile B consisted of acetonitrile with $0.1 \%$ formic acid. The LC gradient started $5 \%$ for 0.5 minutes and then increased to $95 \%$ B over 5 minutes followed by a reequilibration to starting conditions for a period of 2.1 minutes. The flow rate was set to 0.3 $\mathrm{mL} /$ minute.

Targeted metabolites were quantified using multiple reaction monitoring. The transitions that were monitored for psilocybin were $\mathrm{m} / \mathrm{z} 284.5 \rightarrow 205.2$ and 240.1 . Psilocin was monitored at $\mathrm{m} / \mathrm{z}$ $205.2 \rightarrow 116.3$. Mass spectrometer source conditions were set to the following: curtain gas $=15$, ion spray voltage $=4800 \mathrm{~V}$, temperature $=600^{\circ} \mathrm{C}$, gas $1=45$, gas $2=50$. Calibration samples were prepared in $50 \%$ methanol $/ \mathrm{H}_{2} \mathrm{O}$. Calibration concentrations ranged from $0.05,0.1,0.25$, $0.5,1,2.5,5$, to $10 \mathrm{ng} / \mathrm{mL}$ of both psilocin and psilocybin. In order to assess variation in the assay duplicate standard curves were analyzed at the beginning and at the end of the analytical 
run. Absolute quantification data was processed using Analyst software ver. 1.6.3 (SCIEX Inc., Concord, Ontario, Canada).

\section{Results}

A total of 176 specimens of Magicicada species infected with M. cicadina were sampled in this study, of which 31 were from historic collections and 144 were collected from 2016 2017. A total of six of seven known Magicicada species were sampled, including three 17-year cicadas (M. cassini, M. septendecim, M. septendecula) and three 13-year cicadas ( $M$. tredecassini, M. tredecim, M. tredecula). Conidial infections were present in 164 of the Magicicada specimens, with resting spore infections in the remaining twelve individuals (Fig. 1). The disparity likely is a consequence of highly varied sampling times.

Of the 16 M. platypediae-infected specimens of Platypedia putnami examined, 15 had conidial infections. The other infected $P$. putnami specimen had an azygospore infection, which is a first observation for this species (Fig. 1). Of the nine M. levispora-infected specimens of Okanagana rimosa, only one infection producing azygospores was sampled (Fig. 1). Representatives for each Massospora species and mode of sporulation across numerous broods and geographic locations are listed in Tables S2-S3.

\section{$\underline{\text { Morphological studies }}$}

Morphology of azygospores was examined in 12, 1 and 1 specimens of M. cicadina, $M$. platypediae, and M. levispora, respectively. Morphology of conidia were studied in 15, 14, and 8 respective species (Table S2). The conidial specimens of $M$. cicadina-infected cicadas spanned ten Broods and six of the seven Magicicada species (Table S3). 
Mean conidia $(14.76 \mu \mathrm{m} \times 16.65 \mu \mathrm{m})$ and azygospore $(42.42 \mu \mathrm{m})$ dimensions for $M$. cicadina overlapped with previously reported measurements with one exception (Table S2). Mean width for conidia from ARSEF specimen $374(17.4 \mu \mathrm{m})$ barely exceeded the reported range of $10-17 \mu \mathrm{m}$ for this species. Despite the mean width and length values falling within the known reported range for this species, the range of conidial measurements for individual isolates, $(9.7-20.5 \mu \mathrm{m} \times 11.3-25.5 \mu \mathrm{m})$, far exceeded dimensions $(10-17 \mu \mathrm{m} \times 14-20 \mu \mathrm{m})$ reported by Soper (Fig. 1, Table S2). All azygospore measurements fell within the previously reported range for this species: $33.5 \mu \mathrm{m} \times 47.5 \mu \mathrm{m}(40.5 \mu \mathrm{m})$.

Mean conidial $(8.78 \mu \mathrm{m} \times 14.26 \mu \mathrm{m})$ and azygospore $(40.7 \mu \mathrm{m})$ measurements for $M$. levispora overlapped with previously reported conidial $(6.0-11.0 \mu \mathrm{m} \times 9.5-23.0 \mu \mathrm{m}(8.0 \mathrm{x}$ $15.0 \mu \mathrm{m})$ and azygospore $(34.0 \mu \mathrm{m})$ measurements (Fig. 1, Table S2). In contrast, spore dimensions in the majority of $M$. platypediae specimens fell completely outside the reported range for the species (Fig. 1; Table S2). Two additional specimens produced spores with at least one dimension outside the known range. Spore dimensions of four isolates overlapped with those previously reported (Table S2). Interestingly, all the $M$. platypediae measurements fell within the reported range for $M$. levispora, including the single resting spore specimen that was recovered (Fig. 1).
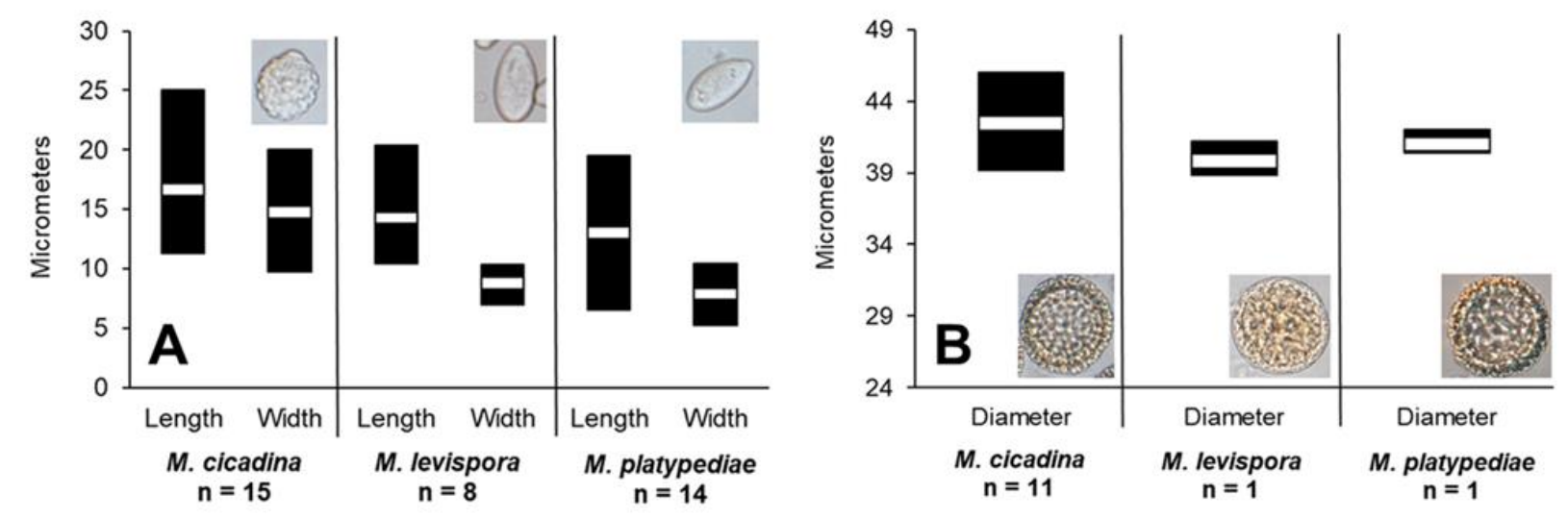
Figure 1. Mean A) conidia and B) azygospore dimensions for three Massospora species infecting . White bars indicate overall mean values while black bars indicate the range of variation in spore dimensions. Depending on the spore stage, 25 conidia or azygospores were measured for each specimen except $M$. platypediae azygospores, in which 50 were measured.

\section{Molecular identification and phylogenetic diversity in Massospora}

Massospora previously was represented in NCBI Genbank by a single isolate (ARSEF 374) of M. cicadina. GenBank blastn results of LSU sequences from M. cicadina, M. levispora, and M. platypediae DNA templates were 86-88\% identical to Eryniopsis caroliniana strain ARSEF 640 (EF392387), but only 82-84\% identical to Massospora cicadina strain ARSEF 374. Independent DNA extraction and sequencing of ARSEF 374 fungal plug tissue failed to generate a high quality LSU sequence and therefore it was not included in the LSU phylogeny. GenBank blastn results of SSU sequences from $M$. cicadina, $M$. levispora, and $M$. platypediae DNA templates were 96-97\% identical to Entomophthora schizophora (AF052402) and Entomophthora thripidum (AF296755). Despite a deposited SSU reference sequence for $M$. cicadina, none of the Massospora species sequenced in this study had a reportable BLAST hit to $M$. cicadina ARSEF 374. In contrast, successful amplification of SSU from the resampled ARSEF 374 specimen did yield a usable sequence $100 \%$ identical to other $M$. cicadina strains from this study using pairwise BLAST searches and $97 \%$ identical to strains of E. schizophora and E. thripidum.

Phylogenetic analysis of the combined dataset using maximum likelihood (ML) resolved all Massospora in a strongly supported monophyletic group sister to a clade containing Entomophthora and Arthrophaga (Fig. 2). Massospora levispora and M. platypediae were not resolved as distinct monophyletic clades. Instead, they grouped together in a single sister clade to 
M. cicadina (Fig. 2). Therefore, these data support resolution of a single species, M. levispora comb. nov. that encompasses a broader host range.

ML bootstrap analysis of the individual LSU (Fig. S1) and SSU (Fig. S2) partitions revealed strong support for two Massospora species although a polytomy in the SSU tree could not fully resolve the relationships among $M$. cicadina, $M$. levispora comb. nov., a clade containing Entomophthora and a fourth clade containing Arthrophaga myriapodina and Eryniopsis ptycopterea.

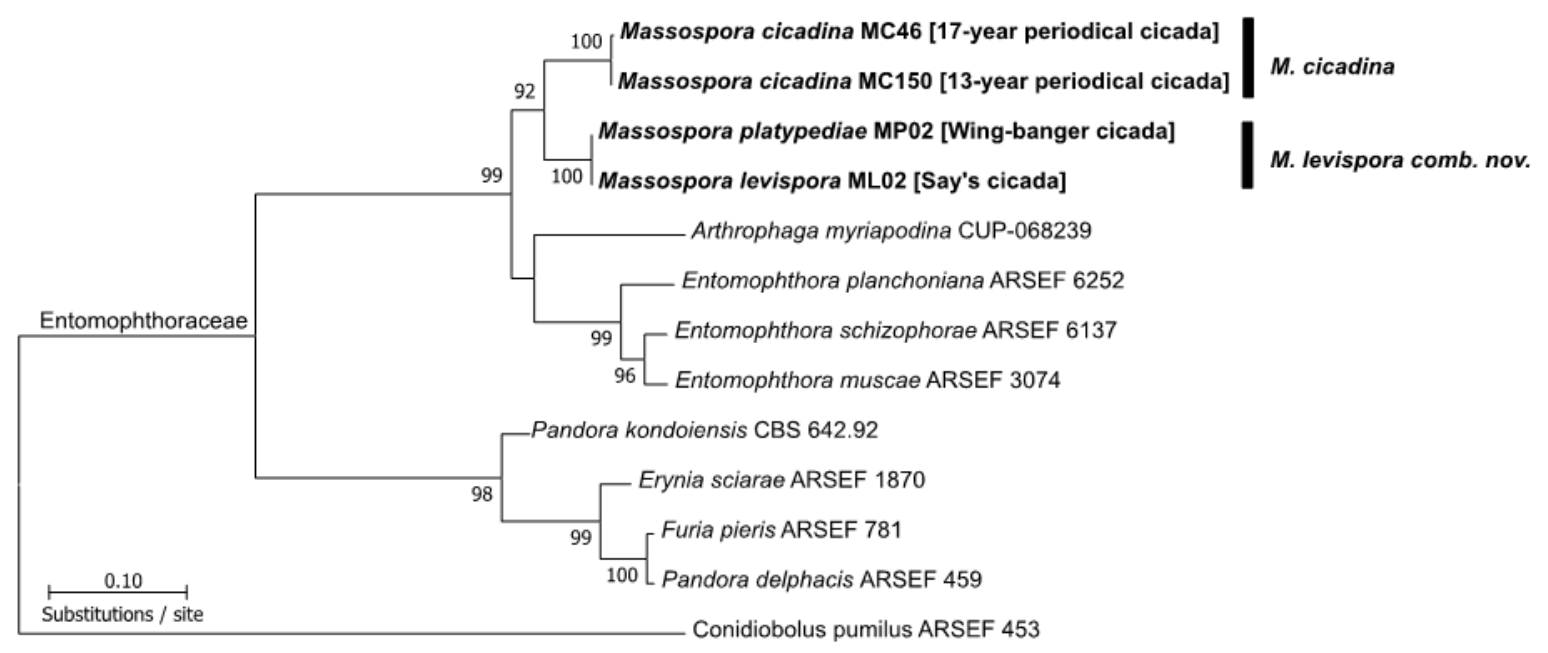

Figure 2. Concatenated LSU+SSU maximum likelihood (ML) tree consisting of Massospora species and related species in the Entomophthorales. M. levispora comb. nov. accommodates both $M$. levispora sensu strictu and M. platypediae. Bootstrap support is indicated near each node and only values greater than $70 \%$ are shown.

\section{$\underline{\text { Global Metabolomics }}$}


The global metabolomes of fungal plugs of M. cicadina and M. platypediae from infections of $P$. putnami yielded over 2000 unique chromatographic and mass to charge peaks in the combined positive and negative polarities. Univariate statistics were performed on all the detected ions to separate unique fungal plug metabolites from the insect host metabolome. Each Massospora species and healthy cicada controls yielded unique metabolomes, with the two fungal species displaying more similar metabolite signatures (Fig. 3). The results of these statistical analyses revealed 678 and 489 fungal plug-specific metabolites in positive and negative ion modes, respectively (Tables S4-S5). These metabolites measured a >20 log fold change and all differed significantly in expression levels $(\mathrm{p}<0.01)$ compared to the healthy cicada control. These highly varying compounds included free amino acids, phospholipids, ceramides, alkaloids, and a diverse assortment of secondary metabolites.

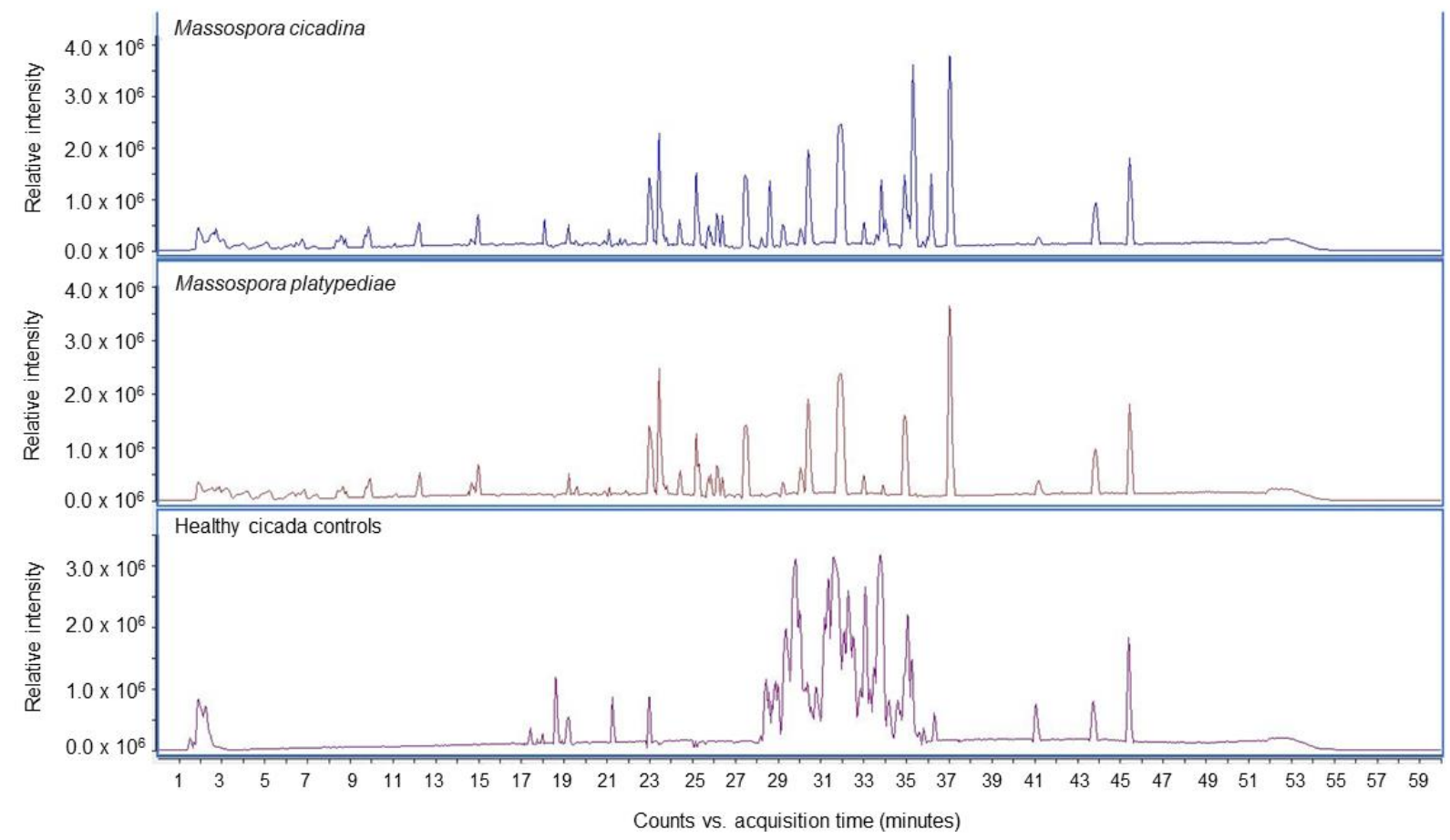

Figure 3. Representative base peak chromotagram (BPC) from the global metabolomics analysis of samples from M. cacadina, M. levispora (as specimens of $M$. platypediae), and a healthy 
control of (cicada species?), comparing the metabolome profiles among fungal plugs and with the non-infected cicada control.

Among the secondary metabolites recovered from the fungal plugs, monoamine alkaloids were abundant and diverse across both Massaspora species and they included substituted tryptamines and substituted amphetamines (Table 1). Psilocybin (a substituted tryptamine) was among the top upregulated metabolites detected in M. levispora, with > 16-fold higher level of expression than both the non-infected control and $M$. cicadina in fungal plugs (Table 1). However, no intermediates in the psilocybin biosynthesis pathway were detected in the global metabolomics dataset. Fragmentation of psilocybin was performed on pooled samples and expected fragmentation patterns were observed (m/z 245.0 and 205.1), thereby verifying the identity of psilocybin (Figure S3). Other tryptamine-containing natural products were recovered from both $M$. cicadina and $M$. levispora at significantly higher levels than the negative controls. In M. levispora, two lysergic acid pathway product intermediates, 4-Dimethylallyl-L-tryptophan (4-DMAT) and agroclavine (ergot alkaloid), were expressed at 17.6x and 16.8x log fold higher change than in M. cicadina and in the non-infected control, respectively. Aspidospermine, another tryptamine-containing alkaloid, was expressed at a16.8x and 14.5x log fold change higher in M. cicadina and M. levispora compared to the uninfected control. Nblignoceroyltryptamine also was measured in M. cicadina at a $16.8 \mathrm{x}$ log fold change higher than M. levispora and the negative control. None of these alkaloids were confirmed via fragmentation. Furthermore, LC/UV analysis failed to confirm the expression of agroclavine.

A second class of monoamine alkaloids, substituted amphetamines, also were detected, but only from M. cicadina plugs (Table 1). Cathinone and two intermediates from its biosynthesis pathway also were found at significantly higher levels than in M. levispora and the uninfected 
control (Table 1, Fig. 4). Cathinone, trans-cinnimac acid, and benzoic acid were measured at a 17.1x, $17.9 \mathrm{x}$, and $18.1 \mathrm{x}$ fold change higher, respectively. Benzealdehyde, a non-pathway specific intermediate, was upregulated in both M. levispora $(16.1 \mathrm{x})$ and $M$. cicadina $(15.0 \mathrm{x})$ compared the negative control. Fragmentation of cathinone was performed on the pooled samples for both conidial and azygospore isolates and expected fragmentation patterns $(\mathrm{m} / \mathrm{z}$ 260.09, 179.07, and 132.08) were ... (Fig. S4) (The fragmentation of Cathinone is currently underway and will be completed by next week) Slaframine, a piperidine alkaloid, also showed a 13.6x log fold change increase in M. cicadina compared to expression in M. levispora and the control.

Table 1. Fold change and up/down regulation of naturally occurring alkaloids from Massospora fungal plugs in infected cicadas using global metabolomics.

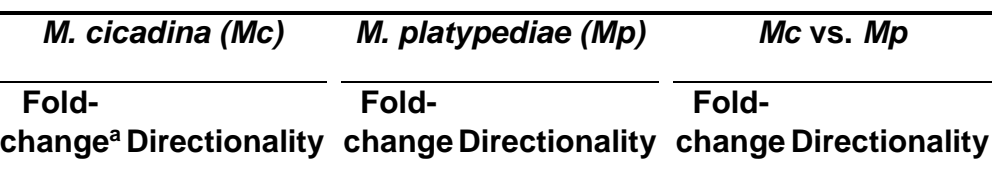

\section{Compound} change $^{a}$ Directionality change Directionality change Directionality

\section{Monoamine alkaloids}

\section{Substituted amphetamines}

\begin{tabular}{|c|c|c|c|c|c|c|}
\hline Trans-cinnimac acid & $\begin{array}{c}17.9 \pm \\
1.0\end{array}$ & Up & NSD & - & $\begin{array}{c}17.9 \pm \\
1.0\end{array}$ & Up \\
\hline Benzealdehyde & $\begin{array}{c}15.0 \pm \\
0.6\end{array}$ & Up & $\begin{array}{c}16.1 \pm \\
1.1\end{array}$ & Up & NSD & - \\
\hline Benzoic acid & $\begin{array}{c}18.1 \pm \\
2.1\end{array}$ & Up & NSD & - & $\begin{array}{c}18.1 \pm \\
2.1\end{array}$ & Up \\
\hline Cathinone & $\begin{array}{c}17.1 \pm \\
0.4\end{array}$ & Up & NSD & - & $\begin{array}{c}17.1 \pm \\
0.4\end{array}$ & Up \\
\hline \multicolumn{7}{|l|}{ Substituted tryptamines } \\
\hline Nb-Lignoceroyltryptamine & $\begin{array}{c}17.9 \pm \\
1.4\end{array}$ & Up & NSD & - & $\begin{array}{c}17.9 \pm \\
1.4\end{array}$ & Up \\
\hline Aspidospermine & $\begin{array}{c}16.8 \pm \\
0.9\end{array}$ & Up & $\begin{array}{c}14.5 \pm \\
1.2\end{array}$ & Up & NSD & - \\
\hline 4-Dimethylallyl-L-tryptophan (4-DMAT) & NSD & - & $\begin{array}{c}17.6 \pm \\
0.3\end{array}$ & Up & $\begin{array}{c}17.6 \pm \\
0.3\end{array}$ & Down \\
\hline
\end{tabular}




\begin{tabular}{|c|c|c|c|c|c|c|}
\hline Agroclavine & NSD & - & $\begin{array}{c}16.8 \pm \\
2.4\end{array}$ & Up & $\begin{array}{c}16.8 \pm \\
2.4\end{array}$ & Down \\
\hline Psilocybin & NSD & - & $\begin{array}{c}16.9 \pm \\
0.6\end{array}$ & Up & $\begin{array}{c}16.9 \pm \\
0.6\end{array}$ & Down \\
\hline
\end{tabular}

\section{Piperidine alkaloids}

$\begin{array}{lcllllll}\text { Slaframine } & 13.6 \pm & \text { Up } & & \text { NSD } & - & 13.6 \pm & \text { Up } \\ & 0.6 & & & 0.6 & & & \end{array}$

Fold change \pm standard error based on comparisons with control. Value is average of five biological replicates.
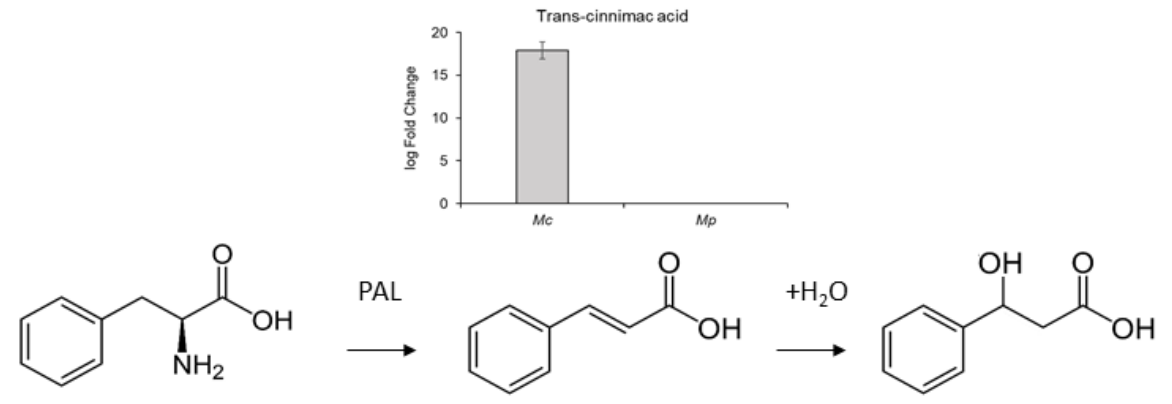

L-Phenylalanine

Trans-cinnamic acid
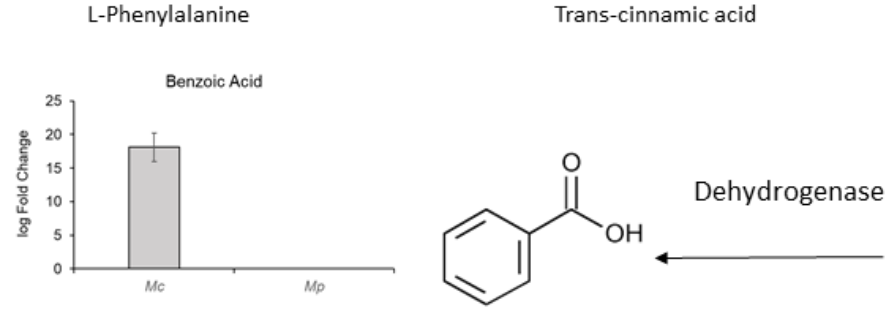<smiles>CC(=O)C(=O)c1ccccc1</smiles>

1-pheylpropane1,2-diene<smiles>CC(N)C(=O)c1ccccc1</smiles>

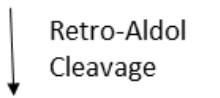<smiles>O=Cc1ccccc1</smiles>

Benzaldehyde
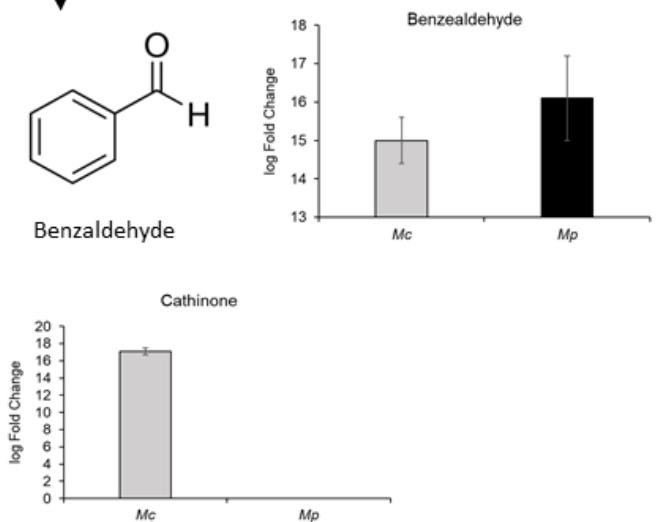

Figure 4. Non-Beta Oxidation pathway for the biosynthesis of S-Cathinone with fold-change results from global metabolomics of $M$. cicadina and M. levispora plugs in infected cicadas.

In addition to alkaloids, other noteworthy compounds were differentially upregulated in $M$. levispora compared to M. cicadina (Fig. S4). These included 2-Hydroxyestradiol, an endogenous 
steroid and metabolite of estradiol and 3-O-acetylecdysone 2-phosphate, a metabolite of ecdysone, a steroidal prohormone of the major insect molting hormone 20-hydroxyecdysone .

Lastly, six other fungus-derived compounds were recovered from M. cicadina at significantly higher levels than those in the M. platypediae samples of $M$. levispora comb. nov. (Table S6). These including two mycotoxins (4-Propanoyl-HT2 toxin and Aflatoxin b1 trialcohol) previously described from Ascomycotan fungi (REF?) and one Basidiomycotan toxin, Ustiloxin C (REF?). Two other fungus-derived compounds (Sarcodon scabrosus Depsipeptide and Azoxystrobin) were differentially upregulated in $M$. platypediae (Table S6). While these compounds were found to be upregulated, a high quality MS/MS fragmentation spectrum was not able to be generated for either.

\section{$\underline{\text { Targeted Metabolomics }}$}

Based on the results of the global metabolomics, targeted LC-MS/MS absolute quantification was performed on extracts of plugs from fungal infections of all three cicada species. Due to submersion in ethanol prior to analysis and inability to properly normalize the samples for global analysis, only targeted quantification of specific metabolites was performed.

Both psilocybin and its biologically relevant metabolite psilocin were monitored in the targeted quantification analysis. The dynamic range of the LC-MS quantification for psilocin and psilocybin encompassed 2.5 orders of magnitude. Signal for these analytes that fell below the lower limit of quantitation, but a peak still was visible, was used to determine presence or absence. Psilocybin was present in 10 of $11 M$. platypediae plugs and seven of eight $M$. levispora

plugs (Table 2, Fig. 4). Of these, psilocybin was only quantifiable in 6 of 7 M. levispora samples, with concentrations ranging from 1.2 to $3.2 \mathrm{ng} / \mathrm{mL}$ of ethanol extract (Table 2). Psilocin was 
detected only in 9 of 11 extracts from $M$. platypediae at concentrations ranging from 0.02 to $4.65 \mu \mathrm{g} / \mathrm{mL}$ (Table 2, Fig. 4).

Note: This section on targeted metabolomics is logically incomprehensible. The reason(s) for targeting only psilocybin and psilocin and the disparity between qualitative versus quantitative data are poorly presented. Clarify!! 
Table 2. Quantification of psilocybin and psilocin from Massospora fungal plugs using targeted LC-MS.

\begin{tabular}{|c|c|c|c|c|c|}
\hline \multirow[b]{2}{*}{ Specimen ID } & \multirow[b]{2}{*}{ Spore type } & \multicolumn{2}{|c|}{ Psilocybin [m/z 285] } & \multicolumn{2}{|c|}{ Psilocin [m/z 205] } \\
\hline & & Present & $\begin{array}{c}\text { Conc. } \\
\text { [ng/mL] }\end{array}$ & Present & $\begin{array}{c}\text { Conc. } \\
{[\mu \mathrm{g} / \mathrm{g}]}\end{array}$ \\
\hline MC139 & Azygospore & ND & - & ND & - \\
\hline MC140 & Azygospore & ND & - & ND & - \\
\hline MC141 & Azygospore & ND & - & ND & - \\
\hline MC142 & Azygospore & ND & - & ND & - \\
\hline $\mathrm{MC23}$ & Conidia & ND & - & ND & - \\
\hline MC33 & Conidia & ND & - & ND & - \\
\hline ML03 & Azygospore & ND & - & ND & - \\
\hline ML01 & Conidia & Yes & 1.2 & ND & - \\
\hline MLO2 & Conidia & Yes & 2.3 & ND & - \\
\hline MLO4 & Conidia & Yes & 1.8 & ND & - \\
\hline ML05 & Conidia & Yes & 2.2 & ND & - \\
\hline ML06 & Conidia & Yes & BLQ & ND & - \\
\hline ML07 & Conidia & Yes & 3.2 & ND & - \\
\hline ML08 & Conidia & Yes & 2.8 & ND & - \\
\hline MP01 & Conidia & Yes & - & Yes & 2.59 \\
\hline MP02 & Conidia & Yes & - & Yes & 1.16 \\
\hline MP03 & Conidia & Yes & - & Yes & 0.18 \\
\hline MP04 & Conidia & Yes & - & No & BLQ \\
\hline MP05 & Conidia & Yes & - & No & BLQ \\
\hline MP06 & Conidia & Yes & - & Yes & 0.02 \\
\hline MP07 & Conidia & Yes & - & Yes & 0.28 \\
\hline MP08 & Conidia & Yes & - & Yes & 4.65 \\
\hline MP09 & Conidia & Yes & - & Yes & 1.38 \\
\hline MP10 & Conidia & Yes & - & Yes & 0.68 \\
\hline MP14 & Conidia & Yes & - & Yes & 0.48 \\
\hline MCNC1 & noninfected & ND & - & ND & BLQ \\
\hline MLNC1 & noninfected & ND & - & ND & BLQ \\
\hline MPNC01 & noninfected & ND & - & ND & BLQ \\
\hline
\end{tabular}

*ND, not detected; $¥ B L Q$, below limit of quantification. Need to define your acronyms pertaining to specimen ID. 

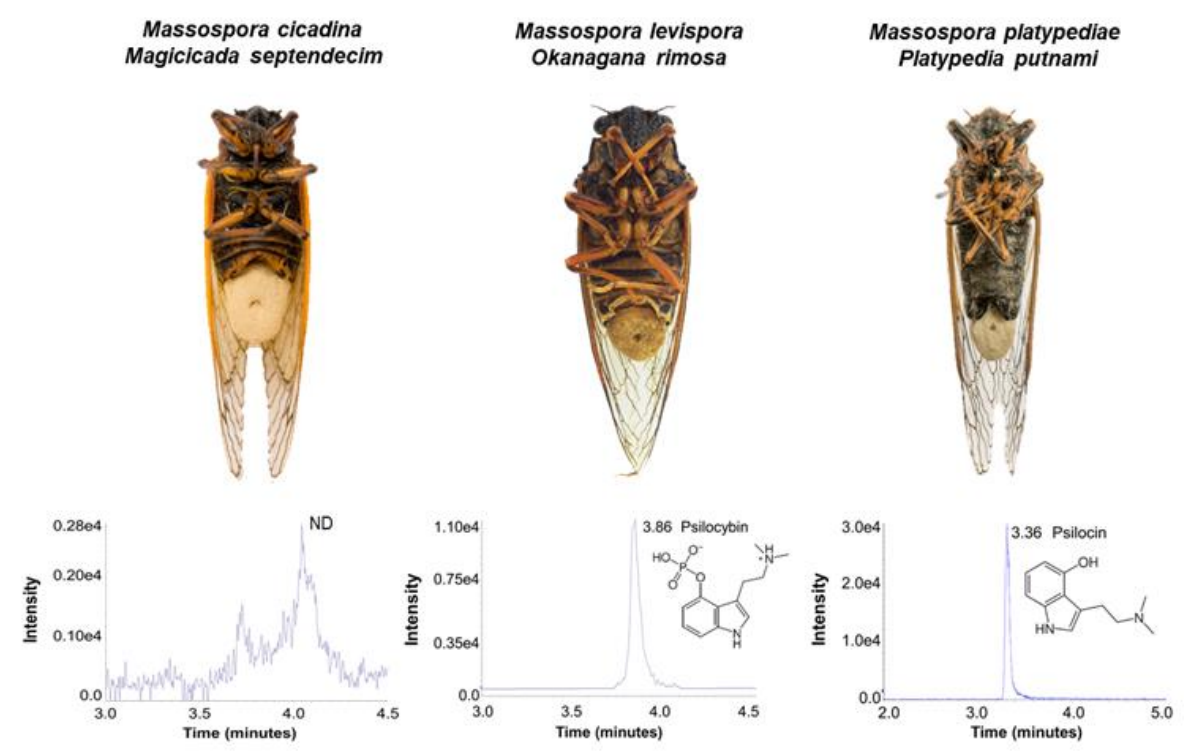

Figure 4. Ion chromatograms of monoamine alkaloids extracted from conidial plugs produced by $M$. cicadina, $M$. levispora and $M$. platypediae infections in adult cicada specimens of $M$. septendecim, $O$. rimosa and $P$. putnami respectively. ND = none detected.

\section{Discussion}

Phylogenetic analyses reveal that $M$. levispora and $M$. platypediae are not distinct species and therefore are combined. Morphology and common metabolite pathways further support their shared lineage. Such combinations of data will be necessary to clarify phylogeny and functional fungus-host interactions in Zoopagomycota because of their obligate nutritional relationships (Hodge et al 2017, Cooley et al. 2017).

The endogenous production of monoamine alkaloids such as psilocybin by both lineages of M. levispora (which includes $M$. platypediae) and cathinone by $M$. cicadina reported here for the first time have opened the door for broader investigations of secondary metabolite production across the diversity of this biologically unique fungal phylum and provides some preliminary insight into the mechanisms of the interplay between microbe and host. Another member of the Entomophthorales, Strongwellsea, causes a similar disease in flies (REF?) resulting in abdominal 
openings that aid in spore dispersal and this species is a potential candidate to assess the extent to which these pathways are conserved phylogenetically.

Even though global metabolomics are comprehensive and provide a robust qualitative snapshot of all the metabolites within an organism or biological system at one point in time, comprehensive databases recording compound identity are largely limited to metabolites of Saccharomyces cerevisiae because of technological and/or financial restraints (Xu et al. 2014). Numerous fungal secondary metabolites have been recovered based on accurate mass, but the lack of MS/MS spectral libraries has limited fragmentation identification, a necessary intermediate validation between global metabolomics and targeted quantification using standards.

The recent observations on Massospora-infected cicadas provide data for generating hypotheses on how these fungi manipulate its cicada host. Massospora, like Hypocrelean entomopathogens, hijacks the infected individual to optimize spore dispersal at the expense of the cicada's own interests (Cooley et al 2017). Massospora renders the cicada more promiscuous as a means of spreading infective spores to both conspecific females and males. The monoamine alkaloids identified in this study may contribute to such hijacking behavior. Several studies have investigated the actions of hallucinogens on arthropods including ants and spiders. Frischknecht and Waser (1978) administered amphetamine, LSD, and THC to the black-backed meadow ant (Formica pratensis). Low doses (1 or 10 ug/ant) of amphetamine caused an increase in intraspecific aggression compared to LSD where doses of $20 \mathrm{ng}$ or more typically impaired locomotion. Although amphetamines didn't seem to influence aggressiveness in spiders, a dose of $1 \mathrm{mg}$ or about $6.7 \mathrm{~g} / \mathrm{kg}$ resulted in irregular web building with frequently interrupted radii and some erratic strands by adult female Araneus diadematus 12-hours after receiving the dose (Witt 
1971). Cathinone is chemically similar to ephedrine, cathine, methcathinone and other amphetamines. The higher levels of cathinone in M. cicadina may confer enhanced aggressiveness that benefit continued spore dispersal despite debilitating infections that likely result in fatigue, decreased muscle strength and general malaise. Similar responses by cathinone ha Similarly, psilocybin and its dephosphorylated metabolite psilocin, a serotonin receptor agonist, may be acting similarly in M. levispora -infected cicadas by increasing euphoria and dispersal despite debilitating infections. Alternatively, psilocybin/psilocin may act as a repellant against predation. Reynolds et al (2017) postulate a similar role by these metabolites in hallucinogenic mushrooms. Masiulionis et al. (2013) report that basidiocarps of Psilocybe coprophila growing on cow dung were actively collected by workers of leaf-cutter ants, Acromyrmex lobicornis, in Santa Fé province, Argentina. While not measured, psychotropic compounds often found in these mushrooms may serve to protect the colony.

Psilocybin causes perceptual distortions in infected animals and may cause similar effects in insects. Reported behavioral observations on Massospora-infected cicadas indicate increased sexual receptivity with greater tolerance to contact by an approaching male (Table S1). These data support the hypothesis that expression of psilocin causes delayed flight initiation and flight orientation in cicadas, which can result in immobile individuals becoming copulatory targets (White et al. 1983). The measurable absence of intermediates in the biosynthetic pathway of psilocybin in this study suggest rapid degradation/conversion within the cicada host.

Another plausible explanation for behavioral bisexuality in infected males is the sharp increase in steroids observed in M. platypediae infected cicadas. 2-Hydroxyestradiol, a catechol estrogen, was significantly elevated in M. platypediae-infected male cicadas (only 1 female was recovered from the collection). Such sharp increases in estrogen in males may be due, in part, to 
castration by Massospora. However, similar outcomes were not obtained in global metabolomics runs of both females and males of $\mathrm{M}$. cicadina.

Together, the identified targeted secondary metabolites identified in this study represent a small fraction of the total metabolites detected. Given the strong body of literature surrounding many of these natural products and their pathways, significant headway is likely to be made in understanding their role in pathogen-cicada interactions have been measured in ants.

\section{Supplementary Materials}

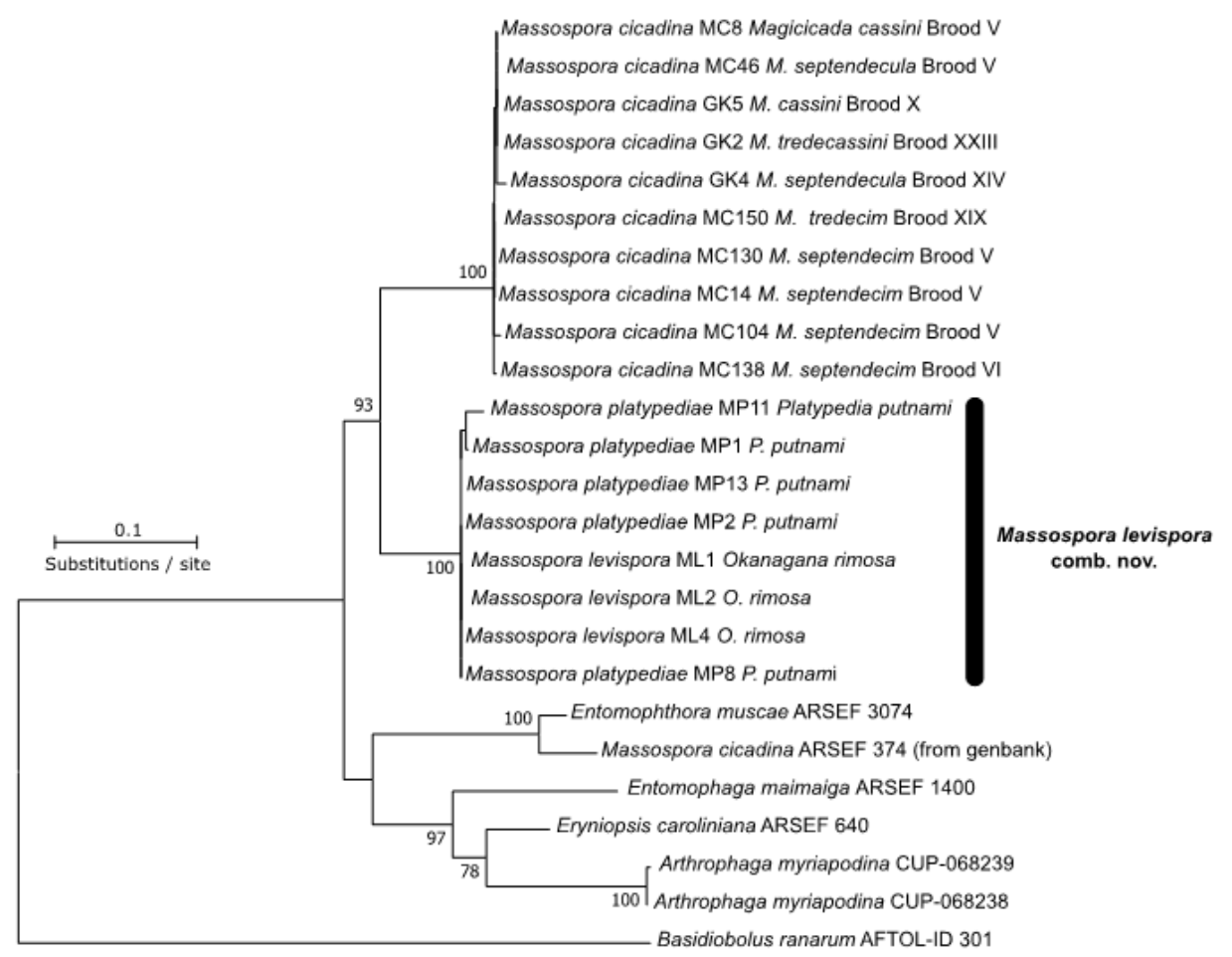

Figure S1. LSU maximum likelihood (ML) phylogenetic tree for Massospora spp. and close allies in the Entomophthorales. M. levispora comb. nov. accommodates both M. levispora sensu 
strictu and $M$. platypediae. Bootstrap support is indicated near each node and only values greater than $50 \%$ are shown.

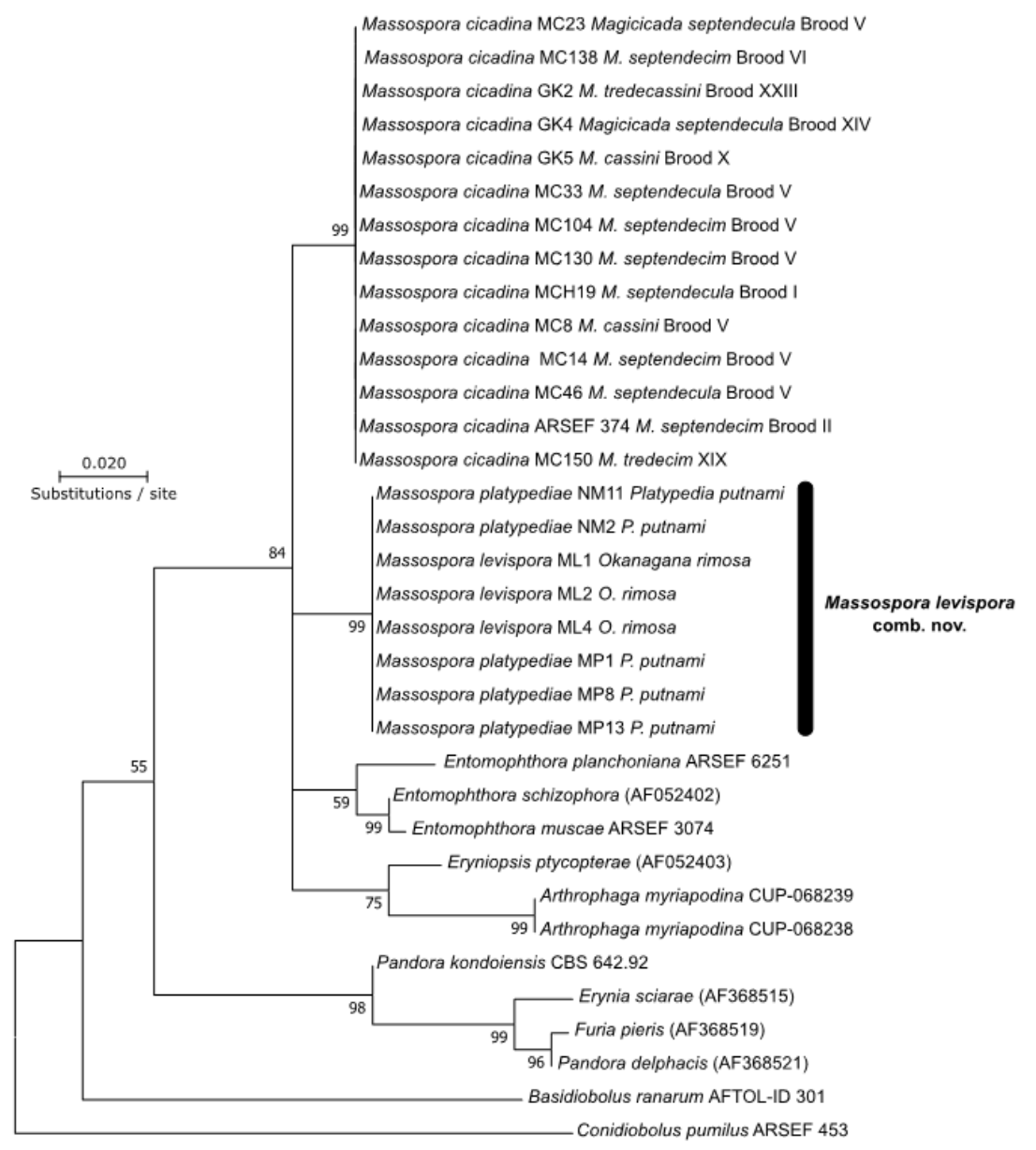

Figure S2. SSU maximum likelihood (ML) phylogenetic tree for Massospora spp. and close allies in the Entomophthorales. M. levispora comb. nov. accommodates both M. levispora sensu strictu and M. platypediae. Bootstrap support is indicated near each node and only values greater than $50 \%$ are shown. 


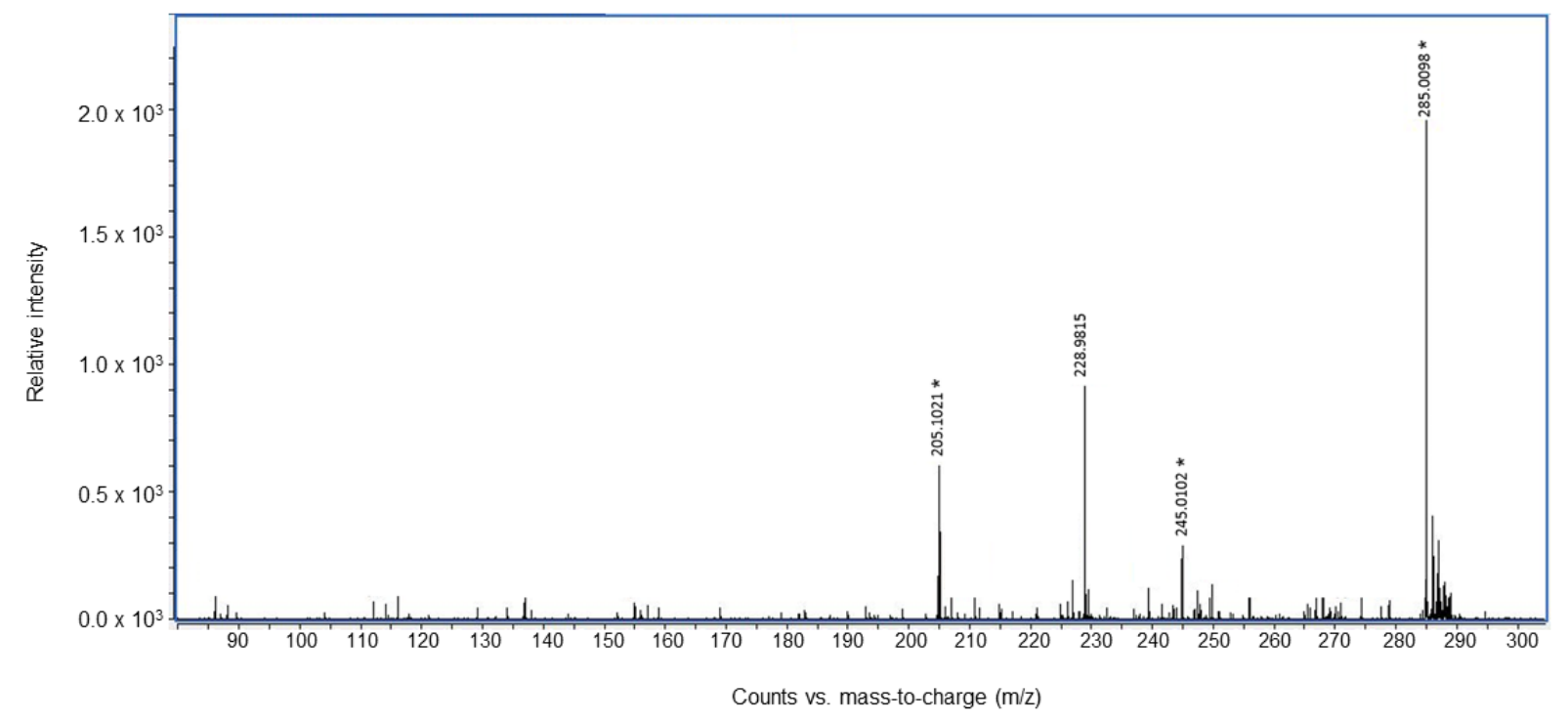

Figure S3. MS/MS fragmentation spectrum of psilocybin (m/z 285.0098) from pooled M.

platypediae fungal plug extracts. An asterisk above a peak indicates predicted fragments from psilocybin fragmentation. 


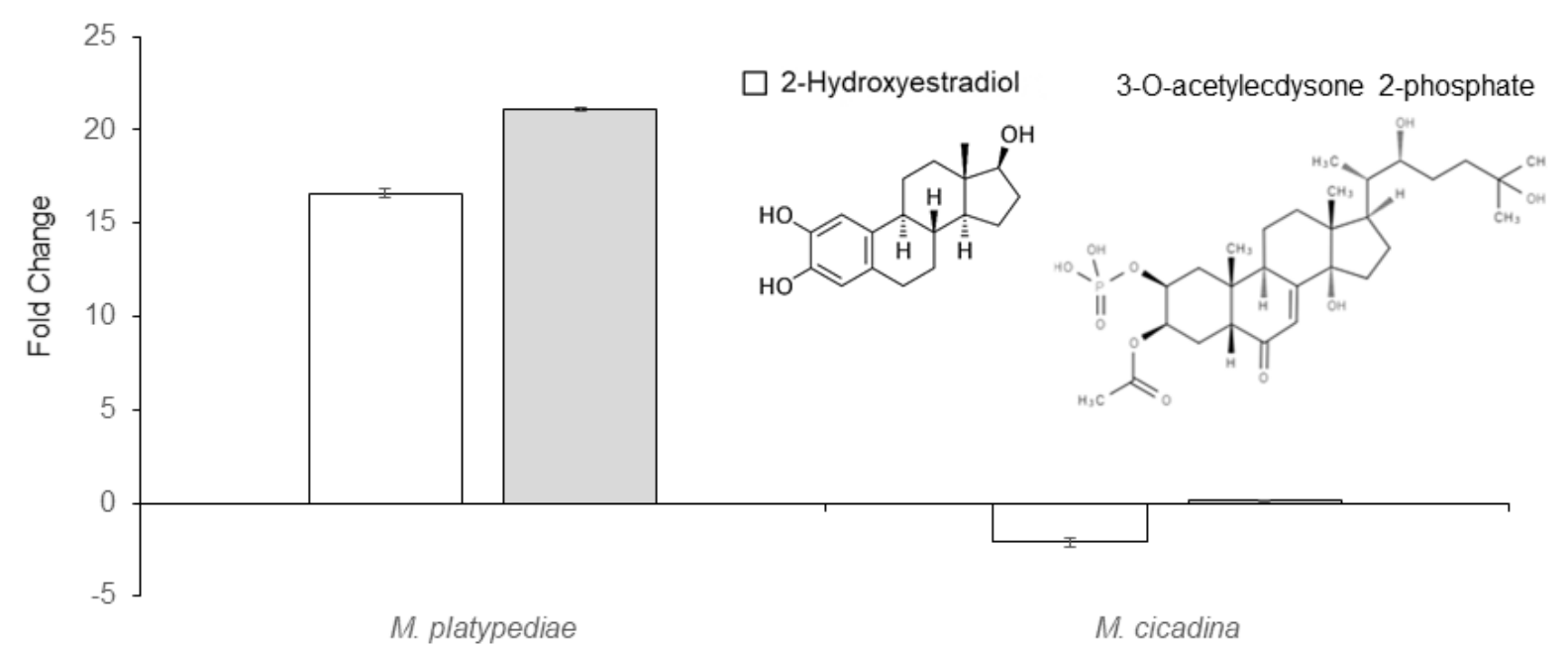

Figure S4. Differential fold change and regulation of 2-Hydroxyestradiol and 3-O-

acetylecdysone 2-phosphate expression in fungal plugs of $M$. platypediae and $M$. cicadina using global metabolomics. The former metabolite is an endogenous steroid and the latter is a product? of ecdysone, a steroidal prohormone of the major insect molting hormone 20hydroxyecdysone. 
Table S1. Changes in cicada behavior as a result of Massospora infection compared to outwardly healthy counterparts.

\begin{tabular}{|c|c|c|c|c|c|c|c|c|}
\hline \multirow[b]{2}{*}{$\begin{array}{l}\text { Massospora - Cicada } \\
\text { consortia }\end{array}$} & \multicolumn{5}{|c|}{ Flight } & \multirow{2}{*}{\multicolumn{2}{|c|}{$\begin{array}{c}\text { Wing- } \\
\text { flick } \\
\text { signal } \\
\text { s by } \\
\text { males } \\
\text { in } \\
\text { respo } \\
\text { nse to } \\
\text { male } \\
\text { courti } \\
\text { ng } \\
\text { calls }\end{array}$}} & \multirow{2}{*}{$\begin{array}{c}\text { Sexual } \\
\text { receptivi } \\
\text { ty by } \\
\text { toleranc } \\
\text { e of } \\
\text { contact } \\
\text { by an } \\
\text { approac } \\
\text { hing } \\
\text { male }\end{array}$} \\
\hline & $\begin{array}{l}\text { Dista } \\
\text { nce }\end{array}$ & $\begin{array}{c}\text { Endura } \\
\text { nce }\end{array}$ & $\begin{array}{l}\text { Initiati } \\
\text { on }\end{array}$ & $\begin{array}{l}\text { Orientat } \\
\text { ion }\end{array}$ & $\begin{array}{l}\text { Spe } \\
\text { ed }\end{array}$ & & & \\
\hline $\begin{array}{l}\text { M. cicadina - Magicicada } \\
\text { spp.* }\end{array}$ & $<$ & None & $\begin{array}{l}\text { Delay } \\
\text { ed }\end{array}$ & $\begin{array}{l}\text { Deviate } \\
\text { d }\end{array}$ & $\begin{array}{c}\text { Non } \\
\mathrm{e}\end{array}$ & None & + & $\begin{array}{c}{[\mathrm{x}] \text { males, }} \\
{[\mathrm{x}]} \\
\text { females }\end{array}$ \\
\hline $\begin{array}{l}\text { M. sp. - Meimuna } \\
\text { boninensis }{ }^{\dagger}\end{array}$ & - & - & - & - & - & Weaker & - & - \\
\hline $\begin{array}{l}\text { M. diceroprocta - } \\
\text { Diceroprocta spp. }{ }^{\ddagger}\end{array}$ & - & - & - & - & - & $>$ & - & + \\
\hline $\begin{array}{l}\text { M. levispora - Okanagana } \\
\text { rimosa* }\end{array}$ & - & - & None & - & - & None & - & + \\
\hline $\begin{array}{l}\text { M. platypediae - } \\
\text { Platypedia putnamis }\end{array}$ & - & - & None & - & - & $\begin{array}{l}\text { Inermedi } \\
\text { ate }\end{array}$ & + & + \\
\hline
\end{tabular}

Based on the results of four studies: * Cooley et al. 2017; $\ddagger$ Hastings, personal communication; $\S$ Murphy and Redden 2003; † Ohbayashi et al. 1999; * White et al. 1983).

Table S2.

\begin{tabular}{|c|c|c|c|}
\hline $\begin{array}{l}\text { Massospora } \\
\text { species }\end{array}$ & Fungal ID & Spore type & $\begin{array}{l}\text { Spore measurements }{ }^{a} \\
\text { [width range } \mathrm{x} \text { length range (mean width } \mathrm{x} \text { mean length)] }\end{array}$ \\
\hline M. platypediae & MP11 & Azygospore & $40.5 \mu \mathrm{m} \times 41.4 \mu \mathrm{m}(40.9 \mu \mathrm{m})$ \\
\hline M.platypediae & Holotype & Conidia & $5.2-7.7 \mu \mathrm{m} \times 6.5-12.9 \mu \mathrm{m}(6.0 \times 9.9 \mu \mathrm{m})$ \\
\hline M.platypediae & MP01 & Conidia & $6.4-9 \mu \mathrm{m} \quad \times 10.49-19.7 \mu \mathrm{m}(8.0 \times 15.0 \mu \mathrm{m})$ \\
\hline M. platypediae & MP02 & Conidia & $7.7-10.5 \mu \mathrm{m} \quad \mathrm{x} 10.3-17.1 \mu \mathrm{m}(9.1 \times 13.1 \mu \mathrm{m})$ \\
\hline M. platypediae & MP03 & Conidia & $5.6-9.2 \mu \mathrm{m} \times 8.3-17.7 \mu \mathrm{m}(\underline{7.2 \times 12.0 \mu \mathrm{m}})$ \\
\hline M. platypediae & MP04 & Conidia & $6.8-9.4 \mu \mathrm{m} \quad$ x $9.2-14.7 \mu \mathrm{m}(\underline{7.7 \times 11.7 \mu \mathrm{m}})$ \\
\hline M. platypediae & MP05 & Conidia & $7.0-9.1 \mu \mathrm{m} \quad \mathrm{x} 11.7-17.1 \mu \mathrm{m}(7.9 \times 13.8 \mu \mathrm{m})$ \\
\hline M. platypediae & MP06 & Conidia & $6.8-9.3 \mu \mathrm{m} \quad \times \quad 9.2-16.2 \mu \mathrm{m}(8.2 \times \underline{12.4} \mu \mathrm{m})$ \\
\hline M. platypediae & MP07 & Conidia & $5.5-8.8 \mu \mathrm{m} \quad$ x $12-19.3 \mu \mathrm{m}(\underline{7.1} \times 15.2 \mu \mathrm{m})$ \\
\hline M. platypediae & MP08 & Conidia & $5.2-7.5 \mu \mathrm{m} \times 8.9-15.1 \mu \mathrm{m}(\underline{6.5} \times 11.6 \mu \mathrm{m})$ \\
\hline M. platypediae & MP09 & Conidia & $7.2-10.1 \mu \mathrm{m} \quad x 10.3-16.9 \mu \mathrm{m}(8.1 \times 13.3 \mu \mathrm{m})$ \\
\hline M. platypediae & MP10 & Conidia & $6.8-10.8 \mu \mathrm{m} \times 9.6-19.4 \mu \mathrm{m}(9.0 \times 14.6 \mu \mathrm{m})$ \\
\hline M. platypediae & MP16 & Conidia & $6.4-9.1 \mu \mathrm{m} \quad \times \quad 9.0-13.6 \mu \mathrm{m}(\underline{7.7 \times 10.9 \mu \mathrm{m}})$ \\
\hline M. platypediae & MP13 & Conidia & $5.4-10.6 \mu \mathrm{m} \quad \times 10.3-18.7 \mu \mathrm{m}(8.0 \times 14.2 \mu \mathrm{m})$ \\
\hline M. platypediae & MP14 & Conidia & $7.4-10.2 \mu \mathrm{m} \times 9.9-18.9 \mu \mathrm{m}(8.6 \times 13.9 \mu \mathrm{m})$ \\
\hline M. platypediae & MP15 & Conidia & $7.1-10.9 \mu \mathrm{m} \times 9.6-20 \mu \mathrm{m}(8.8 \times 13.7 \mu \mathrm{m})$ \\
\hline M. levispora & Holotype & Azygospore & $27.5 \mu \mathrm{m} \times 40.5 \mu \mathrm{m}(34.0 \mu \mathrm{m})$ \\
\hline M. levispora & ML03 & Azygospore & $38.8 \mu \mathrm{m} \times 40.7 \mu \mathrm{m}(\underline{39.8 \mu \mathrm{m}})$ \\
\hline M. levispora & Holotype & Conidia & $6.0-11.0 \mu \mathrm{m} \times 9.5-23.0 \mu \mathrm{m}(8.0 \times 15.0 \mu \mathrm{m})$ \\
\hline
\end{tabular}




\begin{tabular}{|c|c|c|c|}
\hline M. levispora & ML01 & Conidia & $7.5-10.5 \mu \mathrm{m} \times 10.5-17.4 \mu \mathrm{m}(\underline{8.8 \times 12.9 \mu \mathrm{m})}$ \\
\hline M. levispora & ML02 & Conidia & $7.4-10.8 \mu \mathrm{m} \times 12.4-20.9 \mu \mathrm{m}(9.2 \times 16.6 \mu \mathrm{m})$ \\
\hline M. levispora & ML04 & Conidia & $7.5-9.9 \mu \mathrm{m} \times 10.4-16.3 \mu \mathrm{m}(8.8 \times 13.4 \mu \mathrm{m})$ \\
\hline M. levispora & ML06 & Conidia & $7.6-10.8 \mu \mathrm{m} \times 11.7-19.5 \mu \mathrm{m}(\underline{8.7 \times 14.1 \mu \mathrm{m})}$ \\
\hline M. levispora & ML07 & Conidia & $7.1-9.5 \mu \mathrm{m} \times 11.3-17.9 \mu \mathrm{m}(\underline{8.6 \times 14.2 \mu \mathrm{m})})$ \\
\hline M. levispora & ML08 & Conidia & $7.0-10.2 \mu \mathrm{m} \times 11.8-19.6 \mu \mathrm{m}(\underline{8.6 \times 14.4 \mu \mathrm{m}})$ \\
\hline M. levispora & ML10 & Conidia & $7.2-9.6 \mu \mathrm{m} \times 10.8-16.5 \mu \mathrm{m}(\underline{8.2 \times 13.2 \mu \mathrm{m})}$ \\
\hline M. levispora & ML05 & Conidia & $8.5-10.6 \mu \mathrm{m} \times 13.2-18.6 \mu \mathrm{m}(9.4 \times 15.3 \mu \mathrm{m})$ \\
\hline M. cicadina & Holotype & Azygospore & $33.5 \mu \mathrm{m} \times 47.5 \mu \mathrm{m}(40.5 \mu \mathrm{m})$ \\
\hline M. cicadina & MC150 & Azygospore & \\
\hline M. cicadina & MC138 & Azygospore & $39.2 \mu \mathrm{m} \times 41.3 \mu \mathrm{m}(\underline{40.2 \mu \mathrm{m}})$ \\
\hline M. cicadina & MC142 & Azygospore & $42.1 \mu \mathrm{m} \times 43.5 \mu \mathrm{m}(\underline{42.8 \mu \mathrm{m}})$ \\
\hline M. cicadina & MC141 & Azygospore & $39.8 \mu \mathrm{m} \times 41.0 \mu \mathrm{m}(40.4 \mu \mathrm{m})$ \\
\hline M. cicadina & MC139 & Azygospore & $41.8 \mu \mathrm{m} \times 42.8 \mu \mathrm{m}(\underline{42.3 \mu \mathrm{m}})$ \\
\hline M. cicadina & MC140 & Azygospore & $39.7 \mu \mathrm{m} \times 41.0 \mu \mathrm{m}(\underline{40.4 \mu \mathrm{m}})$ \\
\hline M. cicadina & MC145 & Azygospore & $42.1 \mu \mathrm{m} \times 43.3 \mu \mathrm{m}(\underline{42.8 \mu \mathrm{m}})$ \\
\hline M. cicadina & MC143 & Azygospore & $43.0 \mu \mathrm{m} \times 45.1 \mu \mathrm{m}(\underline{44.1 \mu \mathrm{m}})$ \\
\hline M. cicadina & MC144 & Azygospore & $43.7 \mu \mathrm{m} \times 45.5 \mu \mathrm{m}(\underline{44.6 \mu \mathrm{m}})$ \\
\hline M. cicadina & $\mathrm{MCH} 17$ & Azygospore & $41.0 \mu \mathrm{m} \times 42.6 \mu \mathrm{m}(\underline{41.8 \mu \mathrm{m}})$ \\
\hline M. cicadina & MCH05 & Azygospore & $42.8 \mu \mathrm{m} \times 43.7 \mu \mathrm{m}(\underline{43.2 \mu \mathrm{m}})$ \\
\hline M. cicadina & $\mathrm{MCH} 06$ & Azygospore & $43.1 \mu \mathrm{m} \times 45.0 \mu \mathrm{m}(\underline{44.1 \mu \mathrm{m}})$ \\
\hline M. cicadina & Holotype & Conidia & $10-17 \mu \mathrm{m} \times 14-20 \mu \mathrm{m}(15.5 \times 18.5 \mu \mathrm{m})$ \\
\hline M. cicadina & $\mathrm{MCH} 21$ & Conidia & $9.7-14.4 \mu \mathrm{m} \times 11.3-18.1 \mu \mathrm{m}(\underline{12.1 \times 14.4 \mu \mathrm{m}})$ \\
\hline M. cicadina & ARSEF 374 & Conidia & $14.1-20.5 \mu \mathrm{m} \times 16.2-24.5 \mu \mathrm{m}(17.4 \times \underline{19.9 \mu \mathrm{m}})$ \\
\hline M. cicadina & $\mathrm{MCH} 14$ & Conidia & $12.4-17.3 \mu \mathrm{m} \times 13.4-19.1 \mu \mathrm{m}(\underline{14.7 \times 16 \mu \mathrm{m}})$ \\
\hline M. cicadina & $\mathrm{MCH} 12$ & Conidia & $13.8-18.2 \mu \mathrm{m} \times 15.3-22.7 \mu \mathrm{m}(15.7 \times 18.4 \mu \mathrm{m})$ \\
\hline M. cicadina & $\mathrm{MCH} 16$ & Conidia & $12.1-17.3 \mu \mathrm{m} \times 12.2-20.8 \mu \mathrm{m}(\underline{14.6 \times 16.6 \mu \mathrm{m}})$ \\
\hline M. cicadina & MC46 & Conidia & $11.5-15.1 \mu \mathrm{m} \times 11.8-18.5 \mu \mathrm{m}(\underline{13.7 \times 15.4 \mu \mathrm{m}})$ \\
\hline M. cicadina & MC95 & Conidia & $12.9-15.6 \mu \mathrm{m} \times 13.3-17.3 \mu \mathrm{m}(\underline{14.3 \times 15.4 \mu \mathrm{m}})$ \\
\hline M. cicadina & MC94 & Conidia & $13.3-16.9 \mu \mathrm{m} \times 13.6-18.5 \mu \mathrm{m}(\underline{14.6 \times 16.2 \mu \mathrm{m}})$ \\
\hline M. cicadina & MC33 & Conidia & $11.8-15.9 \mu \mathrm{m} \times 12.8-17.3 \mu \mathrm{m}(\underline{13.7 \times 14.9 \mu \mathrm{m}})$ \\
\hline M. cicadina & MC136 & Conidia & $13.7-18.9 \mu \mathrm{m} \times 14.4-25.5 \mu \mathrm{m}(\underline{16.5 \times 19.4 \mu \mathrm{m}})$ \\
\hline M. cicadina & $\mathrm{MCH} 15$ & Conidia & $11.1-15 \mu \mathrm{m} \times 13.6-19.7 \mu \mathrm{m}(\underline{13.4 \times 16.2 \mu \mathrm{m}})$ \\
\hline M. cicadina & GK05 & Conidia & $12.5-16.3 \mu \mathrm{m} \times 13.4-18.5 \mu \mathrm{m}(\underline{14.6 \times 16.2 \mu \mathrm{m}})$ \\
\hline M. cicadina & GK04 & Conidia & $12.3-17 \mu \mathrm{m} \times 12.6-19.3 \mu \mathrm{m}(\underline{14.3 \times 16.1 \mu \mathrm{m}})$ \\
\hline M. cicadina & GK01 & Conidia & $14-19.4 \mu \mathrm{m} \times 14.3-20.1 \mu \mathrm{m}(15.9 \times 17.3 \mu \mathrm{m})$ \\
\hline M. cicadina & GK02 & Conidia & $13.6-17.7 \mu \mathrm{m} \times 14.8-19.7 \mu \mathrm{m}(\underline{16 \times 17.4 \mu \mathrm{m}})$ \\
\hline
\end{tabular}

${ }^{a}$ Conidial and azygospore measurements based on the average of 25 measured spores per fungal isolate. Underlined mean values in parentheses denote that mean length and width fell within the previously reported ranges for that given species 
Table S3. Massospora isolate histories and the type of analyses performed.

\begin{tabular}{|c|c|c|c|c|c|c|c|}
\hline $\begin{array}{l}\text { Fungus } \\
\text { (Massospora } \\
\text { sp.) }\end{array}$ & Fungal ID & Cicada host & Gender & Brood & Location & $\begin{array}{c}\text { Year } \\
\text { collected }\end{array}$ & $\begin{array}{l}\text { Analyses } \\
\text { peformed }^{\mathrm{a}}\end{array}$ \\
\hline M.platypediae & MP01 & Platypedia putnami & Male & $\mathrm{n} / \mathrm{a}$ & $\begin{array}{l}\text { NM, } \\
\text { USA }\end{array}$ & 2017 & GM, TM, MS, PS \\
\hline M. platypediae & MP02 & Platypedia putnami & Male & $\mathrm{n} / \mathrm{a}$ & $\begin{array}{l}\text { NM, } \\
\text { USA }\end{array}$ & 2017 & GM, TM, MS, PS \\
\hline M. platypediae & MP03 & Platypedia putnami & Female & $\mathrm{n} / \mathrm{a}$ & $\begin{array}{l}\text { NM, } \\
\text { USA }\end{array}$ & 2017 & GM, TM, MS \\
\hline M. platypediae & MP04 & Platypedia putnami & Male & $\mathrm{n} / \mathrm{a}$ & $\begin{array}{l}\text { NM, } \\
\text { USA }\end{array}$ & 2017 & GM, TM, MS \\
\hline M. platypediae & MP05 & Platypedia putnami & Male & $\mathrm{n} / \mathrm{a}$ & $\begin{array}{l}\text { NM, } \\
\text { USA }\end{array}$ & 2017 & GM, TM, MS \\
\hline M. platypediae & MP06 & Platypedia putnami & Male & $\mathrm{n} / \mathrm{a}$ & $\begin{array}{l}\text { NM, } \\
\text { USA }\end{array}$ & 2017 & GM, TM, MS \\
\hline M. platypediae & MP07 & Platypedia putnami & Male & $\mathrm{n} / \mathrm{a}$ & $\begin{array}{l}\text { NM, } \\
\text { USA }\end{array}$ & 2017 & GM, TM, MS \\
\hline M. platypediae & MP08 & Platypedia putnami & Male & $\mathrm{n} / \mathrm{a}$ & $\begin{array}{l}\text { NM, } \\
\text { USA }\end{array}$ & 2017 & GM, TM, MS, PS \\
\hline M. platypediae & MP09 & Platypedia putnami & Male & $\mathrm{n} / \mathrm{a}$ & $\begin{array}{l}\text { NM, } \\
\text { USA }\end{array}$ & 2017 & GM, TM, MS \\
\hline M. platypediae & MP10 & Platypedia putnami & Male & $\mathrm{n} / \mathrm{a}$ & $\begin{array}{l}\text { NM, } \\
\text { USA }\end{array}$ & 2017 & GM, TM, MS \\
\hline M. platypediae & MP16 & Platypedia putnami & Male & $\mathrm{n} / \mathrm{a}$ & $\begin{array}{l}\text { NM, } \\
\text { USA }\end{array}$ & 2017 & GM, MS \\
\hline M. platypediae & MP13 & Platypedia putnami & Male & $\mathrm{n} / \mathrm{a}$ & $\begin{array}{l}\text { NM, } \\
\text { USA }\end{array}$ & 2017 & GM, MS, PS \\
\hline M. platypediae & MP14 & Platypedia putnami & Female & $\mathrm{n} / \mathrm{a}$ & $\begin{array}{l}\text { NM, } \\
\text { USA }\end{array}$ & 2017 & GM, TM, MS \\
\hline M. platypediae & MP15 & Platypedia putnami & Female & $\mathrm{n} / \mathrm{a}$ & $\begin{array}{l}\text { NM, } \\
\text { USA }\end{array}$ & 2017 & GM, MS \\
\hline M. platypediae & MP11 & Platypedia putnami & Male & $\mathrm{n} / \mathrm{a}$ & $\begin{array}{l}\text { NM, } \\
\text { USA }\end{array}$ & 2017 & GM, MS, PS \\
\hline M. platypediae & MP12 & Platypedia putnami & Male & $\mathrm{n} / \mathrm{a}$ & $\begin{array}{l}\text { NM, } \\
\text { USA }\end{array}$ & 2017 & GM, TM \\
\hline M. levispora & ML01 & Okanagana rimosa & Female & $\mathrm{n} / \mathrm{a}$ & MI, USA & 1998 & TM, MS, PS \\
\hline M. levispora & ML02 & Okanagana rimosa & Female & $\mathrm{n} / \mathrm{a}$ & MI, USA & 1998 & TM, MS, PS \\
\hline M. levispora & ML04 & Okanagana rimosa & Female & $\mathrm{n} / \mathrm{a}$ & MI, USA & 1998 & TM, MS, PS \\
\hline M. levispora & ML06 & Okanagana rimosa & Female & $\mathrm{n} / \mathrm{a}$ & MI, USA & 1998 & TM, MS \\
\hline M. levispora & ML07 & Okanagana rimosa & Female & $\mathrm{n} / \mathrm{a}$ & MI, USA & 1998 & TM, MS \\
\hline M. levispora & ML08 & Okanagana rimosa & Female & $\mathrm{n} / \mathrm{a}$ & MI, USA & 1998 & TM, MS \\
\hline M. levispora & ML10 & Okanagana rimosa & Female & $\mathrm{n} / \mathrm{a}$ & MI, USA & 1998 & MS \\
\hline M. levispora & ML03 & Okanagana rimosa & Female & $\mathrm{n} / \mathrm{a}$ & MI, USA & 1998 & TM, MS \\
\hline M. levispora & ML05 & Okanagana rimosa & Female & $\mathrm{n} / \mathrm{a}$ & MI, USA & 1998 & TM, MS \\
\hline M. cicadina & MC138 (BVI-01) & Magicicada septendecim & Female & VI & NC, USA & 2017 & GM, TM, MS, PS \\
\hline M. cicadina & MC142 (BVI-05) & Magicicada septendecim & Female & VI & NC, USA & 2017 & GM, TM, MS \\
\hline M. cicadina & MC141 (BVI-06) & Magicicada septendecim & Female & VI & NC, USA & 2017 & GM, TM, MS \\
\hline M. cicadina & MC139 (BVI-07) & Magicicada septendecim & Female & VI & NC, USA & 2017 & GM, TM, MS \\
\hline M. cicadina & MC140 (BVI-08) & Magicicada septendecim & Female & VI & NC, USA & 2017 & GM, TM, MS \\
\hline M. cicadina & MC138 (BVI-03) & Magicicada septendecim & Female & VI & NC, USA & 2017 & MS \\
\hline M. cicadina & MC143 (BVI-02) & Magicicada septendecim & Female & VI & NC, USA & 2017 & MS \\
\hline M. cicadina & MC144 (BVI-04) & Magicicada septendecim & Male & VI & NC, USA & 2017 & MS \\
\hline M. cicadina & $\mathrm{MCH} 17$ & Magicicada tredecim-like & Female & XIX & IL, USA & 1998 & MS \\
\hline M. cicadina & MC150 & Magicicada tredecim & $?$ & $\mathrm{XIX}$ & IL, USA & 1998 & MS, PS \\
\hline M. cicadina & MCH05 & Magicicada tredecim & Male & $\mathrm{XIX}$ & IL, USA & 1998 & MS \\
\hline M. cicadina & $\mathrm{MCH} 06$ & Magicicada tredecim & Female & $\mathrm{XIX}$ & IL, USA & 1998 & MS \\
\hline M. cicadina & $\mathrm{MCH} 21$ & Magicicada septendecula & Female & I & $\begin{array}{l}\text { WV } \\
\text { USA }\end{array}$ & 1978 & MS \\
\hline M. cicadina & ARSEF 374 & Magicicada septendecim & $?$ & II & NY, USA & 1979 & MS, PS \\
\hline M. cicadina & $\mathrm{MCH} 14$ & Magicicada cassini & Female & II & NY, USA & 1979 & MS \\
\hline M. cicadina & $\mathrm{MCH} 12$ & Magicicada septendecim & Female & II & CT, USA & 1979 & MS \\
\hline
\end{tabular}




\begin{tabular}{|c|c|c|c|c|c|c|c|}
\hline M. cicadina & $\mathrm{MCH} 16$ & Magicicada septendecula & Male & $I V / X I X$ & $\begin{array}{l}\text { MO, } \\
\text { USA }\end{array}$ & 1998 & MS \\
\hline M. cicadina & MC46 & Magicicada septendecula & Male & V & $\begin{array}{l}\text { WV, } \\
\text { USA }\end{array}$ & 2016 & MS, PS \\
\hline M. cicadina & MC95 & Magicicada cassini & Male & $\mathrm{V}$ & $\begin{array}{l}\text { WV, } \\
\text { USA }\end{array}$ & 2016 & GM, MS \\
\hline M. cicadina & MC94 & Magicicada cassini & Female & V & $\begin{array}{l}\text { WV, } \\
\text { USA }\end{array}$ & 2016 & GM, MS \\
\hline M. cicadina & MC33 & Magicicada septendecula & Male & V & $\begin{array}{l}\text { WV, } \\
\text { USA }\end{array}$ & 2016 & GM, TM, MS, PS \\
\hline M. cicadina & MC136 & Magicicada septendecim & Female & $\mathrm{V}$ & OH USA & 2016 & MS \\
\hline M. cicadina & MCH15 & Magicicada septendecim & Male & VIII & PA, USA & 2002 & MS \\
\hline M. cicadina & GK05 & Magicicada cassini & Male & $\mathrm{x}$ & $\mathrm{OH}$, USA & 2004 & MS, PS \\
\hline M. cicadina & GK04 & Magicicada septendecula & Female & XIV & $\mathrm{OH}$, USA & 2008 & MS, PS \\
\hline M. cicadina & GK01 & Magicicada tredecula & Female & XXIII & IL, USA & 1989 & MS \\
\hline M. cicadina & GK02 & Magicicada tredecassini & Female & XXIII & IN, USA & 2015 & MS, PS \\
\hline M. cicadina & $\mathrm{MCH} 19$ & Magicicada septendecula & Female & 1 & $\begin{array}{l}\text { WV, } \\
\text { USA }\end{array}$ & 1978 & MS, PS \\
\hline M. cicadina & MCH22 & Magicicada septendecula & Female & $\mathrm{XIX}$ & IL, USA & 1998 & MS \\
\hline M. cicadina & MC19 & Magicicada cassini & Female & V & $\begin{array}{l}\text { WV, } \\
\text { USA }\end{array}$ & 2016 & GM, MS \\
\hline M. cicadina & MC23 & Magicicada septendecula & Male & V & $\begin{array}{l}\text { WV, } \\
\text { USA }\end{array}$ & 2016 & GM, TM, MS, PS \\
\hline M. cicadina & MC104 & Magicicada septendecim & Male & V & $\mathrm{OH}, \mathrm{USA}$ & 2016 & PS \\
\hline M. cicadina & MC130 & Magicicada septendecim & Female & $\mathrm{V}$ & OH, USA & 2016 & PS \\
\hline $\begin{array}{l}\text { No fungus } \\
\text { control }\end{array}$ & MCNC1 & Magicicada septendecim & Female & VI & NC, USA & 2017 & GM, TM \\
\hline $\begin{array}{l}\text { No fungus } \\
\text { control }\end{array}$ & MPNC01 & Platypedia putnami & $?$ & $\mathrm{n} / \mathrm{a}$ & $\begin{array}{l}\text { NM, } \\
\text { USA }\end{array}$ & 2017 & GM, TM \\
\hline $\begin{array}{l}\text { No fungus } \\
\text { control }\end{array}$ & MLNC01 & Okanagana rimosa & $?$ & $\mathrm{n} / \mathrm{a}$ & MI, USA & 1998 & GM, TM \\
\hline
\end{tabular}


Table S4. Positive ion mode metabolites from where?.

\begin{tabular}{|c|c|c|c|c|c|}
\hline Compound Name & Compound Class & $\begin{array}{c}\text { Log FC } \\
\text { ([Contro } \\
\text { I] vs } \\
\text { [MC]) : } \\
\text { Normali } \\
\text { zed }\end{array}$ & $\begin{array}{l}\text { Regulat } \\
\text { ion } \\
\text { ([Contr } \\
\text { ol] vs } \\
\text { [MC]) }\end{array}$ & $\begin{array}{l}\text { Log FC } \\
\text { ([MC] vs } \\
{[\text { MP]) : }} \\
\text { Normaliz } \\
\text { ed }\end{array}$ & $\begin{array}{l}\text { Regulat } \\
\text { ion } \\
\text { ([MC] } \\
\text { vs } \\
\text { [MP]) }\end{array}$ \\
\hline $\begin{array}{l}\text { (+)-Syringaresinol O-beta-D- } \\
\text { glucoside }\end{array}$ & $\mathrm{n} / \mathrm{a}$ & 0 & down & $\begin{array}{c}- \\
16.53521 \\
7\end{array}$ & down \\
\hline 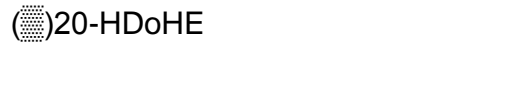 & very long-chain fatty acids & $\begin{array}{c}- \\
15.5996 \\
45\end{array}$ & down & $\begin{array}{c}- \\
0.308893 \\
2\end{array}$ & down \\
\hline $\begin{array}{l}\text { (1R)-N-Acetyl-L-cysteinyl-(2R)- } \\
\text { hydroxy-1,2-dihydronaphthalene }\end{array}$ & $\mathrm{n} / \mathrm{a}$ & 0 & down & $\begin{array}{c}- \\
14.85312 \\
7\end{array}$ & down \\
\hline $\begin{array}{l}\text { (24R)-24,25-dihydroxyvitamin D2 / } \\
\text { (24R)-24,25-dihydroxyergocalciferol }\end{array}$ & $\mathrm{n} / \mathrm{a}$ & 0 & down & $\begin{array}{c}- \\
19.34416 \\
4\end{array}$ & down \\
\hline $\begin{array}{l}\text { (2S)-2-\{[1-(R)- } \\
\text { Carboxyethyl]amino\}pentanoate }\end{array}$ & $\mathrm{n} / \mathrm{a}$ & $\begin{array}{c}- \\
17.4632 \\
85\end{array}$ & down & $\begin{array}{c}17.46328 \\
5\end{array}$ & up \\
\hline (5-D-ribonyl)hopane & Hopanoids & $\begin{array}{c}- \\
16.8587 \\
19\end{array}$ & down & $\begin{array}{c}16.85871 \\
9\end{array}$ & up \\
\hline (Z)-22-Hentriacontene-2,4-dione & beta-diketones & 0 & down & $\begin{array}{c}- \\
16.54594 \\
6\end{array}$ & down \\
\hline $\begin{array}{l}\text { [6]-Gingerdiol 4'-O-beta-D- } \\
\text { glucopyranoside }\end{array}$ & phenolic glycosides & 0 & down & $\begin{array}{c}- \\
15.26454 \\
5\end{array}$ & down \\
\hline $\begin{array}{l}\text { 1-(10-methyl-hexadecanoyl)-2-(8- } \\
\text { [3]-ladderane-octanyl)-sn- } \\
\text { glycerophosphoethanolamine }\end{array}$ & $\begin{array}{c}1 \text {-acyl,2- } \\
\text { alkylglycerophosphoethanol } \\
\text { amines }\end{array}$ & 0 & down & 15.86329 & down \\
\hline 1-(2-Thienyl)-1-heptanone & aryl alkyl ketones. & $\begin{array}{c}- \\
14.6326 \\
63\end{array}$ & down & $\begin{array}{c}14.63266 \\
3\end{array}$ & up \\
\hline $\begin{array}{l}\text { 1,2-Dihydroxy-3-keto-5- } \\
\text { methylthiopentene }\end{array}$ & $\begin{array}{l}\text { alpha-branched alpha,beta- } \\
\text { unsaturated ketones }\end{array}$ & $\begin{array}{l}- \\
14.0850 \\
525\end{array}$ & down & -1.43892 & down \\
\hline $\begin{array}{l}\text { 1,4-Benzenediol, 2,6-bis(1- } \\
\text { methylethyl)-, 4-(hydrogen sulfate) }\end{array}$ & phenylpropanes & 0 & down & $\begin{array}{c}- \\
15.93243 \\
1\end{array}$ & down \\
\hline $\begin{array}{l}\text { 10,11-Epoxy-3,7,11-trimethyl- } \\
\text { 2E,6E-tridecadienoic acid }\end{array}$ & Branched fatty acids & $\begin{array}{c}- \\
16.3010 \\
3\end{array}$ & down & 16.30103 & up \\
\hline 10E,12Z-Tetradecadienyl acetate & Wax monoesters & $\begin{array}{c}- \\
15.0779 \\
46\end{array}$ & down & $\begin{array}{c}15.07794 \\
6\end{array}$ & up \\
\hline $\begin{array}{l}\text { 11,11-Difluoro-9Z-dodecenyl } \\
\text { acetate }\end{array}$ & Wax monoesters & $\begin{array}{c}- \\
16.2996 \\
14\end{array}$ & down & $\begin{array}{c}16.29961 \\
4\end{array}$ & up \\
\hline $\begin{array}{l}\text { 11?-(4-dimethylaminophenyl)-1?,25- } \\
\text { dihydroxyvitamin D3 / 11?-(4- } \\
\text { dimethylaminophenyl)-1?,25- } \\
\text { dihydroxycholecalciferol }\end{array}$ & $\mathrm{n} / \mathrm{a}$ & $\begin{array}{l}19.7231 \\
08\end{array}$ & up & 0 & down \\
\hline 14-Hydroxypergolide glucuronide & $\mathrm{n} / \mathrm{a}$ & 0 & down & $\begin{array}{c}- \\
15.43237 \\
8\end{array}$ & down \\
\hline
\end{tabular}


15-Lipoxygenase Inhibitor 1

18-acetoxy-1?,25-dihydroxyvitamin

D3 / 18-acetoxy-1?,25-

dihydroxycholecalciferol

1-Piperidinecarboxaldehyde

2,2,11,13,15-pentachloro-docosane-

1,14-disulfate

26-Glucosyl-1,3,11,22-

tetrahydroxyergosta-5,24-dien-26-

oate

2alpha-Hydroxypyracrenic acid

2alpha-Hydroxypyracrenic acid

nullnullnull 1.0360001

3'-(2"-Galloylglucosyl)-

phloroacetophenone

3',4'-Dihydroxy-5,6,7-

trimethoxyflavone

3,7-Dihydroxy-2-[4-hydroxy-3-(4-

hydroxy-3-methylbutyl)phenyl]-5,6-

dimethoxy-4H-1-benzopyran-4-one

3?-Hydroxy-4,4-Bisnor-8,11,13-

Podocarpatriene

$32: 4(17 Z, 20 Z, 23 Z, 26 Z)$

3-Methylthiopropanamine

4-

(Hydroxymethyl)benzenediazonium(

$1+)$

4a-Hydroxytetrahydrobiopterin

4'-Hydroxy-7-methoxy-8-

methylflavan

4-Propanoyl-HT2 toxin

5-(1-Hydroxyethyl)-4-methylthiazole

5,7,4'-Trihydroxy-6,8,3'-

trimethoxyflavone 7 -glucoside

5-Acetoxypalisadin B

5-Aminoimidazole-4-carboxamide-1-

?-D-ribofuranosyl 5'-

monophosphate

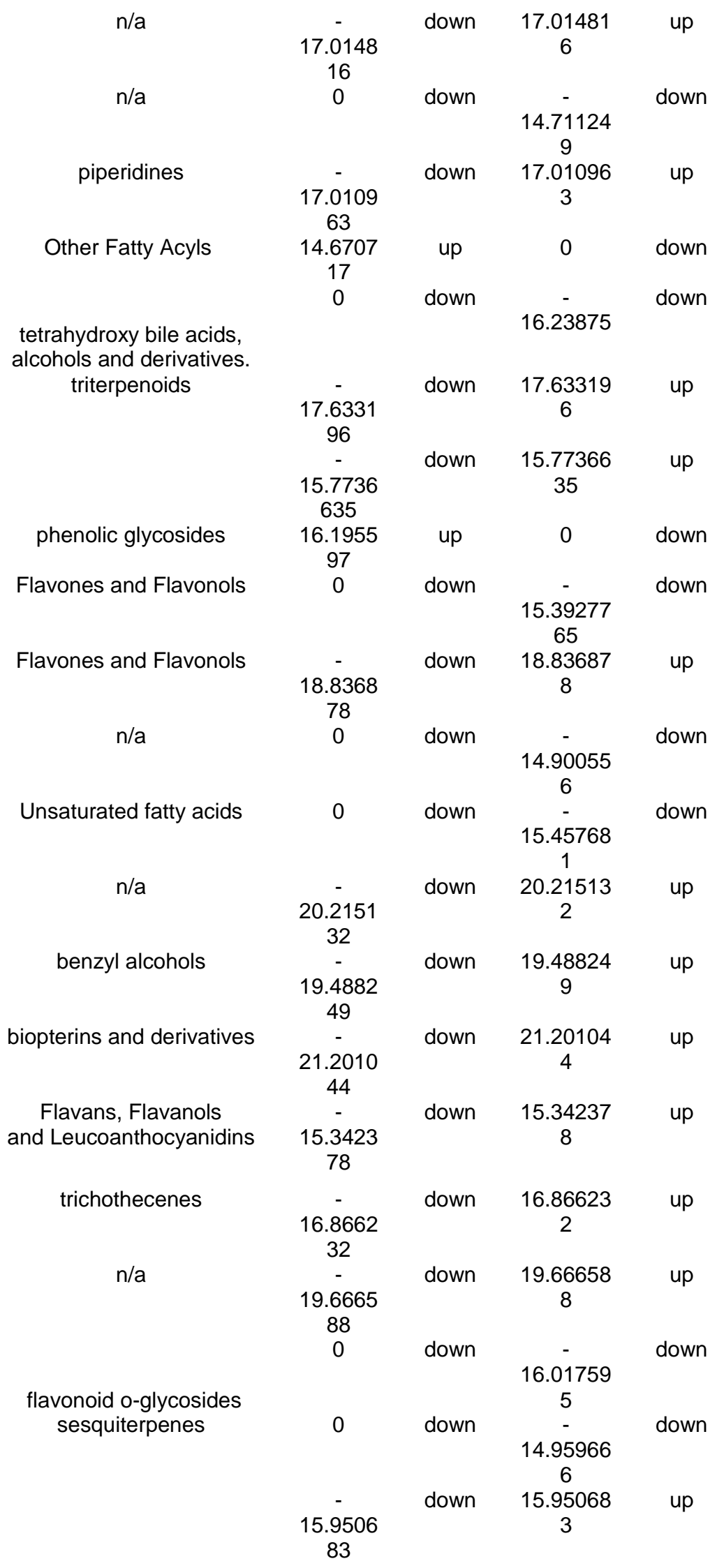


5-Hydroxy-7-methoxy-2-tritriacontyl4H-1-benzopyran-4-one

5-Methyl-2-phenyl-2-hexenal

6,8-Di-C-methylluteolin 7-methyl ether

6?-Naltrexol-3-glucuronide

7-Aminocephalosporanic acid

7-Methoxyflavanone

9,12,15-Hexadecatrienoic acid

9-Thiastearic Acid

Acutilol A

Agavasaponin C

Akeboside Stf

Alkaloid A6

Allocain-S

Amastatin

Arginyl-Hydroxyproline

AS-605240

Asp Glu Trp

Asp Tyr Asn

Asp Val Asp

Benzo[a]fluoranthene

beta-Obscurine

\begin{tabular}{|c|c|c|c|c|}
\hline chromones & 0 & down & $\begin{array}{c}- \\
16.16092 \\
1\end{array}$ & down \\
\hline & 0 & down & 17.04231 & down \\
\hline phenylacetaldehydes & & & 8 & \\
\hline $\mathrm{n} / \mathrm{a}$ & 0 & down & $\begin{array}{c}- \\
18.71800 \\
8\end{array}$ & down \\
\hline $\mathrm{n} / \mathrm{a}$ & 0 & down & $\begin{array}{c}- \\
15.41690 \\
2\end{array}$ & down \\
\hline $\mathrm{n} / \mathrm{a}$ & 0 & down & $\begin{array}{c}- \\
16.20453 \\
6\end{array}$ & down \\
\hline Flavones and Flavonols & $\begin{array}{c}- \\
19.3922 \\
94\end{array}$ & down & 1.034029 & down \\
\hline Unsaturated fatty acids & $\begin{array}{c}- \\
15.0164 \\
84\end{array}$ & down & $\begin{array}{c}15.01648 \\
4\end{array}$ & up \\
\hline $\mathrm{n} / \mathrm{a}$ & 0 & down & $\begin{array}{c}- \\
18.15250 \\
6\end{array}$ & down \\
\hline $\begin{array}{l}\text { C20 isoprenoids } \\
\text { (diterpenes) }\end{array}$ & $\begin{array}{c}- \\
14.8237 \\
66\end{array}$ & down & $\begin{array}{c}1.325707 \\
4\end{array}$ & up \\
\hline steroidal saponins & $\begin{array}{c}- \\
16.4579 \\
64\end{array}$ & down & $\begin{array}{c}16.45796 \\
4\end{array}$ & up \\
\hline $\mathrm{n} / \mathrm{a}$ & $\begin{array}{c}- \\
18.4236 \\
58\end{array}$ & down & $\begin{array}{c}18.42365 \\
8\end{array}$ & up \\
\hline acridones & 0 & down & $\begin{array}{c}- \\
17.39818 \\
6\end{array}$ & down \\
\hline & $\begin{array}{c}- \\
15.8869 \\
35\end{array}$ & down & $\begin{array}{c}15.88693 \\
5\end{array}$ & up \\
\hline $\mathrm{n} / \mathrm{a}$ & $\begin{array}{c}- \\
15.2679 \\
87\end{array}$ & down & $\begin{array}{c}15.26798 \\
7\end{array}$ & up \\
\hline dipeptides & 0 & down & $\begin{array}{c}- \\
15.64634 \\
7\end{array}$ & down \\
\hline$n / a$ & 0 & down & 16.08645 & down \\
\hline $\mathrm{n} / \mathrm{a}$ & 0 & down & $\begin{array}{c}- \\
17.37304 \\
9\end{array}$ & down \\
\hline $\mathrm{n} / \mathrm{a}$ & $\begin{array}{c}- \\
16.5718 \\
29\end{array}$ & down & $\begin{array}{c}- \\
0.913539 \\
9\end{array}$ & down \\
\hline $\mathrm{n} / \mathrm{a}$ & $\begin{array}{c}- \\
16.5142 \\
27\end{array}$ & down & $\begin{array}{c}16.51422 \\
7\end{array}$ & up \\
\hline $\mathrm{n} / \mathrm{a}$ & $\begin{array}{c}-\overline{-} \\
72.1118\end{array}$ & down & $\begin{array}{c}18.11187 \\
2\end{array}$ & up \\
\hline$n / a$ & $\begin{array}{c}- \\
15.4219\end{array}$ & down & $\begin{array}{c}15.42198 \\
7\end{array}$ & up \\
\hline
\end{tabular}




\begin{tabular}{|c|c|c|c|c|c|}
\hline C-6 Ceramide & & $\begin{array}{c}- \\
15.1379 \\
42\end{array}$ & down & $\begin{array}{c}15.13794 \\
2\end{array}$ & up \\
\hline$C 9: 2 n-5,7$ & Unsaturated fatty acids & $\begin{array}{c}- \\
16.3549 \\
98\end{array}$ & down & $\begin{array}{c}16.35499 \\
8\end{array}$ & up \\
\hline Calyculin A & $\mathrm{n} / \mathrm{a}$ & $\begin{array}{c}- \\
16.6401 \\
44\end{array}$ & down & $\begin{array}{c}16.64014 \\
4\end{array}$ & up \\
\hline Capsaicin & methoxyphenols. & $\begin{array}{c}- \\
15.1512 \\
83\end{array}$ & down & $\begin{array}{c}15.15128 \\
3\end{array}$ & up \\
\hline CAY10499 & & 0 & down & $\begin{array}{c}- \\
15.50116 \\
6\end{array}$ & down \\
\hline Cer(d14:1(4E)/20:0(2OH)) & $\mathrm{n} / \mathrm{a}$ & 0 & down & $\begin{array}{c}- \\
17.34730 \\
1\end{array}$ & down \\
\hline Cer(d18:2/16:0) null 1.028 & $\mathrm{n} / \mathrm{a}$ & 0 & down & $\begin{array}{c}- \\
17.08793 \\
8\end{array}$ & down \\
\hline Chalcomoracin & 2-arylbenzofuran flavonoids & $\begin{array}{c}- \\
18.2254 \\
5\end{array}$ & down & 18.22545 & up \\
\hline Chlorophyll d & metallotetrapyrroles. & $\begin{array}{c}- \\
15.6948 \\
9\end{array}$ & down & 15.69489 & up \\
\hline Cinnamyl phenylacetate & styrenes & $\begin{array}{c}- \\
15.3839 \\
6\end{array}$ & down & 15.38396 & up \\
\hline Conchosin B & $\mathrm{n} / \mathrm{a}$ & $\begin{array}{c}- \\
16.2712 \\
02\end{array}$ & down & $\begin{array}{c}16.27120 \\
2\end{array}$ & up \\
\hline CРA(16:0/0:0) & $\begin{array}{l}\text {-acyl-sn-glycerol-2,3-cyclic- } \\
\text { phosphates }\end{array}$ & 0 & down & $\begin{array}{c}- \\
15.52623 \\
5\end{array}$ & down \\
\hline Cyclohexane & cycloalkanes & $\begin{array}{c}- \\
18.2230 \\
3\end{array}$ & down & $\begin{array}{c}- \\
1.045982 \\
4\end{array}$ & down \\
\hline Dehydrotremetone & & $\begin{array}{c}- \\
15.5912 \\
32\end{array}$ & down & $\begin{array}{c}- \\
1.835561 \\
8\end{array}$ & down \\
\hline Descinolone & $\mathrm{n} / \mathrm{a}$ & $\begin{array}{c}- \\
16.8006 \\
27\end{array}$ & down & $\begin{array}{c}16.80062 \\
7\end{array}$ & up \\
\hline DG(12:0/17:2(9Z,12Z)/0:0)[iso2] & Diacylglycerols & $\begin{array}{c}- \\
16.8496 \\
91\end{array}$ & down & $\begin{array}{c}16.84969 \\
1\end{array}$ & up \\
\hline DG(16:1(9Z)/20:3(5Z,8Z,11Z)/0:0) & 1,2-diacylglycerols & $\begin{array}{c}- \\
15.5278 \\
46\end{array}$ & down & $\begin{array}{c}- \\
1.174689 \\
3\end{array}$ & down \\
\hline $\begin{array}{l}\mathrm{DG}(18: 1(11 Z) / 22: 5(7 Z, 10 Z, 13 Z, 16 Z \\
, 19 Z) / 0: 0)\end{array}$ & 1,2-diacylglycerols & 0 & down & $\begin{array}{c}- \\
15.23056 \\
7\end{array}$ & down \\
\hline DG(18:4(6Z,9Z,12Z,15Z)/15:0/0:0) & $\begin{array}{l}\text { lineolic acids and } \\
\text { derivatives }\end{array}$ & $\begin{array}{c}- \\
15.0531 \\
27\end{array}$ & down & $\begin{array}{c}15.05312 \\
7\end{array}$ & up \\
\hline $\begin{array}{l}\text { DG(21:0/22:6(4Z,7Z,10Z,13Z,16Z,1 } \\
\text { 9Z)/0:0)[iso2] }\end{array}$ & Diacylglycerols & $\begin{array}{c}- \\
16.3507 \\
79\end{array}$ & down & $\begin{array}{c}1.550512 \\
3\end{array}$ & up \\
\hline
\end{tabular}




\begin{tabular}{|c|c|c|c|c|c|}
\hline Dicliripariside C & Flavones and Flavonols & $\begin{array}{c}- \\
15.2438 \\
76\end{array}$ & down & $\begin{array}{c}15.24387 \\
6\end{array}$ & up \\
\hline Dihomomethionine & $\mathrm{n} / \mathrm{a}$ & $\begin{array}{c}- \\
17.8169 \\
38\end{array}$ & down & $\begin{array}{c}17.81693 \\
8\end{array}$ & up \\
\hline Dihydrocorynantheine & oxindole alkaloids & $\begin{array}{c}- \\
15.9955 \\
24\end{array}$ & down & $\begin{array}{c}0.135066 \\
03\end{array}$ & up \\
\hline Dihydromikanolide & & $\begin{array}{c}- \\
15.1403 \\
84\end{array}$ & down & $\begin{array}{c}15.14038 \\
4\end{array}$ & up \\
\hline Dimethylarsinous acid & & 0 & down & 16.48190 & down \\
\hline Dioxybenzone & $\begin{array}{l}\text { organoarsinous acids. } \\
\text { n/a }\end{array}$ & $\begin{array}{c}- \\
16.3440 \\
48\end{array}$ & down & $\begin{array}{c}9 \\
0.045965 \\
195\end{array}$ & up \\
\hline Dolastatin 12 & $\begin{array}{l}\text { cytotoxic analogue of } \\
\text { dolastatins }\end{array}$ & $\begin{array}{c}- \\
15.7254 \\
61\end{array}$ & down & $\begin{array}{c}15.72546 \\
1\end{array}$ & up \\
\hline Dulcoside A & steviol glycosides & $\begin{array}{c}- \\
16.8576 \\
93\end{array}$ & down & $\begin{array}{c}16.85769 \\
3\end{array}$ & up \\
\hline Ecalcidene & & 0 & down & $\begin{array}{c}- \\
15.82866 \\
4\end{array}$ & down \\
\hline Enterocin 900 & 2-arylbenzofuran flavonoids & 0 & down & $\begin{array}{c}- \\
15.43837 \\
3\end{array}$ & down \\
\hline Epiafzelechin 3-O-gallate & $\begin{array}{l}\text { Flavans, Flavanols } \\
\text { and Leucoanthocyanidins }\end{array}$ & $\begin{array}{c}- \\
16.8139 \\
29\end{array}$ & down & $\begin{array}{c}16.81392 \\
9\end{array}$ & up \\
\hline Epimedoside D & $\mathrm{n} / \mathrm{a}$ & 0 & down & $\begin{array}{c}- \\
16.03729 \\
2\end{array}$ & down \\
\hline Erythromycin C & aminoglycosides & $\begin{array}{c}- \\
15.9164 \\
86\end{array}$ & down & $\begin{array}{c}15.91648 \\
6\end{array}$ & up \\
\hline Ether & $\mathrm{n} / \mathrm{a}$ & $\begin{array}{c}- \\
17.8074 \\
04\end{array}$ & down & $\begin{array}{c}- \\
0.056489 \\
944\end{array}$ & down \\
\hline Fasciculol E & triterpenoids & $\begin{array}{c}- \\
17.8298 \\
91\end{array}$ & down & $\begin{array}{c}17.82989 \\
1\end{array}$ & up \\
\hline FKGK 11 & $\mathrm{n} / \mathrm{a}$ & $\begin{array}{c}- \\
18.1131 \\
94\end{array}$ & down & $\begin{array}{c}18.11319 \\
4\end{array}$ & up \\
\hline Fluorene & $\mathrm{n} / \mathrm{a}$ & $\begin{array}{c}- \\
18.8844 \\
91\end{array}$ & down & $\begin{array}{c}0.501478 \\
2\end{array}$ & up \\
\hline Gaillardin & Sesquiterpene Lactone & 0 & down & $\begin{array}{c}- \\
14.81690 \\
5\end{array}$ & down \\
\hline Gallamine & $\mathrm{n} / \mathrm{a}$ & 0 & down & $\begin{array}{c}- \\
16.16862 \\
7\end{array}$ & down \\
\hline GalNAc?1-4[Fuc?1-3]GlcNAc?-Sp & $\mathrm{n} / \mathrm{a}$ & 0 & down & $\begin{array}{c}- \\
14.83810 \\
9\end{array}$ & down \\
\hline
\end{tabular}




\begin{tabular}{|c|c|c|c|c|c|}
\hline gamma-L-Glutamyl-butirosin B & $\mathrm{n} / \mathrm{a}$ & 0 & down & $\begin{array}{c}- \\
18.28441 \\
4\end{array}$ & down \\
\hline GlcN?1-6Ins-1-P-Cer(t18:0/26:0) & $\mathrm{n} / \mathrm{a}$ & $\begin{array}{c}- \\
17.0111 \\
75\end{array}$ & down & $\begin{array}{c}17.01117 \\
5\end{array}$ & up \\
\hline Gln Met Met & $\mathrm{n} / \mathrm{a}$ & $\begin{array}{c}- \\
16.7055 \\
87\end{array}$ & down & $\begin{array}{c}16.70558 \\
7\end{array}$ & up \\
\hline Gln Pro Glu & & 0 & down & $\begin{array}{c}- \\
15.57304 \\
3\end{array}$ & down \\
\hline Glu Asn Trp & $\mathrm{n} / \mathrm{a}$ & $\begin{array}{l}14 . \overline{9} 901 \\
35\end{array}$ & down & $\begin{array}{c}14.99013 \\
5\end{array}$ & up \\
\hline Gly Gly Gln & & $\begin{array}{c}- \\
13.3597 \\
11\end{array}$ & down & $\begin{array}{c}13.35971 \\
1\end{array}$ & up \\
\hline Glyceollidin II & furanoisoflavonoids & $\begin{array}{c}- \\
16.2229 \\
9\end{array}$ & down & 16.22299 & up \\
\hline $\begin{array}{l}\text { Glycochenodeoxycholic acid 3- } \\
\text { glucuronide }\end{array}$ & $\begin{array}{l}\text { steroid glucuronide } \\
\text { conjugates }\end{array}$ & 0 & down & $\begin{array}{c}- \\
16.33913 \\
6\end{array}$ & down \\
\hline Gravacridonetriol glucoside & glycosylglycerols & 0 & down & 16.60066 & down \\
\hline GS 1500 & $\mathrm{n} / \mathrm{a}$ & 0 & down & $\begin{array}{c}- \\
16.65462 \\
3\end{array}$ & down \\
\hline Hebevinoside XIV & cucurbitacin glycosides & $\begin{array}{c}- \\
18.1026 \\
67\end{array}$ & down & $\begin{array}{c}18.10266 \\
7\end{array}$ & up \\
\hline His Trp & $\mathrm{n} / \mathrm{a}$ & $\begin{array}{c}- \\
15.3711 \\
1\end{array}$ & down & 15.37111 & up \\
\hline His Trp null 7.188 & & 0 & down & $\begin{array}{c}- \\
15.51259 \\
9\end{array}$ & down \\
\hline HQL-79 & $\mathrm{n} / \mathrm{a}$ & $\begin{array}{c}15.7332 \\
34\end{array}$ & up & 0 & down \\
\hline $\begin{array}{l}\text { Idebenone Metabolite } \\
\text { (Benzenebutanoic acid, 2,5- } \\
\text { dihydroxy-3,4-dimethoxy-6-methyl-) }\end{array}$ & $\mathrm{n} / \mathrm{a}$ & $\begin{array}{c}- \\
19.1196 \\
88\end{array}$ & down & $\begin{array}{c}19.11968 \\
8\end{array}$ & up \\
\hline Insmine & $\mathrm{n} / \mathrm{a}$ & 0 & down & $\begin{array}{c}- \\
14.89348 \\
6\end{array}$ & down \\
\hline Istamycin C1 & $\mathrm{n} / \mathrm{a}$ & $\begin{array}{l}- \\
16.4090 \\
29\end{array}$ & down & $\begin{array}{c}16.40902 \\
9\end{array}$ & up \\
\hline JZL 195 & & 0 & down & $\begin{array}{c}- \\
15.52643 \\
5\end{array}$ & down \\
\hline $\begin{array}{l}\text { KDNalpha2-3Galbeta1-4Glcbeta- } \\
\text { Cer(d18:1/16:0) }\end{array}$ & $\mathrm{n} / \mathrm{a}$ & $\begin{array}{c}- \\
16.4186 \\
9\end{array}$ & down & 16.41869 & up \\
\hline L-Menthone 1,2-glycerol ketal & phenyl-1,3,4-tria & $\begin{array}{c}15.5334 \\
34\end{array}$ & up & $\begin{array}{c}- \\
18.38590 \\
4\end{array}$ & down \\
\hline Lycoperoside D & steroidal saponins. & $\begin{array}{c}- \\
20.3116 \\
25\end{array}$ & down & $\begin{array}{c}20.31162 \\
5\end{array}$ & up \\
\hline
\end{tabular}




\begin{tabular}{|c|c|c|c|c|c|}
\hline Lys Arg Ser & & $\begin{array}{c}- \\
18.0401 \\
52\end{array}$ & down & $\begin{array}{c}4.537039 \\
8\end{array}$ & up \\
\hline Lys Trp & $\mathrm{n} / \mathrm{a}$ & 0 & down & $\begin{array}{c}- \\
19.64739 \\
4\end{array}$ & down \\
\hline $\begin{array}{l}\text { m-(beta-Acetyl-alpha-ethyl-p- } \\
\text { hydroxyphenethyl)benzoic acid }\end{array}$ & fatty alcohols. & -16.3235 & down & 16.3235 & up \\
\hline Madlongiside $\mathrm{C}$ & triterpenoids & $\begin{array}{c}- \\
15.3356 \\
4\end{array}$ & down & 15.33564 & up \\
\hline Majoroside F4 & triterpenoids & 0 & down & $\begin{array}{c}- \\
17.03136 \\
6\end{array}$ & down \\
\hline Methional & $\mathrm{n} / \mathrm{a}$ & $\begin{array}{c}- \\
21.8872 \\
43\end{array}$ & down & $\begin{array}{c}21.88724 \\
3\end{array}$ & up \\
\hline Methionyl-Glycine & dipeptides & 0 & down & $\begin{array}{c}- \\
16.90062 \\
1\end{array}$ & down \\
\hline $\begin{array}{l}\text { Methyl 2-(4-isopropyl-4-methyl-5- } \\
\text { oxo-2-imidazolin-2-yl)-p-toluate }\end{array}$ & & $\begin{array}{c}- \\
1.09191 \\
9\end{array}$ & down & $\begin{array}{c}15.78313 \\
1\end{array}$ & up \\
\hline $\begin{array}{l}\text { Methyl 4,6-di-O-galloyl-beta-D- } \\
\text { glucopyranoside }\end{array}$ & tannin & $\begin{array}{c}16.4605 \\
96\end{array}$ & up & 0 & down \\
\hline Met-Nap-OH & $\mathrm{n} / \mathrm{a}$ & $\begin{array}{c}- \\
16.2445 \\
83\end{array}$ & down & $\begin{array}{c}16.24458 \\
3\end{array}$ & up \\
\hline Met-Nap-OH nullnullnull 0.762 & $\mathrm{n} / \mathrm{a}$ & $\begin{array}{c}- \\
16.7163 \\
33\end{array}$ & down & $\begin{array}{c}16.71633 \\
3\end{array}$ & up \\
\hline MIPC(t18:0/18:0(2OH)) & Ceramide phosphoinositols & $\begin{array}{c}- \\
16.5925 \\
56\end{array}$ & down & $\begin{array}{c}16.59255 \\
6\end{array}$ & up \\
\hline MIPC(t18:0/20:0) & Ceramide phosphoinositols & $\begin{array}{c}- \\
15.7124 \\
8\end{array}$ & down & 15.71248 & up \\
\hline $\mathrm{N}$-(2-hydroxyethyl)henicosanamide & $\mathrm{n} / \mathrm{a}$ & 0 & down & $\begin{array}{c}- \\
14.55800 \\
2\end{array}$ & down \\
\hline $\mathrm{N}$-(naphthalen-1-yl)benzamide & $\mathrm{n} / \mathrm{a}$ & $\begin{array}{c}- \\
17.3373 \\
87\end{array}$ & down & $\begin{array}{c}17.33738 \\
7\end{array}$ & up \\
\hline N2-Succinylglutamic acid & $\mathrm{n} / \mathrm{a}$ & $\begin{array}{c}- \\
19.2768 \\
78\end{array}$ & down & $\begin{array}{c}19.27687 \\
8\end{array}$ & up \\
\hline N-AcetyICilastatin & $\mathrm{n} / \mathrm{a}$ & $\begin{array}{c}- \\
21.4773 \\
7\end{array}$ & down & 21.47737 & up \\
\hline $\begin{array}{l}\text { N-AcetylCilastatin nullnullnull } \\
0.97800004\end{array}$ & $\mathrm{n} / \mathrm{a}$ & $\begin{array}{c}- \\
19.5298 \\
96\end{array}$ & down & $\begin{array}{c}19.52989 \\
6\end{array}$ & up \\
\hline $\mathrm{N}$-arachidonoyl glutamic acid & $\mathrm{N}$-acyl amines & $\begin{array}{c}- \\
18.3753 \\
22\end{array}$ & down & $\begin{array}{c}0.516498 \\
57\end{array}$ & up \\
\hline Natsudaidain & 7-o-methylated flavonoids & 0 & down & $\begin{array}{c}- \\
15.07212 \\
5\end{array}$ & down \\
\hline Nb-Lignoceroyltryptamine & 3-alkylindoles & $\begin{array}{c}- \\
16.1395 \\
85\end{array}$ & down & $\begin{array}{c}16.13958 \\
5\end{array}$ & up \\
\hline
\end{tabular}




\begin{tabular}{|c|c|c|c|c|c|}
\hline NNAL-N-glucuronide & n-glucuronides & $\begin{array}{l}15.2966 \\
46\end{array}$ & up & $\begin{array}{c}15.50921 \\
6\end{array}$ & down \\
\hline $\begin{array}{l}\text { NNAL-N-glucuronide nullnullnull } \\
3.236\end{array}$ & $\mathrm{n} / \mathrm{a}$ & $\begin{array}{c}- \\
16.9751 \\
07\end{array}$ & down & $\begin{array}{c}0.839931 \\
5\end{array}$ & down \\
\hline $\mathrm{N}$-stearoyl glutamine & $\mathrm{N}$-acyl amines & $\begin{array}{c}- \\
14.4030 \\
77\end{array}$ & down & $\begin{array}{c}- \\
2.618130 \\
7\end{array}$ & down \\
\hline OH-Spheroidenone & $\begin{array}{l}\text { C40 isoprenoids } \\
\text { (tetraterpenes }\end{array}$ & 0 & down & $\begin{array}{c}- \\
15.33619 \\
6\end{array}$ & down \\
\hline Oleoside dimethyl ester & terpene glycosides & $\begin{array}{c}- \\
17.3813 \\
6\end{array}$ & down & 17.38136 & up \\
\hline $\mathrm{PA}(18: 0 / 13: 0)$ & Diacylglycerophosphates & $\begin{array}{c}- \\
15.5367 \\
05\end{array}$ & down & $\begin{array}{c}0.329556 \\
47\end{array}$ & up \\
\hline PA(18:3(6Z,9Z,12Z)/18:2(9Z,12Z)) & $\begin{array}{l}\text { 1,2-diacylglycerol-3- } \\
\text { phosphates }\end{array}$ & $\begin{array}{c}- \\
15.4614 \\
37\end{array}$ & down & $\begin{array}{c}0.231830 \\
6\end{array}$ & up \\
\hline $\mathrm{PA}(20: 1(11 Z) / 0: 0)$ & $\begin{array}{l}\text { Monoacylglycerophosphate } \\
\text { s }\end{array}$ & $\begin{array}{c}- \\
16.6810 \\
82\end{array}$ & down & $\begin{array}{c}2.415017 \\
1\end{array}$ & up \\
\hline $\begin{array}{l}\mathrm{PA}(\mathrm{O}- \\
16: 0 / 20: 5(5 Z, 8 Z, 11 Z, 14 Z, 17 Z))\end{array}$ & $\begin{array}{l}\text { 1,2-diacylglycerol-3- } \\
\text { phosphates }\end{array}$ & $\begin{array}{c}- \\
15.7705 \\
19\end{array}$ & down & 1.293642 & down \\
\hline Palustrine & alkaloid & 0 & down & $\begin{array}{c}- \\
15.92930 \\
3\end{array}$ & down \\
\hline Palustrinoside & Flavones and Flavonols & $\begin{array}{c}- \\
16.5030 \\
23 \\
23027\end{array}$ & down & $\begin{array}{c}1.389999 \\
4\end{array}$ & down \\
\hline $\mathrm{PC}(2: 0 / 0-16: 0)[U]$ & $\mathrm{n} / \mathrm{a}$ & $\begin{array}{c}20.9827 \\
38\end{array}$ & up & $\begin{array}{c}- \\
18.96531 \\
1\end{array}$ & down \\
\hline PC(2:0/O-16:0)[U] null 1.164 & $\mathrm{n} / \mathrm{a}$ & $\begin{array}{c}20.1629 \\
6\end{array}$ & up & $\begin{array}{c}- \\
17.59570 \\
3\end{array}$ & down \\
\hline $\begin{array}{l}\text { p-Cresol, a-[2- } \\
\text { (dimethylamino)ethoxy]-a-o-tolyl- }\end{array}$ & $\mathrm{n} / \mathrm{a}$ & $\begin{array}{c}- \\
16.1764 \\
1\end{array}$ & down & 16.17641 & up \\
\hline $\operatorname{PE}(18: 1(9 Z) / 0: 0)[U]$ & $\mathrm{n} / \mathrm{a}$ & $\begin{array}{l}19.6810 \\
84\end{array}$ & up & 0 & down \\
\hline $\mathrm{PE}(19: 1(9 Z) / 20: 3(8 Z, 11 Z, 14 Z))$ & phosphatidylethanolamines & 0 & down & $\begin{array}{c}- \\
17.92779 \\
5\end{array}$ & down \\
\hline $\mathrm{PE}(20: 4(5 Z, 8 Z, 11 Z, 14 Z) / 21: 0)$ & $n / a$ & 0 & down & $\begin{array}{l}- \\
19.90756 \\
2\end{array}$ & down \\
\hline PE(22:2(13Z,16Z)/19:0) & phosphatidylethanolamines & $\begin{array}{c}13.4101 \\
19\end{array}$ & up & 0 & down \\
\hline$P E(P-20: 0 / 0: 0)$ & $\begin{array}{l}1 Z- \\
\text { alkenylglycerophosphoetha } \\
\text { nolamines }\end{array}$ & $\begin{array}{l}19.2309 \\
07\end{array}$ & up & 0 & down \\
\hline PE-Cer(d14:2(4E,6E)/23:0) & $\mathrm{n} / \mathrm{a}$ & $\begin{array}{c}15.2398 \\
49\end{array}$ & up & $\begin{array}{c}- \\
16.02854 \\
3\end{array}$ & down \\
\hline Pentaglutamyl folate & oligopeptides & $\begin{array}{l}17.2797 \\
58\end{array}$ & up & 0 & own \\
\hline
\end{tabular}




\begin{tabular}{|c|c|c|c|c|c|}
\hline$P G(20: 4(5 Z, 8 Z, 11 Z, 14 Z) / 22: 0)$ & $\begin{array}{l}\text { Diacylglycerophosphoglycer } \\
\text { ols }\end{array}$ & $\begin{array}{l}- \\
16.5508 \\
86\end{array}$ & down & $\begin{array}{c}2.044623 \\
4\end{array}$ & up \\
\hline $\begin{array}{l}\mathrm{PG}(22: 1(11 Z) / 20: 5(5 Z, 8 Z, 11 Z, 14 Z, 1 \\
7 Z))\end{array}$ & phosphatidylglycerol & $\begin{array}{c}- \\
16.5752 \\
8\end{array}$ & down & 16.57528 & up \\
\hline$P G(O-16: 0 / 15: 1(9 Z))$ & $\begin{array}{c}\text { 1-alkyl,2- } \\
\text { acylglycerophosphoglycerol } \\
\mathrm{s}\end{array}$ & $\begin{array}{c}- \\
15.5913 \\
32\end{array}$ & down & $\begin{array}{l}2.147785 \\
2\end{array}$ & up \\
\hline Phe Pro Ser & $\mathrm{n} / \mathrm{a}$ & 0 & down & 14.83011 & down \\
\hline Phe Trp Arg & $\mathrm{n} / \mathrm{a}$ & $\begin{array}{c}- \\
16.3940 \\
3\end{array}$ & down & 16.39403 & up \\
\hline Phenylalanyl-Methionine & dipeptides & $\begin{array}{c}- \\
16.5528 \\
47\end{array}$ & down & $\begin{array}{l}16.55284 \\
7\end{array}$ & up \\
\hline Phenylboronic acid & $\mathrm{n} / \mathrm{a}$ & $\begin{array}{c}- \\
19.6320 \\
34\end{array}$ & down & $\begin{array}{l}19.63203 \\
4\end{array}$ & up \\
\hline $\begin{array}{l}\mathrm{PI}(20: 3(8 Z, 11 Z, 14 Z) / 18: 3(6 Z, 9 Z, 12 \\
Z))\end{array}$ & phosphatidylinositols & $\begin{array}{c}- \\
16.3743 \\
25\end{array}$ & down & $\begin{array}{c}16.37432 \\
5\end{array}$ & up \\
\hline $\begin{array}{l}\mathrm{PI}(20: 3(8 Z, 11 Z, 14 Z) / 18: 4(6 Z, 9 Z, 12 \\
Z, 15 Z))\end{array}$ & $\begin{array}{l}\text { Diacylglycerophosphoinosit } \\
\text { ols }\end{array}$ & $\begin{array}{c}- \\
18.5573 \\
9\end{array}$ & down & 18.55739 & up \\
\hline $\mathrm{PI}(21: 0 / 0: 0)$ & $\begin{array}{l}\text { Monoacylglycerophosphoin } \\
\text { ositols }\end{array}$ & $\begin{array}{l}- \\
17.5571 \\
16\end{array}$ & down & $\begin{array}{l}17.55711 \\
6\end{array}$ & up \\
\hline $\begin{array}{l}\mathrm{PI}(22: 6(4 Z, 7 Z, 10 Z, 13 Z, 16 Z, 19 Z) / 0: \\
0)\end{array}$ & $\begin{array}{l}\text { Monoacylglycerophosphoin } \\
\text { ositols }\end{array}$ & $\begin{array}{l}- \\
17.0402 \\
62\end{array}$ & down & $\begin{array}{l}17.04026 \\
2\end{array}$ & up \\
\hline $\mathrm{PI}(\mathrm{O}-18: 0 / 18: 4(6 \mathrm{Z}, 9 \mathrm{Z}, 12 \mathrm{Z}, 15 \mathrm{Z}))$ & $\begin{array}{c}\text { 1-alkyl,2- } \\
\text { acylglycerophosphoinositols }\end{array}$ & $\begin{array}{c}- \\
19.2306 \\
69\end{array}$ & down & $\begin{array}{c}19.23066 \\
9\end{array}$ & up \\
\hline PPM-18 & naphthoquinone derivative & 0 & down & $\begin{array}{l}- \\
14.72791 \\
6\end{array}$ & down \\
\hline Primaquine & $\begin{array}{l}\text { aminoquinolines and } \\
\text { derivatives. }\end{array}$ & $\begin{array}{l}- \\
16.0914 \\
36\end{array}$ & down & $\begin{array}{c}16.09143 \\
6\end{array}$ & up \\
\hline Primaquine null 4.851 & $\mathrm{n} / \mathrm{a}$ & 0 & down & $\begin{array}{c}- \\
14.58673\end{array}$ & down \\
\hline Pro Met His & & $\begin{array}{l}- \\
15.1260 \\
72\end{array}$ & down & $\begin{array}{l}15.12607 \\
2\end{array}$ & up \\
\hline PS(19:0/20:2(11Z,14Z)) & phosphatidylserines. & 0 & down & 19.07366 & down \\
\hline PS(19:0/20:3(8Z,11Z,14Z)) & phosphatidylserines & $\begin{array}{c}14.1142 \\
78\end{array}$ & up & $\begin{array}{c}- \\
17.60986 \\
5\end{array}$ & down \\
\hline $\begin{array}{l}P S(P- \\
18: 0 / 22: 6(4 Z, 7 Z, 10 Z, 13 Z, 16 Z, 19 Z))\end{array}$ & $\begin{array}{c}\text { glycerophosphoethanolamin } \\
\text { es }\end{array}$ & 0 & down & $\begin{array}{c}- \\
16.02034 \\
4\end{array}$ & down \\
\hline Psilocybin & tryptamines and derivatives & 0 & down & $\begin{array}{c}- \\
16.99233 \\
8\end{array}$ & down \\
\hline PU-H71 & & 0 & down & $\begin{array}{c}- \\
15.31135 \\
6\end{array}$ & down \\
\hline
\end{tabular}


Pyropheophytin b

Ribavirin 5'-diphosphate

Ribavirin 5'-diphosphate null 6.763

Rosmic acid

S-Adenosylhomocysteine-d4

Sarcodon scabrosus Depsipeptide

Scutellarein 4'-methyl ether 7glucuronide

Scutellarein 6,7,4'-trimethyl ether 5(6"'-acetylglucosyl)(1-3)-galactoside

Sintaxanthin

Styrene

Sudan I

Sulfacytine

Tetracenomycin D3

Theaspirone A

Thr Glu

Tingenone

Trp Trp Ser

Trp Tyr Asp

Vasicinone

Viscidulin II

Viscidulin II null 5.105 chlorins

n/a

16.1579

5

0

0

terpene lactone 5'-deoxy-5'-thionucleosides

cyclic depsipeptides Flavones and Flavonols

0

$\mathrm{n} / \mathrm{a}$

triterpenoids

17.1565

42

13.2989

61

0

styrenes

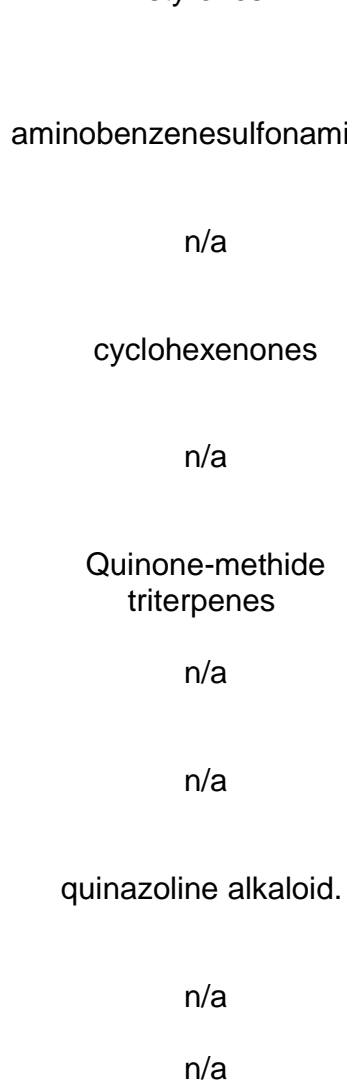

0

5.3676

04

17.4185

66

14.9741

49

17.4022

58

18.5404

36

15.7989

55

17.9629

84

0

0 down

16.15795

up

down

-

16.91783

down

1

down

15.44850

5

5
-15.97

down

-

15.72557

8

down

16.3502

down

8

down

$-$

15.16638

5

down

17.15654

2

down

-

4.256095

down

16.65216

down

6

15.36057

6

down

15.36760

4

down

-

0.770591

74

down $\quad 14.97414$

9

down

17.40225

8

down

18.54043

6

down

-

17.81641

2

down down

0.476574

9

down

17.96298

4

down

down down

up

down

down

down

up

down

up

up

up

down

down

up

down

down
-

18.26062

16.21660

6 
Xanthosine

purine nucleosides

down

15.78105

15.7810

1

51 
Table S5. Negative ion mode metabolites from where?.

\begin{tabular}{|c|c|c|c|c|c|}
\hline Compound Name & Compound Class & $\begin{array}{l}\text { Log FC } \\
\text { ([Contro } \\
\text { I] vs } \\
\text { [MC]) : } \\
\text { Normali } \\
\text { zed }\end{array}$ & $\begin{array}{c}\text { Regulati } \\
\text { on } \\
\text { ([Contro } \\
\text { I] vs } \\
\text { [MC]) }\end{array}$ & $\begin{array}{c}\text { Log FC } \\
\text { ([MC] vs } \\
\text { [MP]) : } \\
\text { Normali } \\
\text { zed }\end{array}$ & $\begin{array}{c}\text { Regulati } \\
\text { on } \\
\text { ([MC] vs } \\
[\mathrm{MP}])\end{array}$ \\
\hline Pyruvophenone & acetophenones & $\begin{array}{c}17.85754 \\
6\end{array}$ & down & 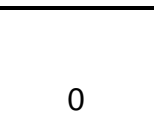 & up \\
\hline $\begin{array}{l}\text { (+/-)-trans- and cis-4,8-Dimethyl-3,7- } \\
\text { nonadien-2-ol }\end{array}$ & $\begin{array}{l}\text { acyclic } \\
\text { monoterpenoids }\end{array}$ & $\begin{array}{c}15.71630 \\
2\end{array}$ & down & 0 & up \\
\hline Chlorzoxazone & benzoxazolones & $\begin{array}{c}- \\
17.42078 \\
4\end{array}$ & down & 0 & up \\
\hline Rodiasıne & $\begin{array}{l}\text { bisbenzylisoquinoline } \\
\text { alkaloid }\end{array}$ & 19.09365 & up & $\begin{array}{c}0.698144 \\
9\end{array}$ & down \\
\hline Propyl 1-(propylthio)propyl disulfide & dialkyldisulfides & 0 & down & $\begin{array}{c}- \\
22.28711 \\
7 \\
-\end{array}$ & down \\
\hline & $\begin{array}{l}\text { diprenylated } \\
\text { flavanones }\end{array}$ & 0 & down & $\begin{array}{c}18.09542 \\
7\end{array}$ & down \\
\hline $\begin{array}{l}\text { Spinosin B } \\
\text { Trilobatin }\end{array}$ & $\begin{array}{l}\text { flavonoid c-glycosides } \\
\text { flavonoid o-glycosides }\end{array}$ & 16.74723 & up & $\begin{array}{c}16.74723 \\
-\end{array}$ & down \\
\hline Rincytin & & 19.35042 & down & $\begin{array}{c}13.35097 \\
5\end{array}$ & up \\
\hline $\begin{array}{l}\text { Biocytin } \\
\text { Kuwanon V }\end{array}$ & $\begin{array}{l}\text { I-alpha-amino acids } \\
\text { linear }\end{array}$ & 0 & down & 18.94593 & down \\
\hline 4-(2-Nitroethyl)phenyl primeveroside & $\begin{array}{l}\text { diarylheptanoids. } \\
\text { phenolic glycosides }\end{array}$ & $\begin{array}{c}17.26686 \\
9 \\
18.13805 \\
8\end{array}$ & $\begin{array}{c}\text { down } \\
\text { up }\end{array}$ & $\begin{array}{c}0 \\
18.13805 \\
8\end{array}$ & $\begin{array}{c}\text { up } \\
\text { down }\end{array}$ \\
\hline Tetrahydro-2-methylthiophen-3-ol & secondary alcohols & $\begin{array}{c}- \\
15.90013 \\
1\end{array}$ & down & 0 & up \\
\hline DL-Tyrosine & $\begin{array}{l}\text { tyrosine and } \\
\text { derivatives }\end{array}$ & $\begin{array}{c}19.69170 \\
4\end{array}$ & down & 0 & up \\
\hline PG(P-16:0/20:5(5Z,8Z,11Z,14Z,17Z)) & $\begin{array}{l}\text { 1-(1z-alkenyl),2-acyl- } \\
\text { glycerophosphocholine } \\
\mathrm{s}\end{array}$ & 17.18546 & up & $\begin{array}{c}- \\
2.198892 \\
6\end{array}$ & down \\
\hline $\begin{array}{l}\mathrm{DG}(20: 1(11 \mathrm{Z}) / 22: 5(4 Z, 7 Z, 10 Z, 13 Z, 16 Z) / \\
0: 0)\end{array}$ & 1,2-diacylglycerols & $\begin{array}{c}- \\
18.60773 \\
7\end{array}$ & down & 0 & up \\
\hline LPA(18:2(9Z,12Z)/0:0) & $\begin{array}{l}\text { 1-acylglycerol-3- } \\
\text { phosphates }\end{array}$ & $\begin{array}{c}14.05884 \\
7\end{array}$ & up & $\begin{array}{c}- \\
7.801830 \\
3\end{array}$ & down \\
\hline Sampangine & 1-azaoxoaporphines & $\begin{array}{c}- \\
16.46670 \\
3\end{array}$ & down & 0 & up \\
\hline $\operatorname{LPA}(0: 0 / 18: 0)$ & $\begin{array}{l}\text { 2-acylglycerol-3- } \\
\text { phosphates }\end{array}$ & $\begin{array}{c}13.66439 \\
4\end{array}$ & down & $\begin{array}{c}- \\
19.41344 \\
5\end{array}$ & down \\
\hline Neomycin B & $\begin{array}{l}\text { 4,5-disubstituted } 2 \text { - } \\
\text { deoxystreptamines. }\end{array}$ & 0 & down & $\begin{array}{c}- \\
20.11220 \\
6\end{array}$ & down \\
\hline
\end{tabular}




\begin{tabular}{|c|c|c|c|c|c|}
\hline Garcinone C & $\begin{array}{l}\text { 8-prenylated } \\
\text { xanthones }\end{array}$ & 0 & down & $\begin{array}{c}17.28347 \\
4\end{array}$ & down \\
\hline Neoacrimarine G & & & & 16.53912 & \\
\hline Phloracetophenone & $\begin{array}{l}\text { acridones. } \\
\text { acylphloroglucinols }\end{array}$ & 0 & down & 5 & down \\
\hline & and derivatives & 18.36511 & up & 18.36511 & down \\
\hline Juliflorine & alkaloid & $\begin{array}{c}- \\
15.25903 \\
7\end{array}$ & down & $\begin{array}{c}- \\
17.24113 \\
5\end{array}$ & down \\
\hline Tecostanine & alkaloid & 0 & down & $\begin{array}{c}- \\
16.00136 \\
8\end{array}$ & down \\
\hline DesmethyldescarbamoyInovobiocin & $\begin{array}{l}\text { aminocoumarin } \\
\text { antibiotics }\end{array}$ & 0 & down & $\begin{array}{c}- \\
17.80751 \\
2\end{array}$ & down \\
\hline Ranitidine $\mathrm{N}$-oxide & aralkvlamines & 0 & down & 18.10718 & down \\
\hline Disulfoton & alainylantintes & 0 & auvin & $\begin{array}{c}- \\
19.11525\end{array}$ & novin \\
\hline Aspidospermine & $\begin{array}{l}\text { aralkylamines } \\
\text { aspidospermatan-type } \\
\text { alkaloids derived from } \\
\text { the fusion of } \\
\text { tryptamine and a } \\
\text { terpene unit }\end{array}$ & 18.85817 & down & 7 & down \\
\hline MIPC(t18:0/16:0(2OH)) & $\begin{array}{l}\text { Ceramide } \\
\text { phosphoinositols }\end{array}$ & $\begin{array}{c}- \\
17.18781 \\
7\end{array}$ & down & 0 & up \\
\hline $\begin{array}{l}\text { 6-[2,3-Dihydroxy-1- } \\
\text { (hydroxymethyl)propyl]-1,2-dihydro-7- } \\
\text { hydroxy-9-methoxy- }\end{array}$ & $\begin{array}{l}\text { coumarins and } \\
\text { derivatives }\end{array}$ & 18.04663 & & & \\
\hline $\begin{array}{l}\text { cyclopenta[c][1]benzopyran-3,4-dione } \\
\text { Ustiloxin C }\end{array}$ & cyclic peptides & $\begin{array}{c}8 \\
- \\
19.15766\end{array}$ & down & 0 & up \\
\hline Vignatic acid B & cyclic peptides & $\begin{array}{c}7 \\
18.64228 \\
2\end{array}$ & $\begin{array}{l}\text { down } \\
\text { up }\end{array}$ & $\begin{array}{c}0 \\
18.64228 \\
2\end{array}$ & up \\
\hline (+)-Quercitol & & & & $\begin{array}{c}- \\
16.33571\end{array}$ & \\
\hline Dipyridamole & cyclohexanols. & 0 & down & $\begin{array}{c}8 \\
- \\
16.82099\end{array}$ & down \\
\hline Dinoseb & dialkyıarylamin & 0 & down & 7 & down \\
\hline gamma-L-Glutamyl-butirosin B & dinitrophenols & 0 & down & $\begin{array}{c}20.70544 \\
2\end{array}$ & down \\
\hline & dipeptides & 0 & down & $\begin{array}{c}18.14529 \\
2\end{array}$ & down \\
\hline & epoxides & $\begin{array}{c}15.22973 \\
4\end{array}$ & up & $\begin{array}{c}7.247741 \\
7\end{array}$ & down \\
\hline $\begin{array}{l}\text { (R)-1-O-b-D-glucopyranosyl-1,3- } \\
\text { octanediol }\end{array}$ & $\begin{array}{l}\text { estrogens and } \\
\text { derivatives. } \\
\text { fatty acyl glycosides of } \\
\text { mono- and } \\
\text { disaccharides }\end{array}$ & $\begin{array}{c}18.14688 \\
1\end{array}$ & down & $\begin{array}{c}18.53171 \\
7\end{array}$ & down \\
\hline
\end{tabular}




Ilicifolinoside A
(-)-epicatechin-3'-O-glucuronide
1,1,1,3,3,3-Hexafluoro-2-
hydroxypropane
Araliacerebroside
Psychosine
GlcCer(d18:1/26:0)
Perlolyrine
Leukotriene D4-d5
4,8-Dihydroxyquinoline
Methyl nigakinone
O-Phospho-4-hydroxy-L-threonine
11?-Acetoxykhivorin
trans-trans-Muconic acid
DL-Tyrosicoxy-octanoic acid

Gly Gln Ala

C-6 NBD-dihydro-Ceramide

Caohuoside D

Ceranib-2

Phe lle Tyr

Phe-Tyr-OH fatty acyl glycosides of mono- and disaccharides flavonoid o-glycosides

18.14392 2.830016

fluorohydrins.

glycosphingolipids

glycosphingolipids

glycosyl-n-

acylsphingosines

harmala alkaloids.

hydroxyeicosapentaen

oic acids

Hydroxyquinolines

indolonaphthyridine

alkaloids

I-alpha-amino acids

limonoid

medium-chain fatty

acids

medium-chain hydroxy

acids and derivatives

monoalkylglycerophos

phates

monoterpene alkaloid

$\mathrm{n} / \mathrm{a}$

$\mathrm{n} / \mathrm{a}$

$\mathrm{n} / \mathrm{a}$

$\mathrm{n} / \mathrm{a}$

n/a

$\mathrm{n} / \mathrm{a}$

n/a up

15.99141

4

down

0
16.75924
3

16.56660

8

0

-

16.61299

7

17.52999

-

24.12721

8

17.05901

3

19.82952

-

17.69851

1

4

15.71697

4

15.52372

3

16.58462

3

21.29210

7

1

down

up

18.78052

down

up

16.75924

3

16.56660

up

8

$17 . \overline{-} 2177$

down

4

down

0

down

0

up

down

0

up

down 0 up

down

0

up

down

0

up

19.13881

down 3

up

0.484127

up $\quad 04$

15.52372

up

3

16.58462

up

3

down

0

20.59899

7

down

0

up

20.46825

2

down

0

up

18.50788

7

18.46154

-

18.45981

6

$-$

18.31223

1

down

down

up

down

up

down

up

up 


\begin{tabular}{|c|c|c|c|c|c|}
\hline MIPC(t20:0/18:0(2OH)) & $\mathrm{n} / \mathrm{a}$ & $\begin{array}{c}- \\
18.16525 \\
8\end{array}$ & down & 0 & up \\
\hline N-Acetyl-O-demethylpuromycin & $\mathrm{n} / \mathrm{a}$ & 18.00672 & & 0 & un \\
\hline Kenusanone E & $\mathrm{n} / \mathrm{a}$ & -17.7087 & down & 0 & up \\
\hline $\mathrm{PI}(22: 4(7 Z, 10 Z, 13 Z, 16 Z) / 0: 0)$ & $\mathrm{n} / \mathrm{a}$ & $\begin{array}{c}17.68889 \\
8\end{array}$ & down & 0 & up \\
\hline $\begin{array}{l}\text { (22E)-(25R)-26,26,26-trifluoro-1?,25- } \\
\text { dihydroxy-22,23-didehydrovitamin D3 / } \\
\text { (22E)-(25R)-26,26,26-trifluoro-1?,25- } \\
\text { dihydroxy-22,23- }\end{array}$ & $\mathrm{n} / \mathrm{a}$ & $\begin{array}{c}- \\
3.367296\end{array}$ & & 14.29869 & \\
\hline $\begin{array}{l}\text { didehydrocholecalciferol } \\
\text { AG-494 }\end{array}$ & $\mathrm{n} / \mathrm{a}$ & $\begin{array}{c}2 \\
- \\
17.65835\end{array}$ & down & 5 & up \\
\hline $\begin{array}{l}\mathrm{Pl}(18: 4(6 Z, 9 Z, 12 Z, 15 Z) / 18: 4(6 Z, 9 Z, 12 Z, \\
15 Z))\end{array}$ & $\mathrm{n} / \mathrm{a}$ & $\begin{array}{c}6 \\
- \\
17.62696 \\
8\end{array}$ & down & 0 & up \\
\hline Methyl 2-benzamidoacetate & $\mathrm{n} / \mathrm{a}$ & $\begin{array}{c}- \\
17.61426 \\
7\end{array}$ & down & 0 & up \\
\hline Methylthiobenzoylglycine & $\mathrm{n} / \mathrm{a}$ & $\begin{array}{c}- \\
17.28078 \\
7 \\
-\end{array}$ & down & 0 & up \\
\hline $\mathrm{N}$-docosahexaenoyl glutamic acid & $\mathrm{n} / \mathrm{a}$ & $\begin{array}{c}- \\
3.133718 \\
5\end{array}$ & down & $\begin{array}{c}14.10179 \\
3\end{array}$ & up \\
\hline 5-O-Methylvisamminol & $\mathrm{n} / \mathrm{a}$ & $\begin{array}{c}- \\
16.67175 \\
5\end{array}$ & down & 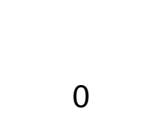 & up \\
\hline Arachidonoyl Glycine-d8 & $\mathrm{n} / \mathrm{a}$ & $\begin{array}{c}- \\
15.58379 \\
5\end{array}$ & down & 0 & up \\
\hline $\begin{array}{l}\text { 2-Butanone, 4-[6-(sulfooxy)-2- } \\
\text { naphthalenyl]- }\end{array}$ & $\mathrm{n} / \mathrm{a}$ & $\begin{array}{c}- \\
22.33132 \\
4\end{array}$ & down & $\begin{array}{c}- \\
19.81743 \\
8\end{array}$ & up \\
\hline Bromotheophylline & $\mathrm{n} / \mathrm{a}$ & $\begin{array}{c}- \\
17.69727 \\
9\end{array}$ & down & $\begin{array}{c}- \\
17.57853 \\
5\end{array}$ & up \\
\hline Dihydromethanophenazine & $\mathrm{n} / \mathrm{a}$ & $\begin{array}{l}21.26796 \\
3 \\
1969152\end{array}$ & up & $\begin{array}{c}21.26796 \\
3 \\
1969452\end{array}$ & down \\
\hline Dihydromethanophenazine null 1.495 & $\mathrm{n} / \mathrm{a}$ & $\begin{array}{c}19.69452 \\
7\end{array}$ & up & $\begin{array}{c}19.69452 \\
7\end{array}$ & down \\
\hline $\begin{array}{l}\text { Methyl 18-bromo-9E,17E-octadecadien- } \\
\text { 5,7,15-triynoate }\end{array}$ & $\mathrm{n} / \mathrm{a}$ & $\begin{array}{c}16.72260 \\
9\end{array}$ & up & $\begin{array}{c}16.72260 \\
9\end{array}$ & down \\
\hline $\operatorname{PE}(17: 0 / 20: 2(11 Z, 14 Z))$ & $\mathrm{n} / \mathrm{a}$ & $\begin{array}{c}17.77072 \\
5\end{array}$ & up & $\begin{array}{c}17.77072 \\
5\end{array}$ & down \\
\hline$P G(16: 1(9 Z) / 0: 0)$ & $\mathrm{n} / \mathrm{a}$ & $\begin{array}{c}16.39646 \\
5\end{array}$ & up & $\begin{array}{c}16.39646 \\
5\end{array}$ & down \\
\hline PS(19:0/18:3(9Z,12Z,15Z)) & $\mathrm{n} / \mathrm{a}$ & $\begin{array}{c}17.35170 \\
2\end{array}$ & up & $\begin{array}{l}17.35170 \\
2\end{array}$ & down \\
\hline SB 431542 & $\mathrm{n} / \mathrm{a}$ & $\begin{array}{c}17.38518 \\
1\end{array}$ & up & $\begin{array}{c}17.38518 \\
1\end{array}$ & down \\
\hline Desmethylnaproxen-6-O-sulfate & $\mathrm{n} / \mathrm{a}$ & $\begin{array}{c}- \\
18.02491 \\
2\end{array}$ & down & $\begin{array}{c}- \\
18.17587 \\
7\end{array}$ & down \\
\hline Carbamazepine N-Glucuronide & $\mathrm{n} / \mathrm{a}$ & $\begin{array}{c}- \\
16.87698 \\
2\end{array}$ & down & $\begin{array}{c}- \\
17.54890 \\
8\end{array}$ & down \\
\hline
\end{tabular}




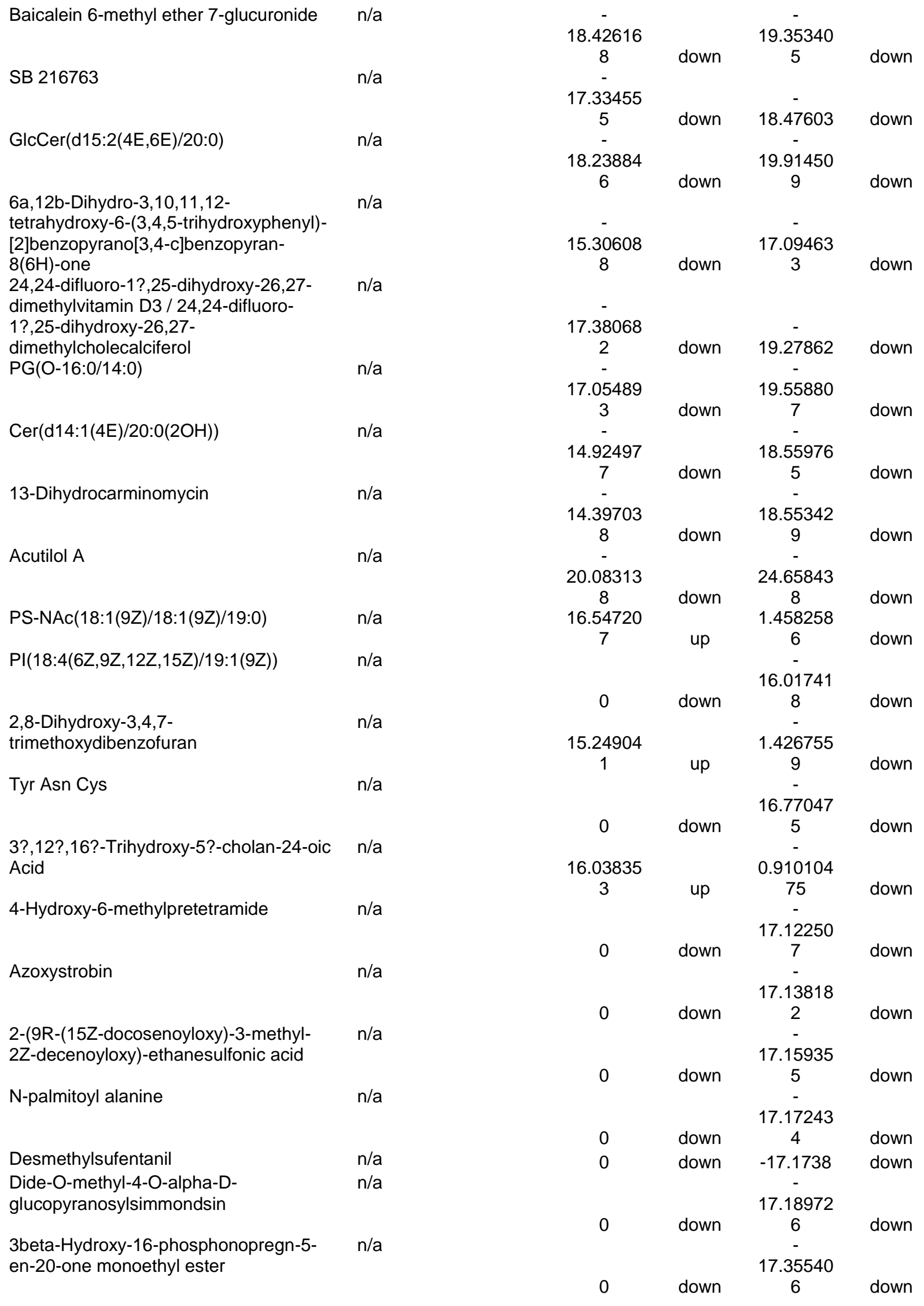




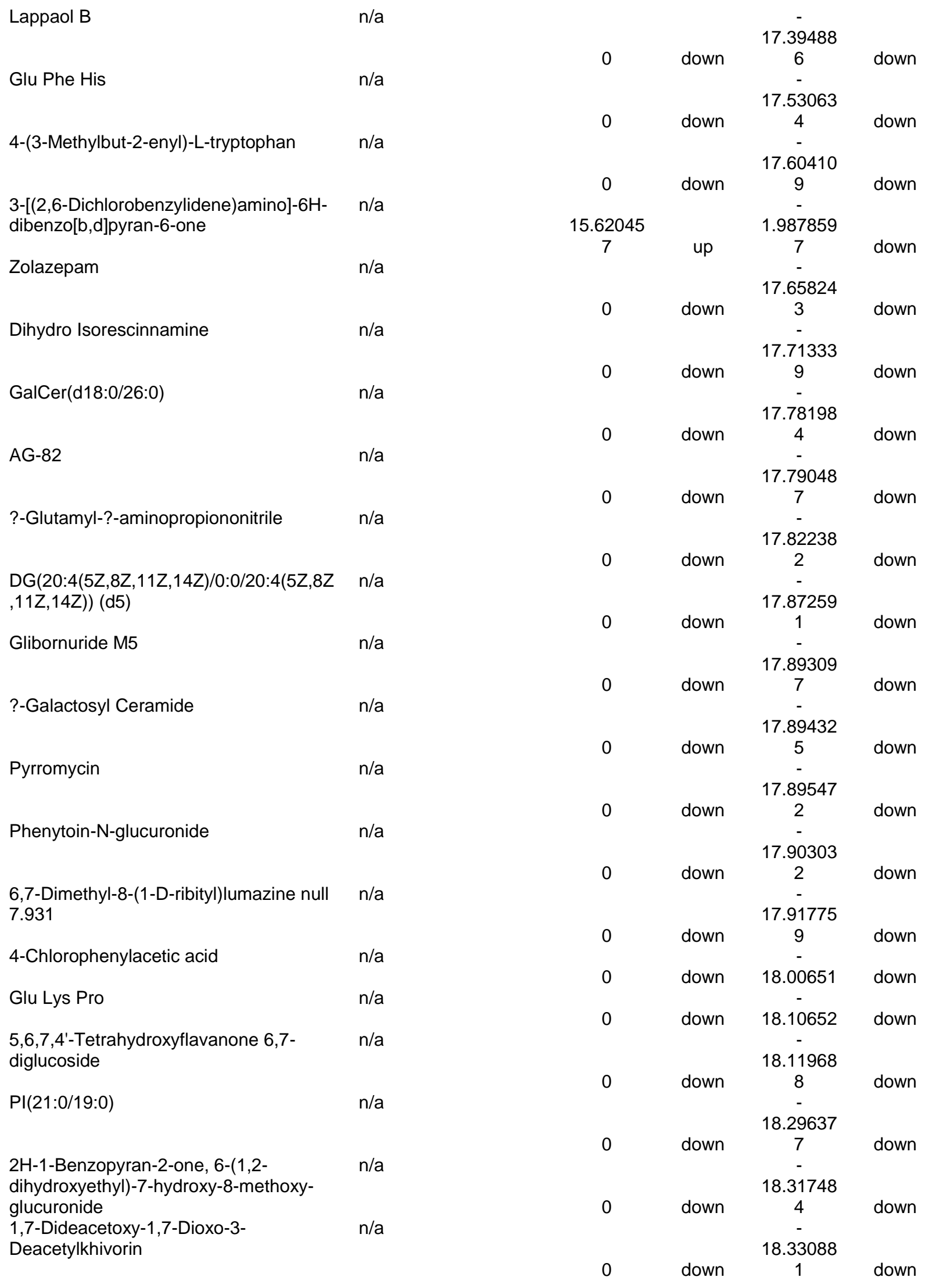




\begin{tabular}{|c|c|c|c|c|c|}
\hline Gly Asn Asn null 11.792 & $\mathrm{n} / \mathrm{a}$ & & & 18.34774 & \\
\hline & & 0 & down & 2 & down \\
\hline Ethofumesate & $\mathrm{n} / \mathrm{a}$ & & & 18.51498 & \\
\hline & & 0 & down & 6 & down \\
\hline $\begin{array}{l}\text { N-Acetyldemethylphosphinothricin null } \\
3.208\end{array}$ & $\mathrm{n} / \mathrm{a}$ & & & 18.54405 & \\
\hline Glu Ala Tyr & $\mathrm{n} / \mathrm{a}$ & 0 & down & $\begin{array}{c}2 \\
- \\
18.55849\end{array}$ & down \\
\hline His Pro Arg & $\mathrm{n} / \mathrm{a}$ & 0 & down & $\begin{array}{c}8 \\
- \\
18.61038\end{array}$ & down \\
\hline o-Monocarboxylfinasteride null 1.851 & $\mathrm{n} / \mathrm{a}$ & 0 & down & $\begin{array}{c}4 \\
- \\
18.64088\end{array}$ & down \\
\hline $\mathrm{PI}(19: 1(9 \mathrm{Z}) / 19: 0)$ & $\mathrm{n} / \mathrm{a}$ & 0 & down & $\begin{array}{c}4 \\
- \\
18.65833\end{array}$ & down \\
\hline Pseudolycorine & $\mathrm{n} / \mathrm{a}$ & 0 & down & $\begin{array}{c}9 \\
- \\
18.68149\end{array}$ & down \\
\hline PS(P-18:0/14:1(9Z)) & $\mathrm{n} / \mathrm{a}$ & $\begin{array}{c}0 \\
14.63165 \\
7\end{array}$ & $\begin{array}{l}\text { down } \\
\text { up }\end{array}$ & $\begin{array}{c}2 \\
- \\
4.105221\end{array}$ & $\begin{array}{l}\text { down } \\
\text { down }\end{array}$ \\
\hline Gly Thr Ser & $\mathrm{n} / \mathrm{a}$ & 0 & down & 18.81537 & down \\
\hline 5-Acetoxypalisadin B & $\mathrm{n} / \mathrm{a}$ & 0 & down & $\begin{array}{c}- \\
19.10119 \\
6\end{array}$ & down \\
\hline N-Acetyldemethylphosphinothricin & $\mathrm{n} / \mathrm{a}$ & 0 & down & 19.11608 & down \\
\hline$P E(P-18: 0 / 18: 2(9 Z, 12 Z))$ & $\mathrm{n} / \mathrm{a}$ & 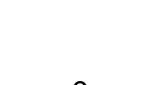 & 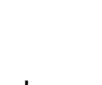 & 19.14023 & \\
\hline Tridesacetoxykhivorin null 1.8360002 & $\mathrm{n} / \mathrm{a}$ & 0 & down & $\begin{array}{c}8 \\
- \\
19.29956\end{array}$ & down \\
\hline Taccalonolide A & $\mathrm{n} / \mathrm{a}$ & 0 & down & $\begin{array}{c}2 \\
- \\
19.33803\end{array}$ & down \\
\hline 35-aminobacteriohopane-32,33,34-triol & $\mathrm{n} / \mathrm{a}$ & 0 & down & $\begin{array}{c}7 \\
- \\
19.72942\end{array}$ & down \\
\hline $\begin{array}{l}\text { Leucomethylene blue (Reduced } \\
\text { Methylene Blue) }\end{array}$ & $\mathrm{n} / \mathrm{a}$ & 0 & down & $\begin{array}{c}4 \\
- \\
19.87034\end{array}$ & down \\
\hline Met Ala Cys & $\mathrm{n} / \mathrm{a}$ & 0 & down & $\begin{array}{c}8 \\
- \\
20.28167\end{array}$ & down \\
\hline Tridesacetoxykhivorin & $\mathrm{n} / \mathrm{a}$ & 0 & down & $\begin{array}{c}5 \\
- \\
20.29859\end{array}$ & down \\
\hline Arg Lys Asn & $\mathrm{n} / \mathrm{a}$ & 0 & down & $\begin{array}{c}4 \\
- \\
20.48858\end{array}$ & down \\
\hline p-Nitroglutethimide & $\mathrm{n} / \mathrm{a}$ & 0 & down & $\begin{array}{c}5 \\
- \\
20.86267\end{array}$ & down \\
\hline & & 0 & down & 7 & down \\
\hline
\end{tabular}




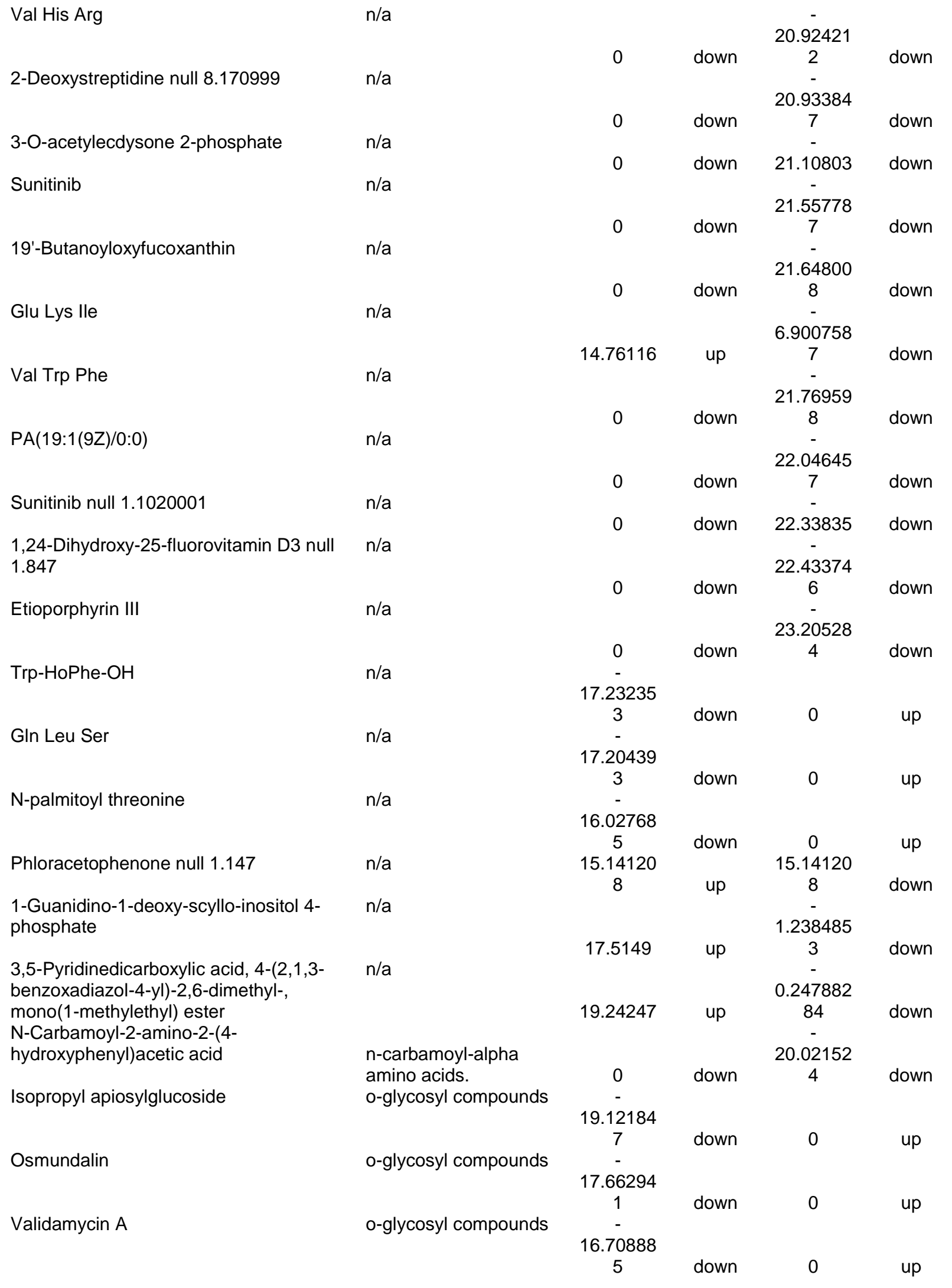


Ethyl beta-D-glucopyranoside

Leonoside A

Succinic anhydride

13,14-DiHDPE

$\mathrm{N}$-Acetyl-leucyl-leucine

(S)-2,3-Dihydro-3,5-dihydroxy-2-oxo-3indoleacetic acid 5-[glucosyl-(1-4)-b-Dglucoside]

Tirofiban

Desmethyl rosuvastatin

Vanilpyruvic acid

$\mathrm{PE}(20: 5(5 Z, 8 Z, 11 Z, 14 Z, 17 Z) / 22: 4(7 Z, 10$

$Z, 13 Z, 16 Z))$

PIP2(18:0/16:0)

PS(18:3(6Z,9Z,12Z)/18:4(6Z,9Z,12Z,15

Z))

PS(18:4(6Z,9Z,12Z,15Z)/0:0)

4,7-Didehydroneophysalin B

Kolanone

all-trans-pentaprenyl diphosphate

11-O-Demethylpradinone II

PGH2-EA

1-Methylinosine

Blasticidin S

Risperidone

Vitamin B6 o-glycosyl compounds

oligosaccharides

oxolanes.

Oxylipin (?)

peptides.

phenolic glycosides

phenylalanine and

derivatives

phenylpyrimidines.

phenylpyruvic acid

derivatives

phosphatidylethanolam

ines

phosphatidylinositol-

4,5-bisphosphates

phosphatidylserine

phosphatidylserines

physalins and

derivatives.

polyisoprenylated

benzophenone

polyprenyl

diphosphates

Pradimicins

prostaglandins and

related compounds

purine nucleosides

pyranoid amino acids and derivatives

pyridopyrimidines.

pyridoxamine 5'-

phosphates $\begin{array}{cccc} & & 19.81764 & \\ 0 & \text { down } & 4 & \text { down } \\ 17.73085 & & 17.73085 & \\ 4 & \text { up } & 4 & \text { down }\end{array}$

17.69932

7
17.97746

17.97746

3

down

$-17.6205$

0.642614

up

36

20.01952

down

2

down

0 down

16.76307

down

0 down

17.75036

down

17.66713

0
18.23601

5

down

up

18.23601

5

down

down

0.857939

7

17.97717

20.09565

7

0

0

0

13.52813

8

down

15.15122

7

up

up

17.97717

down

down

0

up

17.59632

down

9

$-$

16.91787

down

7

$-$

16.94585

down

6

19.07077

0 down

8

17.58487

1

down

16.88987

5

-

20.17225

8

down

down

2
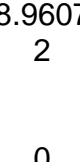

-

17.02934

0

down

3

-

18.81150

down

2

17.17117 down

down

down

down

down

down

up

up

down

up

down 


\begin{tabular}{|c|c|c|c|c|c|}
\hline dCMP & $\begin{array}{l}\text { pyrimidine } 2 \text { - } \\
\text { deoxyribonucleoside }\end{array}$ & - & & 17.82958 & \\
\hline 1-Pyrroline-2-carboxylic acid & pyrrolines & $\begin{array}{c}17.67 / 85 \\
- \\
19.41933 \\
4\end{array}$ & down & 4 & down \\
\hline Licochalcone C & retrochalcones & $\begin{array}{c}- \\
19.03966 \\
9\end{array}$ & down & $\begin{array}{c}- \\
18.09954 \\
3\end{array}$ & up \\
\hline 3-Hydroxy-4-methylanthranilate & $\begin{array}{l}\text { S-adenosyl-L- } \\
\text { methionine:3- } \\
\text { hydroxyanthranilate 4- } \\
\text { C-methyltransferase }\end{array}$ & $\begin{array}{c}- \\
18.01253 \\
5\end{array}$ & down & 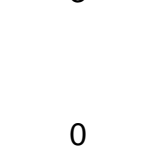 & up \\
\hline p-Hydroxybenzyldesulphoglucosinolate & S-glycosyl compound & $\begin{array}{c}- \\
16.00628 \\
5\end{array}$ & down & 0 & up \\
\hline Progesterone 3-biotin & steroid hormone & $\begin{array}{l}- \\
13.93598 \\
5\end{array}$ & down & 0 & up \\
\hline gamma2-Solamarine & steroidal saponins & $\begin{array}{c}- \\
17.96057 \\
1 \\
17.02527\end{array}$ & down & $\begin{array}{c}0 \\
17.02527\end{array}$ & up \\
\hline D-Glycerate 3-phosphate & $\begin{array}{l}\text { strychnos alkaloids } \\
\text { sugar acids and } \\
\text { derivatives }\end{array}$ & 6 & up & $\begin{array}{c}6 \\
- \\
16.68015\end{array}$ & down \\
\hline Lactobionic acid & $\begin{array}{l}\text { sugar acids and } \\
\text { derivatives }\end{array}$ & 0 & down & $\begin{array}{c}9 \\
- \\
16.87369\end{array}$ & down \\
\hline $\begin{array}{l}\text { (R)-2-Amino-N-(2,2,4,4-tetramethyl-3- } \\
\text { thietanyl)propanamide }\end{array}$ & & 0 & down & $\begin{array}{c}5 \\
- \\
18.06686\end{array}$ & down \\
\hline Pitheduloside D & $\begin{array}{l}\text { thietanes } \\
\text { triterpene saponins }\end{array}$ & $\begin{array}{c}0 \\
- \\
19.16912\end{array}$ & $\begin{array}{l}\text { down } \\
\text { down }\end{array}$ & $\begin{array}{l}6 \\
0\end{array}$ & $\begin{array}{l}\text { down } \\
\text { up }\end{array}$ \\
\hline Momordin le & triterpene saponins & $\begin{array}{c}- \\
18.82578 \\
8\end{array}$ & down & 0 & up \\
\hline Licoricesaponin D3 & triterpene saponins & $\begin{array}{c}17.76941 \\
9\end{array}$ & & $\begin{array}{c}17.76941 \\
9\end{array}$ & down \\
\hline Convallasaponin A & triterpenoids & $\begin{array}{c}- \\
17.71367 \\
8\end{array}$ & down & 0 & up \\
\hline Ganoderic acid H & triterpenoids & 0 & down & $\begin{array}{c}- \\
19.02263 \\
5\end{array}$ & down \\
\hline $\begin{array}{l}\text { Protoveratrine B } \\
\text { trans-Brassidic acid }\end{array}$ & Veratrum Alkaloids & $\begin{array}{c}17.50435 \\
3\end{array}$ & up & $\begin{array}{c}17.50435 \\
3 \\
-\end{array}$ & down \\
\hline & $\begin{array}{l}\text { very long-chain fatty } \\
\text { acids }\end{array}$ & 0 & down & $\begin{array}{c}18.51780 \\
1\end{array}$ & down \\
\hline Fucoxanthin & & & & 17.94895 & \\
\hline $\begin{array}{l}\text { 4'-Hydroxy-5,7-dimethoxyflavanone 4'- } \\
\text { [2-(5-Cinnamoyl)-beta-D-- } \\
\text { apiofuranosyllalucoside }\end{array}$ & xanthophylls & $\begin{array}{c}0 \\
- \\
18.50231 \\
6\end{array}$ & $\begin{array}{l}\text { down } \\
\text { down }\end{array}$ & 7 & down \\
\hline
\end{tabular}


Table S6?. Dual polarity measurements for fungus-specific metabolites recovered from $M$. cicadina and the $M$. platypediae samples of M. levispora comb. nov.

\begin{tabular}{|c|c|c|c|c|c|c|c|c|}
\hline Compound & $\begin{array}{l}\text { lon } \\
\text { mode }\end{array}$ & $\begin{array}{l}\text { Compou } \\
\text { nd } \\
\text { Class }\end{array}$ & $\begin{array}{l}\text { Previous } \\
\text { ly } \\
\text { confirme } \\
\text { d fungal } \\
\text { host }\end{array}$ & $\begin{array}{l}\text { Fungal } \\
\text { phylum }\end{array}$ & $\begin{array}{l}\text { Log } \\
\text { FC } \\
\text { ([Contr } \\
\text { ol] vs } \\
\text { [MC]): } \\
\text { Norma } \\
\text { lized } \\
\end{array}$ & $\begin{array}{l}\text { Regula } \\
\text { tion } \\
\text { ([Contr } \\
\text { ol] vs } \\
\text { [MC]): } \\
\text { Norma } \\
\text { lized } \\
\end{array}$ & $\begin{array}{l}\text { Log } \\
\text { FC } \\
([\mathrm{MC}] \\
\text { vs } \\
\text { [MP]) : } \\
\text { Norma } \\
\text { lized } \\
\end{array}$ & $\begin{array}{l}\text { Regula } \\
\text { tion } \\
\text { ([MC] } \\
\text { vs } \\
\text { [MP]) : } \\
\text { Norma } \\
\text { lized }\end{array}$ \\
\hline $\begin{array}{l}\text { Sarcodon scabrosus } \\
\text { Depsipeptide }\end{array}$ & $\begin{array}{l}\text { Positi } \\
\text { ve }\end{array}$ & $\begin{array}{l}\text { cyclic } \\
\text { depsipep } \\
\text { tides }\end{array}$ & $\begin{array}{l}\text { Sarcodon } \\
\text { scabrosu } \\
\text { s }\end{array}$ & $\begin{array}{l}\text { Basidiom } \\
\text { ycota }\end{array}$ & 0 & down & $\begin{array}{c}- \\
16.350 \\
218\end{array}$ & down \\
\hline 4-Propanoyl-HT2 toxin & $\begin{array}{l}\text { Positi } \\
\text { ve }\end{array}$ & $\begin{array}{l}\text { trichothe } \\
\text { cenes }\end{array}$ & $\begin{array}{l}\text { Fusarium } \\
\text { sporotrich } \\
\text { ioides }\end{array}$ & $\begin{array}{l}\text { Ascomyc } \\
\text { ota }\end{array}$ & $\begin{array}{l}- \\
16.866 \\
232\end{array}$ & down & $\begin{array}{l}16.866 \\
232\end{array}$ & up \\
\hline Fasciculol E & $\begin{array}{l}\text { Positi } \\
\text { ve }\end{array}$ & $\begin{array}{l}\text { triterpen } \\
\text { oids }\end{array}$ & $\begin{array}{l}\text { Naematol } \\
\text { oma } \\
\text { fascicular } \\
e\end{array}$ & $\begin{array}{l}\text { Basidiom } \\
\text { ycota }\end{array}$ & $\begin{array}{c}- \\
17.829 \\
891\end{array}$ & down & $\begin{array}{l}17.829 \\
891\end{array}$ & up \\
\hline Hebevinoside XIV & $\begin{array}{l}\text { Positi } \\
\text { ve }\end{array}$ & $\begin{array}{l}\text { cucurbita } \\
\text { cin } \\
\text { glycosid } \\
\text { es }\end{array}$ & $\begin{array}{l}\text { Hebelom } \\
\text { a } \\
\text { vinosoph } \\
\text { yllum }\end{array}$ & $\begin{array}{l}\text { Basidiom } \\
\text { ycota }\end{array}$ & $\begin{array}{c}- \\
18.102 \\
667\end{array}$ & down & $\begin{array}{c}18.102 \\
667\end{array}$ & up \\
\hline $\begin{array}{l}\text { 4- } \\
\text { (Hydroxymethyl)benzene } \\
\text { diazonium }(1+)\end{array}$ & $\begin{array}{l}\text { Positi } \\
\text { ve }\end{array}$ & $\begin{array}{l}\text { benzyl } \\
\text { alcohols }\end{array}$ & $\begin{array}{l}\text { Agaricus } \\
\text { bisporus }\end{array}$ & $\begin{array}{l}\text { Basidiom } \\
\text { ycota }\end{array}$ & $\begin{array}{c}- \\
19.488 \\
249\end{array}$ & down & $\begin{array}{c}19.488 \\
249\end{array}$ & up \\
\hline $\begin{array}{l}\text { 6-[2,3-Dihydroxy-1- } \\
\text { (hydroxymethyl)propyl]- } \\
\text { 1,2-dihydro-7-hydroxy-9- } \\
\text { methoxy- } \\
\text { cyclopenta[c][1]benzopyra } \\
\text { n-3,4-dione }\end{array}$ & $\begin{array}{l}\text { Negat } \\
\text { ive }\end{array}$ & $\begin{array}{l}\text { coumarin } \\
\text { s and } \\
\text { derivativ } \\
\text { es }\end{array}$ & $\begin{array}{l}\text { Aspergillu } \\
\text { s flavus }\end{array}$ & $\begin{array}{l}\text { Ascomyc } \\
\text { ota }\end{array}$ & $\begin{array}{c}- \\
18.046 \\
638\end{array}$ & down & 0 & down \\
\hline Ustiloxin C & $\begin{array}{l}\text { Negat } \\
\text { ive }\end{array}$ & $\begin{array}{l}\text { cyclic } \\
\text { peptides }\end{array}$ & $\begin{array}{l}\text { Ustilagino } \\
\text { idea } \\
\text { virens }\end{array}$ & $\begin{array}{l}\text { Basidiom } \\
\text { ycota }\end{array}$ & $\begin{array}{c}- \\
19.157 \\
667\end{array}$ & down & 0 & down \\
\hline Azoxystrobin & $\begin{array}{l}\text { Negat } \\
\text { ive }\end{array}$ & $n / a$ & & $\begin{array}{l}\text { Basidiom } \\
\text { ycota }\end{array}$ & 0 & down & $\begin{array}{c}- \\
17.138 \\
182 \\
\end{array}$ & down \\
\hline
\end{tabular}




\section{References}

Albrecht, C., R. Geurts and T. Bisseling (1999). "Legume nodulation and mycorrhizae formation; two extremes in host specificity meet." The EMBO Journal 18(2): 281-288.

Aliasgharzadeh, N., S. N. Rastin, H. Towfighi and A. Alizadeh (2001). "Occurrence of arbuscular mycorrhizal fungi in saline soils of the Tabriz Plain of Iran in relation to some physical and chemical properties of soil." Mycorrhiza 11(3): 119-122.

Alkan, N., O. Davydov, M. Sagi, R. Fluhr and D. Prusky (2009). "Ammonium Secretion by Colletotrichum coccodes Activates Host NADPH Oxidase Activity Enhancing Host Cell Death and Fungal Virulence in Tomato Fruits." Molecular Plant-Microbe Interactions 22(12): 1484-1491.

Aly, A. H., A. Debbab, J. Kjer and P. Proksch (2010). "Fungal endophytes from higher plants: a prolific source of phytochemicals and other bioactive natural products." Fungal Diversity 41(1): 1-16.

Bago, B., P. E. Pfeffer, D. D. Douds, Jr., J. Brouillette, G. Becard and Y. Shachar-Hill (1999). "Carbon metabolism in spores of the arbuscular mycorrhizal fungus Glomus intraradices as revealed by nuclear magnetic resonance spectroscopy." Plant Physiol 121(1): 263-272.

Bago, B., P. E. Pfeffer and Y. Shachar-Hill (2000). "Carbon Metabolism and Transport in Arbuscular Mycorrhizas." Plant Physiology 124(3): 949-958.

Bever, J. D. and M. Wang (2005). "Arbuscular mycorrhizal fungi: hyphal fusion and multigenomic structure." Nature 433(7022): E3-4; discussion E4.

Bhadauria, V., W.-S. Zhao, L.-X. Wang, Y. Zhang, J.-H. Liu, J. Yang, L.-A. Kong and Y.-L. Peng (2007). "Advances in fungal proteomics." Microbiological Research 162(3): 193-200.

Bolan, N. S. (1991). "A critical review on the role of mycorrhizal fungi in the uptake of phosphorus by plants." Plant and Soil 134(2): 189-207.

Butler, A.W., 1886. The periodical cicada in Southwestern Indiana. Bul. 12, Div. Ent. US Dept. Agri, p.24 
Chen, S., W. Jin, A. Liu, S. Zhang, D. Liu, F. Wang, X. Lin and C. He (2013). "Arbuscular mycorrhizal fungi (AMF) increase growth and secondary metabolism in cucumber subjected to low temperature stress." Scientia Horticulturae 160: 222-229.

Clark, R. B., S. K. Zeto and R. W. Zobel (1999). "Arbuscular mycorrhizal fungal isolate effectiveness on growth and root colonization of Panicum virgatum in acidic soil." Soil Biology and Biochemistry 31(13): 1757-1763.

Cooley, John R., Marshall, David C., Hill, Kathy B. R. (in press) A specialized fungal parasite turns periodical cicadas into sexual zombies (Hemiptera: Cicadidae: Magicdicada spp.). Scientific Reports. Cooley, J.R., 1999. Sexual behavior in North American cicadas of the genera Magicicada and Okanagana (Doctoral dissertation, University of Michigan).

Coughlan, A. P., Y. Dalpé, L. Lapointe and Y. Piché (2000). "Soil pH-induced changes in root colonization, diversity, and reproduction of symbiotic arbuscular mycorrhizal fungi from healthy and declining maple forests." Canadian Journal of Forest Research 30(10): 1543-1554.

Davison, J., M. Moora, M. Öpik, A. Adholeya, L. Ainsaar, A. Bâ, S. Burla, A. G. Diedhiou, I. Hiiesalu, T. Jairus, N. C. Johnson, A. Kane, K. Koorem, M. Kochar, C. Ndiaye, M. Pärtel, Ü. Reier, Ü. Saks, R. Singh, M. Vasar and M. Zobel (2015). "Global assessment of arbuscular mycorrhizal fungus diversity reveals very low endemism." Science 349(6251): 970-973.

de Bekker, C., P. B. Smith, A. D. Patterson and D. P. Hughes (2013). "Metabolomics Reveals the Heterogeneous Secretome of Two Entomopathogenic Fungi to Ex Vivo Cultured Insect Tissues." PLOS ONE 8(8): e70609.

Dighton, J., J. White and P. Oudemans (1992). The Fungal Community: Its Organization and Role in the Ecosystem, Second Edition, Taylor \& Francis.

Dona, A. C., M. Kyriakides, F. Scott, E. A. Shephard, D. Varshavi, K. Veselkov and J. R. Everett (2016). "A guide to the identification of metabolites in NMR-based metabonomics/metabolomics experiments." Computational and Structural Biotechnology Journal 14: 135-153. 
Doyle, S. (2011). "Fungal proteomics: from identification to function." FEMS Microbiology Letters 321(1): 1-9.

Frischknecht, H.R. and Waser, P.G., 1978. Actions of hallucinogens on ants (Formica pratensis)—II. Effects of amphetamine, LSD and delta-9-tetrahydrocannabinol. General Pharmacology: The Vascular System, 9(5), pp.375-380.

Gerdemann JW, T. J. (1974). "The Endogonaceae of the Pacific Northwest." Mycologia Memoir 5: 1-76. Ito, K., T. Tanaka, R. Hatta, M. Yamamoto, K. Akimitsu and T. Tsuge (2004). "Dissection of the host range of the fungal plant pathogen Alternaria alternata by modification of secondary metabolism." Mol Microbiol 52(2): 399-411.

Goldstein, B., 1929. A cytological study of the fungus Massospora cicadina, parasitic on the 17-year cicada, Magicicada septendecim. American Journal of Botany, pp.394-401.

Gryganskyi, A.P., Humber, R.A., Smith, M.E., Hodge, K., Huang, B., Voigt, K. and Vilgalys, R., 2013. Phylogenetic lineages in Entomophthoromycota. Persoonia: Molecular Phylogeny and Evolution of Fungi, 30, p.94.

Gryganskyi, A.P., Humber, R.A., Smith, M.E., Miadlikovska, J., Wu, S., Voigt, K., Walther, G., Anishchenko, I.M. and Vilgalys, R., 2012. Molecular phylogeny of the Entomophthoromycota. Molecular phylogenetics and evolution, 65(2), pp.682-694.

Gryganskyi, A.P., Mullens, B.A., Gajdeczka, M.T., Rehner, S.A., Vilgalys, R. and Hajek, A.E., 2017. Hijacked: Co-option of host behavior by entomophthoralean fungi. PLoS pathogens, 13(5), p.e1006274. Hopkins, A.D., 1898. The Periodical Cicada in W. Va (Vol. 50). West Virginia Agricultural Experiment Station.

Hughes, D.P., Araujo, J.P.M., Loreto, R.G., Quevillon, L., De Bekker, C. and Evans, H.C., 2016. Chapter eleven-from so simple a beginning: the evolution of behavioral manipulation by fungi. Advances in genetics, 94, pp.437-469. 
Hodge, K.T., Hajek, A.E. and Gryganskyi, A., 2017. The first entomophthoralean killing millipedes, Arthrophaga myriapodina n. gen. n. sp., causes climbing before host death. Journal of Invertebrate Pathology, 149, pp.135-140.

Jeffries, P., S. Gianinazzi, S. Perotto, K. Turnau and J.-M. Barea (2003). "The contribution of arbuscular mycorrhizal fungi in sustainable maintenance of plant health and soil fertility." Biology and Fertility of Soils 37(1): 1-16.

Kumar, S., Stecher, G. and Tamura, K., 2016. MEGA7: Molecular Evolutionary Genetics Analysis version 7.0 for bigger datasets. Molecular biology and evolution, 33(7), pp.1870-1874.

Li, Z., Yao, Q., Dearth, S.P., Entler, M.R., Castro Gonzalez, H.F., Uehling, J.K., Vilgalys, R.J., Hurst, G.B., Campagna, S.R., Labbé, J.L. and Pan, C., 2017. Integrated proteomics and metabolomics suggests symbiotic metabolism and multimodal regulation in a fungal-endobacterial system. Environmental microbiology, 19(3), pp.1041-1053.

Małagocka, J., Grell, M.N., Lange, L., Eilenberg, J. and Jensen, A.B., 2015. Transcriptome of an entomophthoralean fungus (Pandora formicae) shows molecular machinery adjusted for successful host exploitation and transmission. Journal of invertebrate pathology, 128, pp.47-56.

Masiulionis, V.E., Weber, R.W. and Pagnocca, F.C., 2013. Foraging of Psilocybe basidiocarps by the leaf-cutting ant Acromyrmex lobicornis in Santa Fé, Argentina. SpringerPlus, 2(1), p.254.

Małagocka, J., M. N. Grell, L. Lange, J. Eilenberg and A. B. Jensen (2015). "Transcriptome of an entomophthoralean fungus (Pandora formicae) shows molecular machinery adjusted for successful host exploitation and transmission." Journal of invertebrate pathology 128: 47-56.

Markley, J. L., R. Brüschweiler, A. S. Edison, H. R. Eghbalnia, R. Powers, D. Raftery and D. S. Wishart (2017). "The future of NMR-based metabolomics." Current Opinion in Biotechnology 43(Supplement C): $34-40$. 
Martin, G., M. Guggiari, D. Bravo, J. Zopfi, G. Cailleau, M. Aragno, D. Job, E. Verrecchia and P. Junier (2012). "Fungi, bacteria and soil pH: the oxalate-carbonate pathway as a model for metabolic interaction." Environmental Microbiology 14(11): 2960-2970.

Meier, S. M., B. Muqaku, R. Ullmann, A. Bileck, D. Kreutz, J. C. Mader, S. Knasmuller and C. Gerner (2015). "Proteomic and Metabolomic Analyses Reveal Contrasting Anti-Inflammatory Effects of an Extract of Mucor Racemosus Secondary Metabolites Compared to Dexamethasone." PLoS One 10(10): $\mathrm{e} 0140367$.

Mensah, J. A., A. M. Koch, P. M. Antunes, E. T. Kiers, M. Hart and H. Bücking (2015). "High functional diversity within species of arbuscular mycorrhizal fungi is associated with differences in phosphate and nitrogen uptake and fungal phosphate metabolism." Mycorrhiza 25(7): 533-546.

Miyara, I., H. Shafran, M. Davidzon, A. Sherman and D. Prusky (2010). "pH Regulation of ammonia secretion by Colletotrichum gloeosporioides and its effect on appressorium formation and pathogenicity." Mol Plant Microbe Interact 23(3): 304-316.

Morton JB, B. G. (1990). "Revised classification of arbuscular mycorrhizal fungi (Zygomycetes): a new order, Glomales, two new suborders, Glomineae and Gigasporineae, and two families, Acaulosporaceae and Gigasporaceae, with an emendation of Glomaceae." Mycotaxon(

37): 471-491.

Msiska, Z. and J. B. Morton (2008). "Phylogenetic analysis of the Glomeromycota by partial $\beta$-tubulin gene sequences." Mycorrhiza 19(4): 247-254.

Orozco-Patiño, F. and M. Medina-Sierra (2013). "Effects of arbuscular mycorrhizal fungal species and the medium pH on the growth of Pueraria phaseoloides (Roxb.) Benth." Symbiosis 60(2): 65-71. Peregrín-Alvarez, J. M., C. Sanford and J. Parkinson (2009). "The conservation and evolutionary modularity of metabolism." Genome Biology 10(6): R63-R63. 
Pfeffer, P. E., D. D. Douds, G. Bécard and Y. Shachar-Hill (1999). "Carbon Uptake and the Metabolism and Transport of Lipids in an Arbuscular Mycorrhiza." Plant Physiology 120(2): 587-598.

Redecker, D., A. Schüßler, H. Stockinger, S. L. Stürmer, J. B. Morton and C. Walker (2013). "An evidence-based consensus for the classification of arbuscular mycorrhizal fungi (Glomeromycota)." Mycorrhiza 23(7): 515-531.

Reynolds, H.T., Vijayakumar, V., Gluck-Thaler, E., Korotkin, H.B., Matheny, P.B. and Slot, J.C., 2017. Horizontal gene cluster transfer increased hallucinogenic mushroom diversity. bioRxiv, p.176347. Riley, C.V., 1885. The periodical cicada: An account of cicada septendecim and its tredecim race, with a chronology of all broods known (No. 8). US Department of Agriculture, Division of Entomology. Rousk, J., P. C. Brookes and E. Bååth (2009). "Contrasting Soil pH Effects on Fungal and Bacterial Growth Suggest Functional Redundancy in Carbon Mineralization." Applied and Environmental Microbiology 75(6): 1589-1596.

Roy, H.E., Steinkraus, D.C., Eilenberg, J., Hajek, A.E. and Pell, J.K., 2006. Bizarre interactions and endgames: entomopathogenic fungi and their arthropod hosts. Annu. Rev. Entomol., 51, pp.331-357. Russell, C. W., S. Bouvaine, P. D. Newell and A. E. Douglas (2013). "Shared Metabolic Pathways in a Coevolved Insect-Bacterial Symbiosis." Applied and Environmental Microbiology 79(19): 6117-6123. Saito, M. (1995). "Enzyme activities of the internal hyphae and germinated spores of an arbuscular mycorrhizal fungus, Gigaspora margarita Becker \& Hall." New Phytologist 129(3): 425-431.

Sauer, M., P. Lu, R. Sangari, S. Kennedy, J. Polishook, G. Bills and Z. An (2002). "Estimating polyketide metabolic potential among nonsporulating fungal endophytes of Vaccinium macrocarpon." Mycological Research 106(4): 460-470.

Savary, R., F. G. Masclaux, T. Wyss, G. Droh, J. Cruz Corella, A. P. Machado, J. B. Morton and I. R. Sanders (2017). "A population genomics approach shows widespread geographical distribution of cryptic genomic forms of the symbiotic fungus Rhizophagus irregularis." The Isme Journal. 
Schardl, C. L., A. Leuchtmann and M. J. Spiering (2004). "SYMBIOSES OF GRASSES WITH

SEEDBORNE FUNGAL ENDOPHYTES." Annual Review of Plant Biology 55(1): 315-340.

SCHÜßLER, A., D. SCHWARZOTT and C. WALKER (2001). "A new fungal phylum, the

Glomeromycota: phylogeny and evolution." Mycological Research 105(12): 1413-1421.

Sharma, E., G. Anand and R. Kapoor (2017). "Terpenoids in plant and arbuscular mycorrhiza-reinforced defence against herbivorous insects." Annals of Botany 119(5): 791-801.

Shulaev, V. (2006). "Metabolomics technology and bioinformatics." Briefings in Bioinformatics 7(2): 128-139.

Short, D.P., Double, M., Nuss, D.L., Stauder, C.M., MacDonald, W. and Kasson, M.T., 2015. Multilocus PCR assays elucidate vegetative incompatibility gene profiles of Cryphonectria parasitica in the United States. Applied and environmental microbiology, 81(17), pp.5736-5742

Siddiqui, M. S., K. Thodey, I. Trenchard and C. D. Smolke (2012). "Advancing secondary metabolite biosynthesis in yeast with synthetic biology tools." FEMS Yeast Research 12(2): 144-170.

Smith, S. E., I. Jakobsen, M. Grønlund and F. A. Smith (2011). "Roles of Arbuscular Mycorrhizas in Plant Phosphorus Nutrition: Interactions between Pathways of Phosphorus Uptake in Arbuscular Mycorrhizal Roots Have Important Implications for Understanding and Manipulating Plant Phosphorus Acquisition." Plant Physiology 156(3): 1050-1057.

Smith, S. E. and D. Read (2008). 1 - The symbionts forming arbuscular mycorrhizas. Mycorrhizal Symbiosis (Third Edition). S. E. S. Read. London, Academic Press: 13-II.

Soper, R.S., 1963. Massospora levispora, a new species of fungus pathogenic to the cicada, Okanagana rimosa. Canadian Journal of Botany, 41(6), pp.875-878.

Soper, R.S., 1974. The genus Massospora, entomopathogenic for cicadas, Part I, Taxonomy of the Genus. Mycotaxon Vol. I, No. 1, pp. 13-40.

Soper, R.S., 1981. New cicada pathogens: Massospora cicadettae from Australia and Massospora pahariae from Afghanistan [Fungi]. Mycotaxon (USA). 
Soper, R.S., Smith, L.F. and Delyzer, A.J., 1976. Epizootiology of Massospora levispora in an Isolated Population of Okanagana rimosa 1, 2, 3. Annals of the Entomological Society of America, 69(2), pp.275283.

Spatafora, J.W., Chang, Y., Benny, G.L., Lazarus, K., Smith, M.E., Berbee, M.L., Bonito, G., Corradi, N., Grigoriev, I., Gryganskyi, A. and James, T.Y., 2016. A phylum-level phylogenetic classification of zygomycete fungi based on genome-scale data. Mycologia, 108(5), pp.1028-1046.

Sugimoto, M., M. Kawakami, M. Robert, T. Soga and M. Tomita (2012). "Bioinformatics Tools for Mass Spectroscopy-Based Metabolomic Data Processing and Analysis." Current Bioinformatics 7(1): 96-108.

Sun, J., Li, H., Sun, X. and Yuan, Q., 2012. Trisporic acid stimulates gene transcription of terpenoid biosynthesis in Blakeslea trispora. Process biochemistry, 47(12), pp.1889-1893.

Thaxter, R., 1888. The entomophthoreae of the United States. Boston Society of Natural History.

Tisserant, E., M. Malbreil, A. Kuo, A. Kohler, A. Symeonidi, R. Balestrini, P. Charron, N. Duensing, N. Frei dit Frey, V. Gianinazzi-Pearson, L. B. Gilbert, Y. Handa, J. R. Herr, M. Hijri, R. Koul, M. Kawaguchi, F. Krajinski, P. J. Lammers, F. G. Masclaux, C. Murat, E. Morin, S. Ndikumana, M. Pagni, D. Petitpierre, N. Requena, P. Rosikiewicz, R. Riley, K. Saito, H. San Clemente, H. Shapiro, D. van Tuinen, G. Becard, P. Bonfante, U. Paszkowski, Y. Y. Shachar-Hill, G. A. Tuskan, J. P. Young, I. R. Sanders, B. Henrissat, S. A. Rensing, I. V. Grigoriev, N. Corradi, C. Roux and F. Martin (2013).

"Genome of an arbuscular mycorrhizal fungus provides insight into the oldest plant symbiosis." Proc Natl Acad Sci U S A 110(50): 20117-20122.

Tohge, T., M. Watanabe, R. Hoefgen and A. R. Fernie (2013). "Shikimate and Phenylalanine Biosynthesis in the Green Lineage." Frontiers in Plant Science 4: 62.

Van der Heijde, M. G. A., R. D. Bardgett and N. M. Van Straalen (2008). "The unseen majority: soil microbes as drivers of plant diversity and productivity in terrestrial ecosystems." Ecology Letters 11(3): 296-310. 
Verduyn, C., E. Postma, W. A. Scheffers and J. P. Van Dijken (1992). "Effect of benzoic acid on metabolic fluxes in yeasts: A continuous-culture study on the regulation of respiration and alcoholic fermentation." Yeast 8(7): 501-517.

Vilgalys, R. and Hester, M., 1990. Rapid genetic identification and mapping of enzymatically amplified ribosomal DNA from several Cryptococcus species. Journal of bacteriology, 172(8), pp.4238-4246. Vylkova, S. (2017). "Environmental pH modulation by pathogenic fungi as a strategy to conquer the host." PLOS Pathogens 13(2): e1006149.

Welling, M. T., L. Liu, T. J. Rose, D. L. Waters and K. Benkendorff (2016). "Arbuscular mycorrhizal fungi: effects on plant terpenoid accumulation." Plant Biol (Stuttg) 18(4): 552-562.

Yee, T. L., R. Tajuddin, N. M. I. Mohamed Nor, M. H. Mohd and L. Zakaria (2016). "Filamentous ascomycete and basidiomycete fungi from beach sand." Rendiconti Lincei 27(4): 603-607.

White, J.A., Ganter, P., McFarland, R., Stanton, N. and Lloyd, M., 1983. Spontaneous, field tested and tethered flight in healthy and infected Magicicada septendecim L. Oecologia, 57(3), pp.281-286.

White, J. and Lloyd, M., 1983. A Pathogenic Fungus, Massospora cicadina Peck (Entomophthorales), in Emerging Nymphs of Periodical Cicadas 1 (Homoptera: Cicadidae). Environmental Entomology, 12(4), pp.1245-1252.

Witt, P.N., 1971. Drugs alter web-building of spiders: A review and evaluation. Systems Research and Behavioral Science, 16(1), pp.98-113.

Xu, Y.J., Wang, C., Ho, W.E. and Ong, C.N., 2014. Recent developments and applications of metabolomics in microbiological investigations. TrAC Trends in Analytical Chemistry, 56, pp.37-48. Yoshida, H., J. Yamazaki, S. Ozawa, T. Mizukoshi and H. Miyano (2009). "Advantage of LC-MS Metabolomics Methodology Targeting Hydrophilic Compounds in the Studies of Fermented Food Samples." Journal of Agricultural and Food Chemistry 57(4): 1119-1126.

Zhou, B., J. F. Xiao, L. Tuli and H. W. Ressom (2012). "LC-MS-based metabolomics." Molecular BioSystems 8(2): 470-481. 
